\title{
Índice de contenidos
}

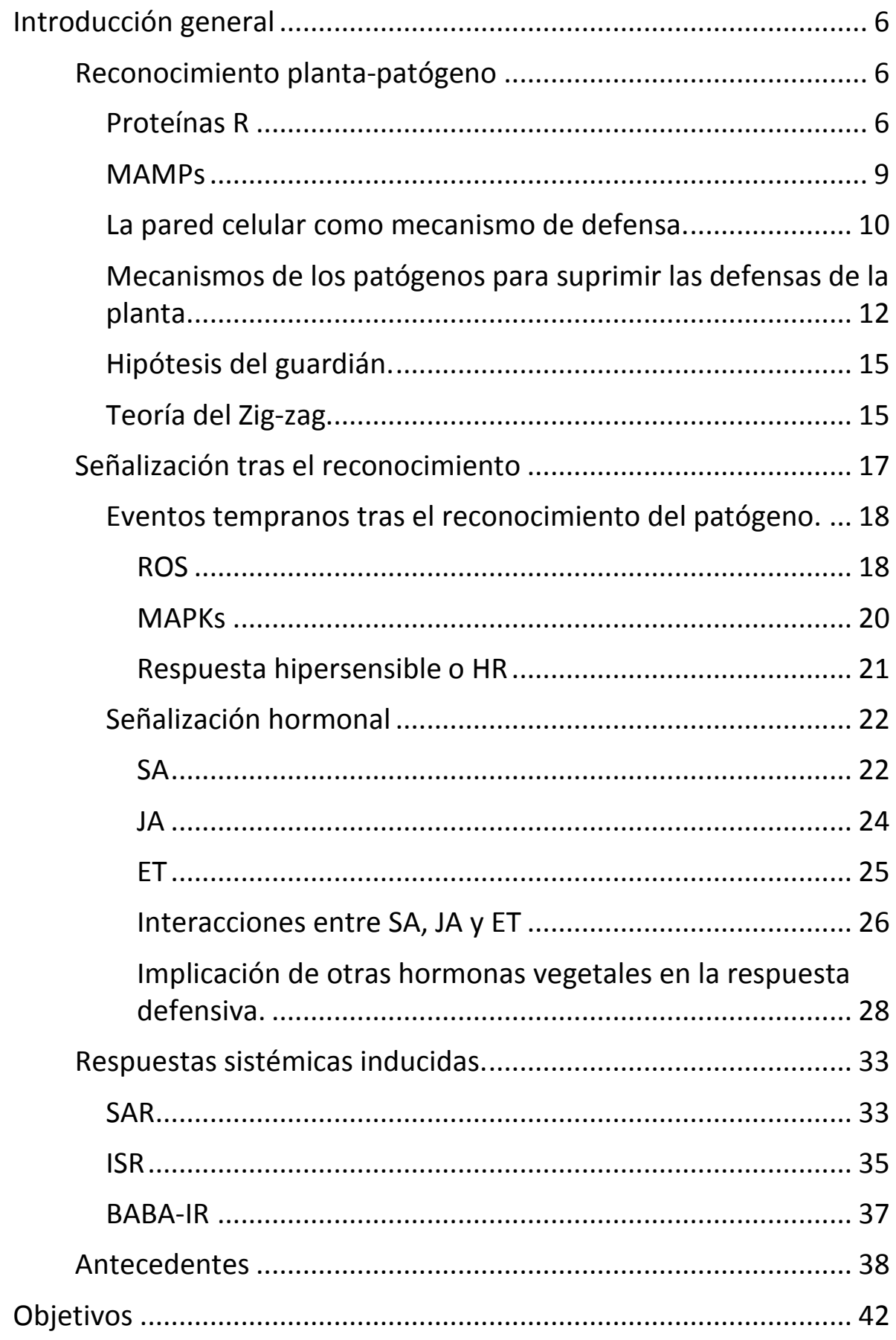


OCP3, un nuevo componente de la Resistencia Sistémica Inducida (ISR).

La mutación ocp3 revierte la susceptibilidad a Pst DC3000 en algunos mutantes de la ruta de señalización mediada por SA.

La resistencia aportada por ocp3 es independiente de la expresión de genes $P R$ dependientes de SA.

La inducción de resistencia frente a Pst DC3000 mediada por

JA está alterada en el mutante ocp3. 48

El mutante ocp3 esta alterado en el establecimiento de ISR. 50

Discusión general del capítulo .53

OCP3, un regulador negativo de la resistencia a hongos necrotrofos y a sequía. 58

Introducción. 58

La fosfatasa 2 C ABI1. 60

OCP3 interacciona físicamente con varios componentes de la cascada de señalización dependiente de ABA que regulan la respuesta adaptativa de las plantas frente al estrés hídrico. 61 El mutante ocp3 es hipersensible a ABA. 64 Las plantas ocp3 presentan una mayor tolerancia a la sequía. 65

La expresión del gen OCP3 se reprime en respuesta tanto a la aplicación exógena de ABA como a la deshidratación. 66

El mutante oсp3 no presenta alteraciones en los niveles de expresión de genes de respuesta a deshidratación.

El mutante ocp3 no muestra alteraciones en respuesta a la desecación......

El mutante ocp3 no presenta alteraciones en la disposición y número de estomas 71

Las plantas ocp3 son más sensibles al cierre estomático promovido por ABA. 
La mutación abi1-1 suprime la susceptibilidad a ABA del mutante ocp3 y su resistencia a sequía.

La resistencia a sequía asociada a ocp3 es independiente de JA y dependiente de $A B A$, mientras que la resistencia a patógenos necrotrofos es independiente de $A B A$ y dependiente de JA 77

Discusión general del capítulo ........................................... 82

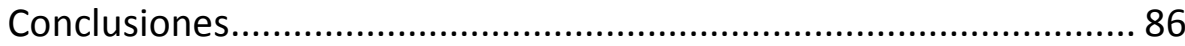

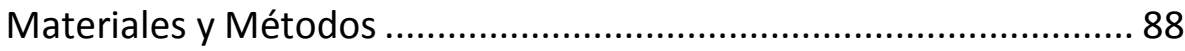

Material vegetal utilizado y crecimiento de las plantas. ........... 88

Ensayos de deshidratación y aplicación de ABA exógeno. ......... 88

Ensayos de desecación............................................................. 89

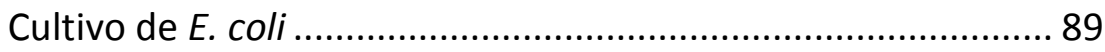

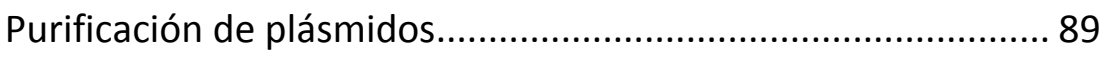

Purificación de fragmentos de ADN ............................................. 89

Extracción de plásmidos de levadura........................................ 89

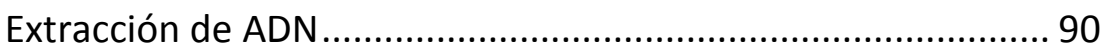

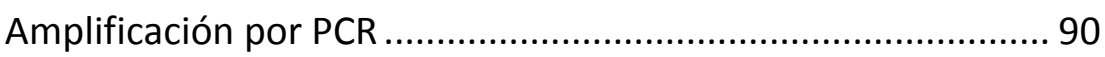

Análisis de la expresión génica por RT-PCR............................. 90

RT-PCR cuantitativa en tiempo real ......................................... 91

Rastreo por doble híbrido en levadura .................................... 91

Medida de la actividad $\beta$-galactosidasa.................................. 92

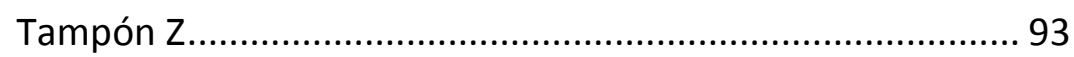

Ensayos de infección con B.cinerea ......................................... 93

Ensayos de infección con Pst DC3000 ....................................... 94

Ensayos de infección con $H$. arabidopsidis ............................... 94

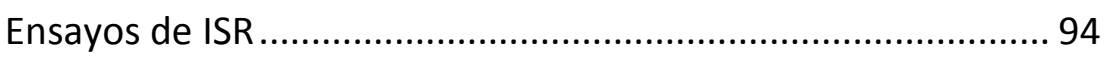

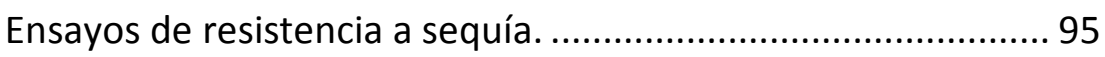

Medida de la apertura estomática......................................... 95

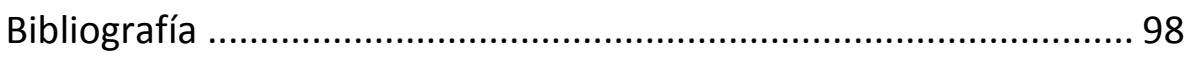


Índice

4 
INTRODUCCIÓN GENERAL 


\section{Introducción general}

En la naturaleza las plantas han de adaptarse continuamente para poder persistir en condiciones ambientales cambiantes. El hecho de que sean capaces de generar energía orgánica a través de la fotosíntesis resulta además muy atractivo para organismos patógenos y oportunistas. Esto hace que se establezcan complejas interacciones planta-huésped. Aunque algunos organismos han desarrollado estrategias no agresivas para explotar el potencial energético de las plantas como es el caso de las relaciones simbióticas, muchas otras son hostiles. El sistema inmune juega un papel fundamental en estas interacciones planta-patógeno y ayuda a la planta a determinar la composición de su ambiente biótico y a establecer la respuesta defensiva más adecuada en cada caso.

El estudio de las interacciones entre diferentes combinaciones de plantas y microorganismos, ha permitido esclarecer que es la combinación de señales disparadas en respuesta a un ataque determinado la que permite al sistema inmune activar una defensa eficaz y específica para cada patógeno en concreto.

\section{Reconocimiento planta-patógeno}

En la mayoría de las ocasiones, las plantas son inmunes a muchos patógenos potenciales que se encuentran en el medio, evitando la infección o siendo capaces de disminuir la gravedad de las enfermedades. Ambas situaciones implican, como primer paso, el reconocimiento del patógeno al iniciar la infección y supone una habilidad crucial para la supervivencia de las plantas. Se ha avanzado mucho en este campo desde los trabajos de Flor en 1971, en los que se describía el paradigma de la resistencia "gen a gen", donde los productos de los genes de resistencia de las plantas (o genes $R$ ) reconocen específicamente a los productos de genes de avirulencia (genes Avr) desencadenando una respuesta defensiva específica que habitualmente va acompañada de una respuesta hipersensible o HR, un programa de muerte celular programada que restringe en última instancia la invasión (Abramovitch \& Martin, 2004; Flor, 1971; Nimchuk et al., 2003; Nurnberger et al., 2004).

El concepto desarrollado por Flor ha evolucionado y actualmente los genes de avirulencia se consideran, en muchos casos, efectores o elicitores patogénicos que promueven virulencia en hospedadores que no poseen el correspondiente gen $R$.

\section{Proteínas $\mathbf{R}$}

Se han identificado genes $R$ funcionales en multitud de especies vegetales que otorgan resistencia frente a bacterias, virus, hongos, oomicetos e incluso insectos y nematodos, patógenos todos ellos con estilos de vida y modos de infección muy diferentes (Bent, 1996; Dangl \& Jones, 2001a; Ellis et al., 2000; 
Falk et al., 1999). Existe una gran variabilidad de genes $R$, pero las proteínas que codifican se agrupan habitualmente en cinco clases distintas (Figura 1). La clase más abundante codifica proteínas con repeticiones ricas en leucina (LRRs) y un sitio de unión a nucleótidos (NB) (clase NB-LRR). La característica más importante de esta clase es la existencia de un número variable de LRRs en el extremo N-terminal que funcionan como sitios de unión para proteínas, ligandos y carbohidratos (Dangl \& Jones, 2001a; Jones \& Jones, 1996; Kajava, 1998). El dominio NB está muy conservado y su función no es muy clara. Esta clase puede dividirse según las características del dominio N-terminal. Muchos tienen homología con dominios intracelulares de señalización de los receptores tipo Toll de Drosophilla o interleukin (IL)-1 de mamíferos y son denominados TIR-NB-LRR, mientras que otros, los llamados CC-NB-LRR contienen dominios coiled-coil. Análisis de comparación de secuencias han demostrado que la especificidad de las proteínas de esta clase reside básicamente en los dominios LRR, que están en continua selección para incrementar la variabilidad en la composición aminoacídica en residuos expuestos al solvente (Botella, 1998; Dangl \& Jones, 2001a; McDowell, 1998; Meyers, 1998; Michelmore \& Meyers, 1998). Los mecanismos para la evolución de nuevas especificidades incluyen recombinación y conversión génica, así como acumulación de cambios que alteran la secuencia de aminoácidos tras duplicación génica (Dangl \& Jones, 2001a).

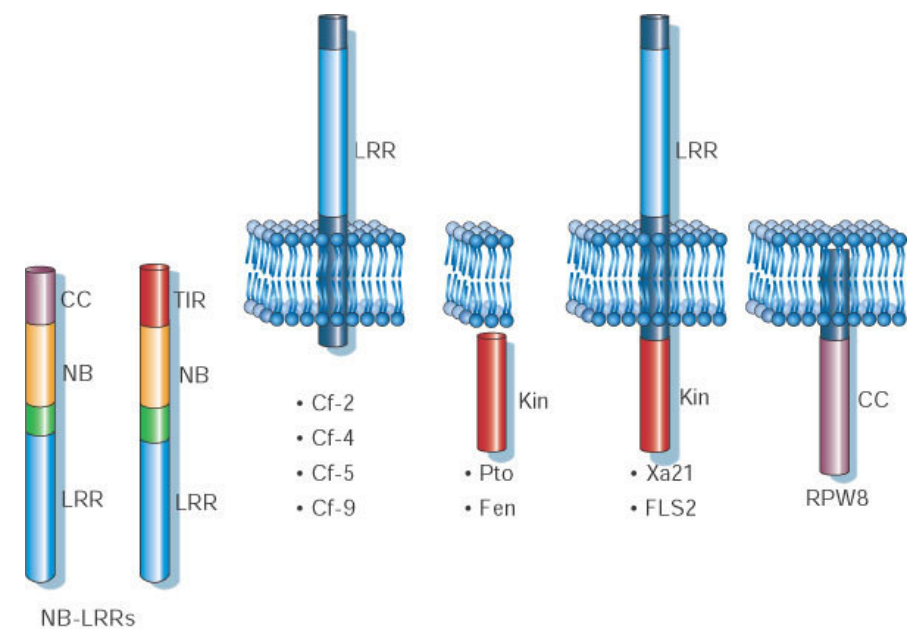

Figura 1. Representación de la estructura y localización de las cinco principales clases de proteínas $\mathbf{R}$ de plantas. Las proteínas Xa21 y Cf-X poseen un dominio transmembrana y otro LRR extracelular. El producto del gen $R \quad R P W 8$ tiene una posible señal de anclaje a la membrana en su extremo N-terminal. El gen Pto codifica una serín/treonín quinasa que se asocia a la membrana a través de un sitio de myristoilación. La clase NB-LRR está formada por proteínas presumiblemente citoplásmicas, que también pueden estar asociadas a la membrana a través de sus extremos N-terminales. (adaptado de Dangl \& Jones, 2001)

Se conocen también algunos casos de formas truncadas de las clases CC-NB y TIR-NB donde está ausente el dominio LRR (Medzhitov, 1998). También se han identificado versiones de proteínas TIR-NB-LRR resultantes de splicing 
alternativos (Dinesh-Kumar \& Baker, 2000). Otras estructuras que no cumplen los cánones son por ejemplo la existencia de dominios WRKY y/o dominios proteín-quinasa extra. El dominio WRKY confiere capacidad de unión a ADN y está presente en factores de transcripción específicos de plantas activados durante algunas respuestas defensivas. No está claro si estos genes son vestigios de eventos pasados de mutación o poseen un papel activo y desconocido en defensa (Eulgem et al., 2000).

Existen otras cuatro clases de genes $R$ que son estructuralmente muy diversas. Además algunos de los miembros de estas clases tienen funciones conocidas en procesos celulares que no tienen nada que ver con defensa. El gen Pto de tomate tiene actividad serín/treonín quinasa y confiere resistencia frente a las razas de Pseudomonas syringae que poseen el gen de avirulencia avrPto (Dangl \& Jones, 2001a; Salmeron, 1996; Tang, 1996). En arroz, el gen Xa21 codifica un receptor de membrana con un dominio extracelular formado por LRRs y un dominio intracelular con actividad proteín quinasa (Song, 1995). Un homólogo estructural en Arabidopsis es FLS2, que reconoce la secuencia de aminoácidos fls22 presente en la flagelina de multitud de bacterias (Gomez-Gomez \& Boller, 2000b). Los genes $C f-X$ de tomate codifican proteínas con dominios LRRs extracelulares que posiblemente colaboran conjuntamente en el reconocimiento de los productos de genes de avirulencia (Jones et al., 1994). $R P W 8$ codifica una pequeña proteína de membrana con un posible dominio CC y sin homología a ninguna otra proteína conocida (Xiao, 2001). Existen evidencias que parecen indicar la posibilidad de que estas otras clases de proteínas $\mathrm{R}$ utilicen cascadas de señalización similares a las de la clase NB-LRR e incluso que puedan actuar conjuntamente en algunos casos (Dangl \& Jones, 2001a).

Una anotación de los genes $R$ de Arabidopsis continuamente revisada por B. Meyers y colaboradores puede encontrarse en http://pgfsun.ucdavis.edu/ niblrrs/At_RGenes/. Actualmente hay en torno a 100 loci distribuidos por los distintos cromosomas, número que parece sorprendentemente pequeño si pensamos que han de mediar el reconocimiento de multitud de ligandos codificados por el ámplio abanico de patógenos al que se enfrenta esta especie. Es por esto que la realidad ha de ser más compleja. Varias proteínas del sistema de reconocimiento y las rutas de respuesta son funcionalmente polimórficas, siendo necesaria una evolución conjunta. La existencia de proteínas transmembrana y citosólicas indica que unas pueden estar especializadas en el reconocimiento de los ligandos secretados por el patógeno o componentes estructurales, mientras que las otras podrían dedicarse a reconocer ligandos que aparecen en el interior de la célula. La identificación de múltiples clases de dominios transmembrana e intracelulares hace pensar que no solo existen polimorfismos en el reconocimiento, sino que también existen en muchos elementos de las rutas de respuesta. Así, la selección podría estar actuando diversificando y regulando finamente la respuesta final, confiriendo al sistema redundancia funcional, flexibilidad y robustez (Dangl \& Jones, 2001a). 


\section{MAMPs}

En la actualidad se considera que, en esencia, existen dos grandes ramas del sistema inmune de las plantas. Además de la rama ya comentada que emplearía el reconocimiento de efectores patogénicos utilizando proteínas $\mathrm{R}$, existe otra que utilizaría receptores con dominios transmembrana que reconocerían una serie de patrones moleculares asociados a patógenos (PAMPS) que elicitan una respuesta defensiva. Ampliando más aún, y dado que esos patrones moleculares se encuentran en otros microorganismos no patógenos, se acuñó el término MAMPs (patrones moleculares asociados a microbios) (Mackey \& McFall, 2006). Estos MAMPs son reconocidos por los denominados PRRs (pattern recognition receptors) que se encuentran en la superficie de las células. La activación de estos PRRs dispara una respuesta defensiva tanto en el caso de la resistencia non-host como en la resistencia basal (Jones \& Dangl, 2006). La naturaleza de estos MAMPs es muy diversa, siendo habitualmente moléculas esenciales para la vida del microbio pero sin jugar necesariamente algún papel en la patogenicidad de este. Ejemplos bien conocidos son algunos componentes estructurales de las paredes y membranas celulares de algunos hongos como el ergosterol y la quitina; lipopolisacáridos que forman parte de las membranas celulares de las bacterias Gram negativas (LPS); o la flagelina, el componente mayoritario de los órganos de motilidad de las bacterias (Zipfel \& Felix, 2005). En el caso de algunos MAMPs se ha acotado la zona que es reconocida por los PRRs. En la mayoría de ocasiones coincide con la región más conservada de la proteína, como el fragmento de la flagelina fls22, de 22 aminoácidos. El tratamiento con este péptido es capaz de elicitar la típica respuesta asociada a la inmunidad en varias especies de plantas (Felix et al., 1999b). Diferentes familias y especies de plantas han desarrollado sistemas de reconocimiento para distintas moléculas de un mismo microbio. Este es el caso por ejemplo del factor de elongación Tu (EF-Tu) o las proteínas de choque por frío (CSP). Ambas proteínas son muy abundantes en las bacterias, pero la percepción de EF-Tu está restringida a Brassicaceas, mientras que las CSPs son propias de las Solanaceas (Felix \& Boller, 2003; Kunze et al., 2004).

Así pues, las plantas poseen receptores de superficie extremadamente sensibles y específicos capaces de monitorizar las comunidades de microbios con los que se encuentra en su ambiente atendiendo a una serie de patrones moleculares, lo que les permite controlar las infecciones patogénicas. Los receptores consisten habitualmente de un dominio extracelular encargado de unir al ligando (formado normalmente por repeticiones ricas en leucina o LRR), un dominio transmembrana y un dominio intracelular de señalización con actividad serin/treonin quinasa encargado de iniciar la cascada de señalización tras el reconocimiento. Además de estos receptores denominados RLK, existe un segundo gran grupo llamado RLP con una estructura similar pero sin el dominio quinasa citoplásmico. En Arabidosis se han identificado 610 RLKs y 56 RLPs (Fritz-Laylin et al., 2005; Shiu \& Bleecker, 2001), pero solamente unas pocas se han caracterizado funcionalmente. Algunos ejemplos de RLKs son BRI1 (Brassinosteroid 1) y CLV1 (Clavata 1), involucradas en desarrollo; FLS2 
(Flagellin sensing 2), EFR (EF-Tu receptor) o Xa21 (que reconoce a la proteína AvrXa21), implicadas en defensa (Gomez-Gomez \& Boller, 2000a; Lee et al., 2006; Robatzek et al., 2006a; Xu et al., 2006; Zipfel et al., 2006; Zipfel et al., 2004). Como ejemplos más representativos de RLPs podemos destacar a CEBiP, que posee un sitio de reconocimiento para la quitina de los hongos; o LeEix1 y LeEix2, que median el reconocimiento de la xilanasa fúngica EIX (Kaku et al., 2006).

Típicamente las respuestas que desencadena el reconocimiento mediado por MAMPs son muy rápidas y transitorias, e incluyen la activación de flujos iónicos a través de la membrana plasmática, generación de ROS, NO y etileno, así como deposición de calosa y otros compuestos antimicrobianos (Felix et al., 1999b; Zipfel \& Felix, 2005). Además, la señalización mediada por MAMPs utiliza al menos dos cascadas de MAP quinasas diferentes (Asai et al., 2002b; Meszaros et al., 2006; Shen et al., 2007; Suarez-Rodriguez et al., 2007). Existen evidencias que indican que diferentes MAMPs elicitan cambios en la transcripción de grupos de genes con un grado de solape muy elevado, posiblemente utilizando señalizaciones convergentes (Desaki et al., 2006). Además, la expresión de genes identificados por jugar un papel importante en la defensa basal (como PAD4) y non-host (como PEN1, PEN2 y PEN3), es inducida por algunos MAMPs (como fls22), lo que indica que muy posiblemente la señalización mediada por el reconocimiento de MAMPs es importante tanto para la defensa pre-invasión como para la defensa post-invasión (Lipka et al., 2005; Zipfel et al., 2004).

\section{La pared celular como mecanismo de defensa.}

El primer desafío al que se ve sometido un patógeno es entrar en el tejido de su planta hospedadora. Los patógenos bacterianos colonizan los espacios intercelulares en las hojas entrando por estomas y otras estructuras, mientras que los hongos biotrofos y los oomicetos penetran en las células elaborando austorios intracelulares a través de los cuales absorben los nutrientes. Otros patógenos entre los que se encuentran un gran número de virus son inyectados directamente por insectos vectores como los áfidos (revisado por Goggin, 2007). La defensa de las plantas a la penetración de los patógenos es una estrategia extremadamente efectiva que permite una respuesta muy rápida frente a la infección sobre todo de hongos y oomicetos. Esta respuesta se caracteriza por la formación de deposiciones en la pared celular (CWA, del inglés cell wall appositions) o papillae que constituyen una barrera física y química en el sitio por donde intenta penetrar el patógeno (Hardham et al., 2007; Schmelzer, 2002). En cuestión de minutos las células vegetales son capaces de reorganizar las redes de microfilamentos de actina y redirigir los aparatos de secreción hacia el sitio de infección, fortaleciendo la pared y depositando calosa y otras sustancias antimicrobianas. Este fenómeno implica por tanto la polarización de la red de microtúbulos de actina, la síntesis de proteínas antimicrobianas, componentes estructurales de la pared y membranas celulares, la formación de agregados citosólicos, así como el transporte y secreción dirigidos hacia el sitio de penetración (Kobayashi \& 
Hakuno, 2003; Lipka \& Panstruga, 2005; Takemoto \& Hardham, 2004; Takemoto et al., 2003). Las CWAs tienen apariencias diferentes y su composición es muy heterogénea, conteniendo una gama muy diversa de compuestos con actividad antimicrobiana como fitoalexinas, compuestos fenólicos, calosa, $\mathrm{H}_{2} \mathrm{O}_{2}$ y proteínas que incluyen peroxidasas e inhibidores enzimáticos (Hardham et al., 2007; Remans et al., 2006; Schmelzer, 2002).

La calosa, un $\beta-1,3$ glucano, es quizás el componente mayoritario de las CWAs y juega un papel central en la prevención de la entrada de multitud de patógenos en la planta, sobre todo bacterias, hongos y oomicetos. La síntesis y deposición de calosa es inducida por estrés de naturaleza tanto biótica como abiótica y ocurre muy rápidamente a través de la acción de sintasas de calosa que se encuentran ancladas en la cara externa de la membrana plasmática (Hardham et al., 2007). Se ha sugerido que el papel de la calosa en la defensa frente a la penetración del patógeno es el de revestir a otros compuestos depositados en la membrana impidiendo así su degradación e incluso que podría servir de plataforma donde los compuestos antimicrobianos podrían ser secuestrados y concentrados (Assaad et al., 2004; Bhat et al., 2005; Mongrand et al., 2004; Stein et al., 2006). En el caso de otros compuestos, la síntesis se produce intracelularmente, son transportados en el interior de vesículas y depositados en las CWA. Es el caso del $\mathrm{NO}$ o del $\mathrm{H}_{2} \mathrm{O}_{2}$ sintetizados en el apoplasto y transportados en cuerpos multivesiculares a las CWA (Bolwell et al., 2002; Prats et al., 2005; Remans et al., 2006). Esa deposición de compuestos a través de vesículas implica además procesos de endo y exocitosis, con el consiguiente reciclaje de componentes estructurales de la membrana en el sitio de infección. Tienen especial relevancia en los casos de algunos receptores de membrana que son endocitados tras el reconocimiento del elicitor para iniciar la señalización defensiva (Remans et al., 2006; Robatzek et al., 2006b; Schornack et al., 2006).

Otro grupo de componentes de la pared celular implicados en este tipo de resistencia son los arabinogalactanos (Sardar et al., 2006). La naturaleza de estas glicoproteínas es extremadamente compleja y diversa y aunque no se conoce exactamente cual es su función, parecen estar involucradas en la detección de la invasión del patógeno y son objetivos habituales de muchos factores de virulencia (Celio et al., 2004).

La reorganización de las redes de actina y la deposición de muchos de estos compuestos puede imitarse mediante el tratamiento con diferentes toxinas purificadas de hongos y oomicetos (Binet et al., 2001; Yuan et al., 2006). Por otro lado se ha demostrado que la presión mecánica ejercida con microagujas activa, entre otras, la acumulación de agregados citoplásmicos, migración nuclear o inducción de genes relacionados con defensa basal (Gus-Mayer et al., 1998; Kennard \& Cleary, 1997; Wick et al., 2003). Sin embargo estas señales nunca llegan a inducir todo el abanico de barreras defensivas sugiriendo que es la percepción de múltiples señales producidas por el patógeno la que confiere la gran especificidad que posee este mecanismo defensivo. 
En suma, las plantas son capaces de defenderse efectivamente de la gran mayoría de los patógenos que las atacan impidiendo que éstos penetren en su interior. La clave del éxito de este tipo de resistencia es el gran abanico de estrategias que la componen. A lo largo del tiempo los patógenos han desarrollado mecanismos para suprimir selectivamente componentes de esta respuesta defensiva, pero la presencia de los múltiples métodos de desencadenar la señalización permite, en muchos casos, impedir su penetración. Además de reconocer directamente elicitores de los patógenos, las plantas han desarrollado mecanismos para controlar el estado de componentes clave en su propio sistema defensivo (comentado extensamente en el apartado "hipótesis del guardián"). Se ha demostrado por ejemplo que algunas bacterias fitopatógenas suprimen la acción de sintasas de calosa para promover virulencia, pero esa inactivación dispara un mecanismo de contraataque que frena el avance de la infección (Hauck et al., 2003; Yun et al., 2006). Un caso similar se ha documentado recientemente en el que la interferencia en la síntesis de proteínas requeridas para la resistencia a la penetración (sintaxinas como PEN1 y AtSYP122 o transportadores ABC como PEN3) dispara la señalización defensiva (Nishimura et al., 2003; Stein et al., 2006; Zhang et al., 2007).

\section{Mecanismos de los patógenos para suprimir las defensas de la planta.}

Los patógenos han coevolucionado con las diferentes especies de plantas hospedadoras y han desarrollado una serie de mecanismos que les permiten penetrar en la planta evitando la activación de estas defensas. Estos mecanismos van desde evadir la percepción hasta interferir con las respuestas defensivas de la planta. Además, para promover la virulencia los patógenos producen efectores que reducen o suprimen las defensas activadas mediante el reconocimiento mediado por MAMPs o incluso por proteínas R. Este cóctel de efectores está formado gran cantidad de moléculas (entre 20 y 100) que incluye toxinas y proteínas secretadas por sistemas de secreción de tipo III (TTSS, del inglés type III secretion system). Estos TTSS están compuestos por un pilus de naturaleza proteica que ejerce la función de jeringa, inyectando directamente proteínas efectoras de tipo III (TTEs, del inglés type III effector) en el interior de la célula (Cunnac et al., 2004; Lindeberg et al., 2006). Es la combinación de efectores secretados la que determina el éxito de la infección, por lo que los TTEs están sujetos a una gran presión de selección. Las bacterias mantienen un grado muy alto de heterogeneidad de sus efectores debida a la transferencia horizontal de genes, generando además variabilidad a través, entre otros procesos, del denominado "barajado de genes" (Stavrinides et al., 2006). Así pues, razas bacterianas muy relacionadas pueden diferir mucho en la composición y/o número de efectores, lo que en última instancia va a determinar su rango de hospedadores.

Estos efectores interfieren en multitud de procesos defensivos de las plantas, tanto a nivel subcelular como a nivel multicelular (Figura 2). Se conocen 
ejemplos de efectores que promueven virulencia a través de la alteración del sistema de ubiquitinación de la planta, como es el caso de HopAB2 (AvrPtoB) (Abramovitch et al., 2003). El extremo C-terminal de esta proteína es muy similar a algunos componentes de las E3-ligasas involucradas en el marcaje por ubiquitinación y posterior degradación de proteínas. Se ha sugerido que HopAB2 es un inhibidor de mecanismos como la señalización defensiva dependiente de MAMPs (de Torres et al., 2006; Hann \& Rathjen, 2007) o de la proteína R Rsb (Abramovitch et al., 2006; Janjusevic et al., 2006). Otros casos parecidos son los de la familia GALA de TTEs presente en Ralstonia solanacearum (Angot et al., 2006). Estas proteínas contienen dominios F-box que interaccionan con las proteínas SKP1 de Arabidopsis, uno de los integrantes de los complejos SCF de ubiquitinación. El TTE de P. syringae HopM1 contribuye a la virulencia en Arabidopsis y tomate suprimiendo la deposición de calosa, promoviendo la degradación vía proteosoma de proteínas como AtMIN7, un regulador del trafico vesicular (Badel et al., 2006; DebRoy et al., 2004; Nomura et al., 2006).

Otros efectores tienen un modo de acción diferente, siendo capaces de modificar directamente proteínas del hospedador. Miembros de la familia HopX1 (AvrPphE) de TTEs presentes en P. syringae y Xanthomonas campestris contienen tríadas catalíticas características de proteasas de cisteína así como un dominio N-terminal conservado. Se ha propuesto que estas proteínas pueden promover virulencia a través de la proteolisis de proteínas propias de la planta (Nimchuk et al., 2007). Otras como HopAR1 (AvrPphB) y AvrRpt2 de $P$. syringae, también funcionan como proteasas de cisteína, provocando la proteólisis de PBS1, y RIN4 respectivamente, lo que suprime la señalización defensiva mediada por MAMPs y por el reconocimiento de proteínas $\mathrm{R}$ (Anderson et al., 2004; Axtell et al., 2003; Kim et al., 2005; Shao et al., 2003). Otros TTEs con actividad cisteín-proteasa eliminan pequeñas modificaciones proteicas similares a la ubiquitina (SUMO, del inglés small ubiquitin-like modifier). Por ejemplo, X. campestris posee dos familias de TTEs (YopJ y YopD) con actividad proteasa de SUMO (Hotson et al., 2003; Roden et al., 2004). Cuando se expresan estas proteínas en células vegetales reducen la cantidad de proteínas sumoiladas. Además, se ha demostrado que poseen localización subcelular diferente, lo que podría indicar especificidad de sustrato para este mecanismo (Chosed et al., 2007).

Los TTEs también son capaces de alterar el grado de fosforilación de algunas proteínas de las plantas para contribuir a la virulencia del patógeno. AvrRpm1 y AvrB1 son TTEs de P. syringae que inducen la fosforilación de RIN4, suprimiendo la respuesta defensiva (Mackey et al., 2002). Otros TTEs tienen actividad fosfatasa de tirosinas (como HopAO1 (HopPtoD2)) o liasa de fosfotreoninas (como HopAI1) y promueven la desfosforilación de diversas proteínas de la planta para interferir en la señalización defensiva como la cascada de MAPKKs (Bretz et al., 2003; Espinosa et al., 2003; Li et al., 2007; Li et al., 2005). 


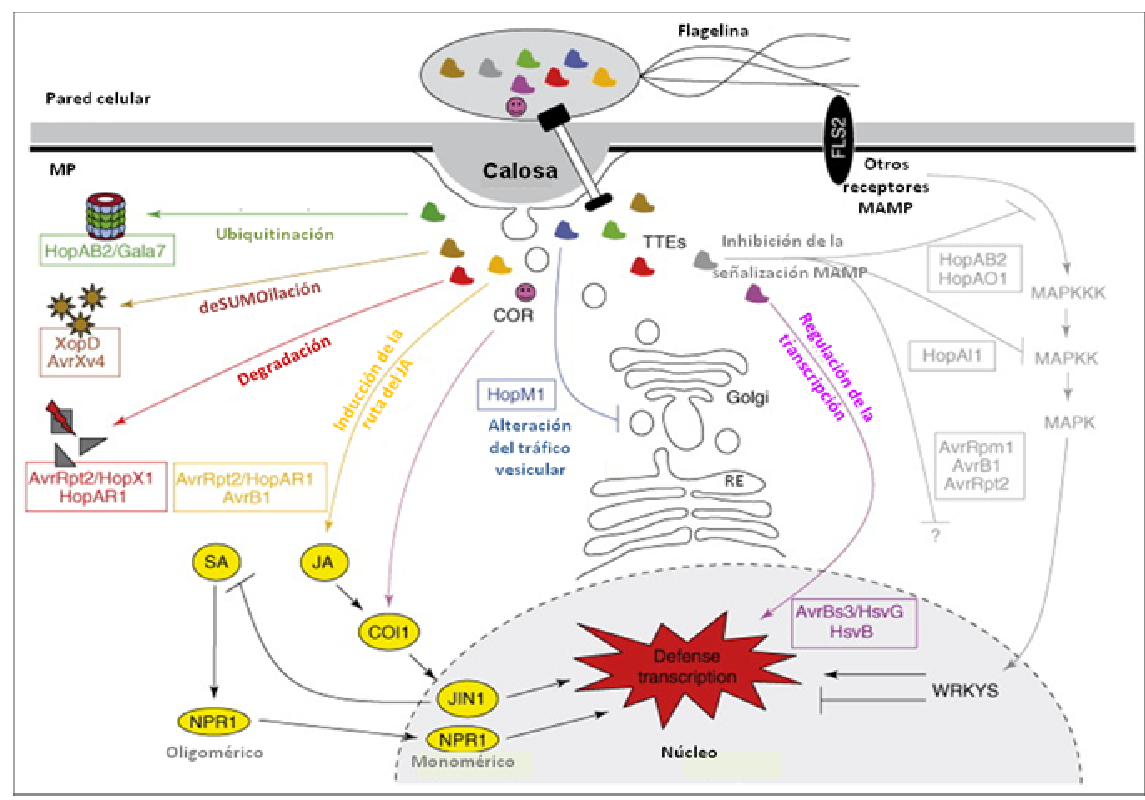

Figura 2. Esquematización de los diversos modos de acción de los efectores bacterianos para perturbar las defensas de la planta hospedadora. Las dianas de los diferentes tipos de efectores incluyen multitud de procesos celulares como la ubiquitinación, señalización por MAPKs, tráfico vesicular, transcripción, modificación y degradación de proteínas o señalización hormonal. RE, retículo endoplásmico; MP, membrana plasmática; COR, coronatina; TTEs, proteínas efectoras de tipo III; MAMP, patrones moleculares asociados a microbios. (Adaptado de Hardham et al., 2007).

Otro tipo de interferencias son producidas por TTEs como los de la familia AvrBs3/PthA de Xanthomonas y Ralstonia o AvrXa27 de X. oryzae que poseen dominios de localización nuclear (NLS) y un dominio acídico de activación (AAD) (Marois et al., 2002; Schornack et al., 2006). El modo de acción de estos TTEs se basa en modular la transcripción de genes del hospedador suprimiendo las defensas. Otros como HsvG o HsvB son TTEs de Pantoea agglomerans que funcionan como factores de transcripción que contribuyen a la formación de agallas en los hospedadores susceptibles (Nissan et al., 2006; Valinsky et al., 1998).

Otros TTEs son utilizados por los patógenos para modular la señalización hormonal de las plantas. Se ha observado el caso de bacterias que, para promover su virulencia, inducen la señalización mediada por auxinas a través tanto de un aumento en la síntesis como de la alteración de la manipulación de la respuesta a esta hormona (Navarro et al., 2006; Uppalapati et al., 2005). También se han descrito que fitotoxinas como la coronatina (COR), un análogo funcional del JA, es utilizada por $P$. syringae para promover la señalización mediada por JA y suprimir las defensas, así como para manipular la apertura estomática, facilitando la entrada del patógeno en la planta (Cohn \& Martin, 
2005; He et al., 2004; Thilmony et al., 2006; Uppalapati et al., 2005). Recientemente se ha demostrado que las plantas cierran los estomas bloqueando la entrada de bacterias patógenas como P.syringae y no patógenas como E.coli, pero solamente aquellas bacterias virulentas son capaces de superar esa barrera orquestando una reapertura a través de la manipulación de las propias rutas de señalización hormonales de las plantas (Melotto et al., 2006). Un gran número de patógenos fúngicos y oomicetos tienen también como mecanismo de penetración en su hospedador la entrada por los estomas, así que es muy posible que este mecanismo de supresión de las defensas demostrado para bacterias, esté ampliamente distribuido en la naturaleza.

\section{Hipótesis del guardián.}

Son muchas las evidencias emergentes que apoyan la denominada "hipótesis del guardián". Este modelo propuesto por van der Biezen y Jones en 1998 defiende que muchas proteínas $\mathrm{R}$ reconocen efectores patogénicos de manera indirecta, y sin implicar una interacción física. Así, las proteínas $\mathrm{R}$ monitorizarían la integridad de importantes componentes del sistema inmune, dianas de la acción de los efectores (Dangl \& Jones, 2001b; van der Biezen \& Jones, 1998). Esto podría explicar cómo las plantas son capaces de reconocer a miles de patógenos diferentes utilizando tan solo unos cientos de genes $R$. El concepto de que las proteínas $\mathrm{R}$ reconocen esas modificaciones inducidas por patógenos es similar a los modelos utilizados en mamíferos (Jones \& Dangl, 2006). Las evidencias más claras vienen del estudio de la interacción entre $P$. syringae y Arabidopsis. RPS2 y RPS5 son proteínas R que reconocen indirectamente a los efectores AvrRpt2 y HopAR1. Estos efectores tienen como diana a componentes importantes en la señalización defensiva como son RIN4 y PBS1, e inducen su eliminación vía degradación y proteólisis respectivamente para promover su virulencia. RPS2 y RPS5 no interaccionan físicamente con los efectores que reconocen, sino que lo hacen con estos componentes de la planta monitorizando su integridad en todo momento, actuando así como "guardianes". Así, en el momento que detectan la degradación de RIN4 y PBS1, activan una respuesta defensiva que detiene el avance del patógeno (Ade et al., 2007; Axtell \& Staskawicz, 2003; Day et al., 2005; Mackey et al., 2003; Shao et al., 2003).

\section{Teoría del Zig-zag}

Recientes avances en el conocimiento del sistema inmune de las plantas están indicando que existe un solape significativo entre las resistencias basal, nonhost y la específica de raza. Estas defensas precisan de elementos comunes y en muchos casos utilizan señalizaciones similares produciendo cambios transcripcionales y celulares parecidos (da Cunha et al., 2006). 


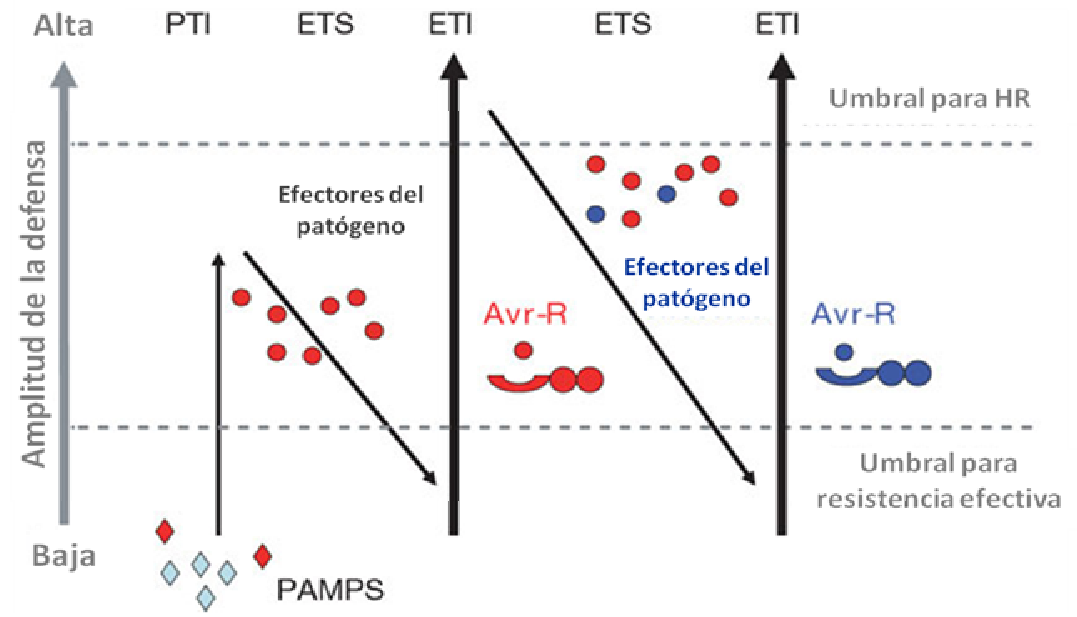

Figura 3. Modelo del "Zig-zag" que esquematiza el conocimiento actual del sistema inmune de las plantas. La amplitud de la resistencia o la susceptibilidad es proporcional a [PTI - ETS + ETI]. En la fase 1, las plantas detectan una serie de PAMPs/MAMPs a través de los PRRs para desencadenar una inmunidad asociada a PAMPs (PTI). En la fase 2, algunos patógenos consiguen vencer esa resistencia generando efectores que interfieren con la PTI, lo que resulta en una susceptibilidad asociada a efectores (ETS). En la fase 3, uno de los efectores (coloreado en rojo) es reconocido por una proteína $\mathrm{R}$ activando una inmunidad asociada a efectores (ETI), que amplifica la PTI pudiendo traspasar el umbral de la respuesta hipersensible (HR). En la fase 4, la selección natural hace que algunos aislados del patógeno pierdan el efector reconocido (rojo) y que puedan ganar nuevos efectores a través de flujo génico horizontal (en azul) lo que les permite superar la ETI. De nuevo la selección favorece la aparición de nuevas especificidades de las proteínas $\mathrm{R}$ permitiendo a las plantas reconocer al nuevo efector, lo que resulta en la activación de nuevo de una ETI. (Adaptado de Jones \& Dangl, 2006).

La visión actual del sistema inmune puede resumirse en cuatro fases, según el llamado modelo del "zigzag" (Jones \& Dangl, 2006). En la fase 1, los MAMPs son reconocidos por los PRRs, lo que resulta en el establecimiento de una respuesta defensiva que impide la colonización del patógeno. Los patógenos que superan con éxito esta fase despliegan, en la fase 2 , efectores que contribuyen a la virulencia interfiriendo en esa resistencia mediada por el reconocimiento de los MAMPs. En la fase 3, los efectores son reconocidos específicamente por las proteínas $\mathrm{R}$ lo que desencadena la resistencia generalmente a través de una respuesta hipersensible o HR en el sitio de infección. Este reconocimiento puede ser indirecto (hipótesis del guardián) o directo (implicando interacción física). En la fase 4, la selección natural hace que evolucionen y sean capaces de suprimir este reconocimiento específico bien a través de la eliminación del efector, bien modificándolo, o bien utilizando nuevos efectores capaces de interferir en el reconocimiento y/o posterior señalización defensiva. Esa selección natural hace que también aparezcan nuevas proteínas $\mathrm{R}$ o con nuevas especificidades que activen de nuevo la respuesta defensiva (Jones \& Dangl, 2006). 


\section{Señalización tras el reconocimiento}

Como ya se ha comentado, tras el reconocimiento de patógenos muy diferentes entre sí, las plantas responden activando mecanismos altamente conservados que utilizan componentes comunes de un número limitado de rutas de señalización. La caracterización de las resistencias mediadas por genes $R$ en tomate, cebada o Arabidopsis, ha proporcionado datos genéticos muy valiosos para determinar la organización de esta respuesta así como las interconexiones entre diferentes rutas de señalización. Así, se han identificado genes complementarios necesarios para el correcto funcionamiento de múltiples genes $R$, que fortalecen esta idea. Por ejemplo, análisis genéticos de la interacción entre la cebada y el hongo Erysiphe graminis f sp hordei han desvelado el papel fundamental de dos genes, RAR1 y $R A R 2$, en la resistencia mediada por el gen $R$ Mla-12 (Freialdenhoven et al., 1994; Torp \& Jorgensen, 1986). Esta resistencia va acompañada de una acumulación bifásica de $\mathrm{H}_{2} \mathrm{O}_{2}$. Un primer estallido oxidativo se da a nivel local en el sitio de penetración del hongo, mientras que el segundo se da a nivel de toda la célula coincidiendo con una HR localizada (Shirasu et al., 1999). El mutante rar1 está afectado en ese segundo estallido oxidativo, así como en la HR localizada, sugiriendo un papel para RAR1 como potenciador de la acumulación de $\mathrm{H}_{2} \mathrm{O}_{2}$ que contiene el avance del patógeno promoviendo la HR (Shirasu et al., 1999). RAR1 codifica una proteína con homología a SGT1, que en levadura regula la degradación de proteínas a través de complejos SCF (Kitigawa et al., 1999). Así pues, se ha propuesto que tras la activación de RAR1 este podría marcar a algún regulador negativo de la resistencia para degradarlo (Halterman et al.). Además el complejo SCF que contiene a RAR1 es un objetivo crítico para varios efectores de hongos y es vigilado por varios productos de genes $R$ Mla. La mutación rar1 compromete por esto el reconocimiento de diferentes hongos, situando a RAR1 como punto de convergencia de las señalizaciones mediadas por diferentes proteínas R (Jorgensen, 1996; Peterhansel et al., 1997).

Por otro lado, estudios fenotípicos de mutantes alterados en la respuesta defensiva de Arabidopsis frente a P. syringae e Hyaloperonospora arabidopsidis (también llamado Peronospora parasitica o Hyaloperonospora parasitica) han demostrado que los genes EDS1 y NDR1 son también necesarios para la función de diversas clases de genes $R$ (Aarts et al., 1998). Además, los genes $R$ suprimidos por eds1 no son suprimidos por $n d r 1$ y viceversa. Así, mutaciones en la lipasa EDS1, eliminan la resistencia mediada por genes $R$ de la clase TIRNB-LRR, mientras que mutaciones en NDR1 suprimen la resistencia conferida por una clase de CC-NB-LRR de genes $R$ (Aarts et al., 1998; Falk et al., 1999; McDowell et al., 1998).

En otros casos, rastreos para detectar mutantes alterados en resistencia mediada por diferentes genes $R$ han resultado en la identificación de genes requeridos específicamente para la función de genes $R$ individuales. Es el caso del mutante de tomate $r c r 3$, que específicamente compromete la resistencia a Cladosporium fulvum asociada a Cf- 2 pero no a Cf-5, a pesar de que las dos proteínas tienen una similitud de secuencia aminoacídica del 93\% (Dixon et al., 
2000). En Arabidopsis, mutaciones en PBS1 suprimen la resistencia a P.syringae mediada por el gen $R$ RPS5 y sin embargo no afecta a la función de los otros genes $R$ analizados (Warren et al., 1999).

Aunque estas observaciones sugieren un modelo en el que EDS1 y RAR1 estarían regulando las señalizaciones defensivas mediadas por diferentes genes $R$, son muchos los casos conocidos de genes $R$ de la clase CC-NB-LRR que funcionan de manera independiente a ambos genes, por lo que podría existir una tercera ruta con componentes aún desconocidos (Aarts, 1998; McDowell, 2000; McDowell et al., 2000). Además, en Arabidopsis parece haber una serie de proteínas con funciones solapantes que regulan las resistencias asociadas a genes $R$, lo que complicaría aún más este modelo (Feys \& Parker, 2000b; Warren et al., 1999).

\section{Eventos tempranos tras el reconocimiento del patógeno.}

Así pues, la resistencia de las plantas frente a infecciones patogénicas está formada por un sofisticado sistema de percepción de señales pero también comprende una activación posterior de respuestas muy complejas. Después del reconocimiento del ataque de un patógeno, se producen una serie de cambios en las células vegetales que incluyen flujos de calcio, alcalinización del espacio extracelular, activación de proteín-quinasas, reprogramación transcripcional y la síntesis rápida y transitoria de una serie de moléculas que incluyen especies reactivas de oxígeno (ROS, del inglés Reactive oxygen species) y nitrógeno (Kotchoni \& Gachomo, 2006; Veronese et al., 2006). La rapidez e intensidad de la activación de esa cascada de reacciones son las que van a marcar el éxito de la resistencia. Diferentes estudios han revelado que estos cambios son similares independientemente del patógeno o efector utilizado (Felix et al., 1999a; Jabs et al., 1997; Piedras et al., 1998).

A los 15 minutos de la infección, se han identificado cambios en la acumulación de transcritos de aproximadamente el 1\% de los genes de Arabidopsis, que codifican además moléculas señalizadoras adicionales como factores de transcripción o proteín quinasas (Durrant et al., 2000). Las ROS y el NO contribuyen además a esta rápida activación transcripcional de una batería de genes de defensa en los alrededores del sitio de infección con funciones que incluyen la biosíntesis de hormonas como el SA o el ET, reforzamiento de la pared celular, lignificación, producción de compuestos antimicrobianos o el establecimiento de la HR (Scheel, 1998). Estos cambios transcripcionales son claramente el efecto de la integración de diversas rutas de señalización, pero no se sabe con certeza cuáles son directamente resultado del reconocimiento del patógeno y cuáles no.

\section{ROS}

Las ROS son uno de los componentes más importantes de esta señalización, pero tienen un papel dual dependiendo de los niveles de acumulación. Niveles intracelulares elevados pueden causar grandes daños y la muerte de la célula, mientras que son utilizadas en concentraciones moderadas como segundos 
mensajeros en las cascadas de transducción de la señal defensiva, diferenciación de la pared celular o la activación de proteín-quinasas activadas por mitógeno (MAPKs, del inglés mitogen-activated protein kinases) en complejos procesos utilizados por las plantas para adaptarse a multitud de clases de estrés (Conrath et al., 2002; Kotchoni \& Gachomo, 2006). En animales clásicamente se han relacionado con procesos como la inflamación o el cáncer mientras que su papel en interacciones planta-patógeno es relativamente reciente habiéndose descrito la influencia en procesos como la HR, el entrecruzamiento de glicoproteínas para reforzar la pared celular, la acumulación de fitoalexinas o la inducción de genes involucrados en defensa (Desikan et al., 2001; Lamb \& Dixon, 1997). Las ROS, que incluyen radicales hidroxilo y superóxido, peróxido de hidrógeno y oxígeno singlete son moléculas producidas como una consecuencia del metabolismo normal de las células en la fase aeróbica de la fotosíntesis (Asada, 1999; Mittler, 2002), aunque son rápidamente metabolizadas con la ayuda de enzimas antioxidantes presentes de manera constitutiva así como por otras vías no enzimáticas como vitaminas antioxidantes, proteínas o tioles (Kovtun et al., 2000; Scandalios, 1997). Se cree que la fuente principal de ROS es el cloroplasto, pero también se han descrito otras como peroxidasas de pared celular o las mitocóndrias (Davletova et al., 2005; Mittler, 2002; Mittler et al., 2004). Lógicamente existen sistemas de destoxificación de ROS, entre los que se encuentran el ciclo del ascorbatoglutatión, dismutasas de superóxido (SOD), ascorbato peroxidasas (APX) y catalasas, que regulan finamente los niveles de estas moléculas en cada compartimento celular (Apel \& Hirt, 2004; Asada, 1999; Mittler, 2002).

Por otro lado, tipos de estrés como el frío, el exceso de luz, el ozono, la sequía, la alta salinidad, la irradiación con luz UV o la infección por patógenos generan un exceso de ROS que precisa a su vez de la activación de defensas adicionales para regular los niveles de estas moléculas y reducir el daño oxidativo sobre lípidos en membranas, proteínas y otros componentes celulares que pueden llegar a provocar la muerte celular (Doke et al., 1996; Foyer \& Noctor, 2005; Scandalios, 1997). De hecho, se ha demostrado que la rápida generación de $\mathrm{H}_{2} \mathrm{O}_{2}$ es uno de los primeros eventos citológicamente observables en los procesos de penetración de muchos patógenos, y que es uno de los determinantes del éxito o el fracaso de la infección (Mellersh et al., 2002). Además se ha detectado acumulación de ROS extracelular durante diferentes interacciones planta-patógeno (ThordalChristensen et al., 1997) y se ha demostrado un efecto antimicrobiano sobre muchos patógenos (Bestwick et al., 1997; Kotchoni \& Gachomo, 2006). Otros datos que avalan el papel de las ROS en defensa son por ejemplo el hecho de que, en Arabidopsis, en respuesta a la infección patogénica, el metabolismo de estos compuestos se regula mediante una red que abarca 152 genes (Mittler et al., 2004) o la observación de que concentraciones subletales de $\mathrm{H}_{2} \mathrm{O}_{2}$ son capaces de inducir la expresión de numerosos genes requeridos en defensa (Chamnongpol et al., 1998; Rao \& Davis, 1999). Actualmente se piensa que las ROS, además de tener un efecto directo sobre el proceso de penetración del patógeno, sirven como amplificadores o transductores de la señal defensiva que actúan conjuntamente 
con componentes de las rutas mediadas por diferentes reguladores hormonales en el establecimiento de la respuesta defensiva.

\section{MAPKs}

Recientemente se ha establecido que las MAPKs juegan un papel muy importante en la respuesta defensiva de las plantas, dado que la percepción de diversos patógenos inicia una serie de señalizaciones que convergen en la activación de cascadas conservadas de MAPKs, quinasas activadas por mitógeno (Asai et al., 2002a; Nakagami et al., 2005). Se ha detectado una inducción de la activación de MAPKs en respuesta a numerosos tipos de estrés (Xiong \& Yang, 2003), y se ha asociado directamente a la acumulación de ROS (Moon et al., 2003). Las cascadas de señalizaciónpor MAPKs incluyen tres componentes básicamente: las MAP quinasas (MAPKs), las MAPK quinasas (MAPKKs) y las MAPKK quinasas (MAPKKKs). Durante la transducción de señal, las MAPKKKs son fosforiladas $y$ esto les permite activar MAPKKs fosforilándolas y éstas últimas a su vez fosforilan MAPKs activándolas. Estas MAPKs activadas (fosforiladas), son generalmente transportadas al núcleo donde activan componentes de la señalización como factores de transcripción, que regulan directamente la expresión de los genes de respuesta (Khokhlatchev et al., 1998).

Son claras las evidencias de la importancia de las cascadas de MAP quinasas en la resistencia mediada tanto por proteínas $\mathrm{R}$ como por MAMPs. Tras el reconocimiento del patógeno, generalmente se produce un estallido oxidativo, y la activación de estas rutas de MAP quinasas. Se han descrito numerosos efectores capaces de elicitar una respuesta defensiva dependiente de la activación de cascadas de MAP quinasas. Por ejemplo, se produce una activación transitoria de las quinasas NTF6 y WIPK de tomate, en respuesta al reconocimiento de avrPtoB durante la infección con $P$. syringae. Además, la resistencia a esta bacteria se ve comprometida al silenciar las MAPKKs MEK1 y MEK2, indicando que todas estas quinasas son reguladores clave (Ekengren et al., 2003; Kovtun et al., 2000). Por otro lado, la expresión transitoria de formas activas de las quinasas SIPK y las quinasa-quinasas SIPKK o NtMEK2 resultan en la aparición de algunas respuestas como la HR o la inducción de genes relacionados con defensa (Kim et al., 2003; Zhang \& Liu, 2001). Inversamente, una reducción en la expresión de SIPK, WIPK o NtMEK2 mediante silenciamiento inducido por virus, resulta en una atenuación de la resistencia al Virus del Mosaico del Tabaco o TMV (Jin et al., 2003; Sharma et al., 2003).

Ha sido descrito que bacterias, hongos y diferentes elicitores inducen la actividad de AtMPK6 pero no la de AtMPK3 en Arabidopsis (Nuhse et al., 2000). Sin embargo, ambas son parte de una cascada de señalización recientemente diseccionada, que es activada por el elicitor fls22 y que induce respuestas generales de defensa pero no HR (Asai et al., 2002a; Gomez-Gomez \& Boller, 2000a). La unión de la flagelina bacteriana al receptor FLS2 induce la activación de cascadas de MAP quinasas que a su vez activan a factores de transcripción de la familia WRKY, estableciendo un vínculo directo entre los receptores de membrana y la señalización mediada por MAP quinasas (Asai et al., 2002a). 
AtMPK4 también funciona como un regulador de la respuesta defensiva. Recientemente se ha identificado un sustrato de esta quinasa, MKS1, cuya sobreexpresión es suficiente para la expresión de genes de defensa regulados por WRK25 y WRK33, haciendo a las plantas más resistentes (Ekengren et al., 2003).

Así pues, aunque es clara la implicación en las plantas de las MAP quinasas en varios procesos metabólicos que incluyen respuestas defensivas, el conocimiento en detalle de cómo funcionan estas cascadas es muy pobre comparado con otros sistemas. Es mucho el esfuerzo que queda por hacer para diseccionar las complejas relaciones existentes entre estas MAP quinasas y las señalizaciones hormonales, así como para entender el funcionamiento de los receptores que monitorizan la activación de este tipo de señalización (Mishra et al., 2006b).

\section{Respuesta hipersensible o HR}

Generalmente la respuesta defensiva mediada por genes $R$ (Asai et al., 2002a; Nakagami et al., 2005) producida en las interacciones incompatibles incluye la muerte de las células que están en contacto con el patógeno, fenómeno denominado respuesta hipersensible o HR. Se desconoce si la aparición de esta HR está causada por el avance del patógeno o si es la consecuencia de la acción de sustancias producidas por la propia planta para obstaculizar el crecimiento de éste, el hecho es que está asociada a una serie de procesos como la generación de ROS, cambios en la polaridad de la membrana y en la permeabilidad de ésta a varios iones, reforzamiento de la pared celular, fosforilación/desfosforilación de proteínas y acumulación de algunas moléculas como el SA y las proteínas PR (Talarczyk \& Hennig, 2001). Algunos de estos eventos contribuyen a la limitación del avance del patógeno en el tejido infectado como parte de la respuesta defensiva local mientras que otros constituyen además puntos de partida para la activación de una respuesta defensiva de carácter sistémico que recibe el nombre de Respuesta Sistémica Adquirida o SAR (del inglés Systemic Acquired Resistance) y que proporciona una defensa frente a sucesivas infecciones de una amplia gama de patógenos (Durrant \& Dong, 2004; Hammerschmidt, 1999; Ryals et al., 1994; Sticher et al., 1997). Sin embargo el papel que juega la HR en la respuesta defensiva no se conoce con exactitud. En el caso de patógenos biotrofos, la necrosis del tejido puede dificultar mucho el avance del microorganismo, ya que este tipo de patógenos precisa de células vivas para su desarrollo, pero en el caso de agentes hemibiotrofos y necrotrofos el papel de la HR está menos claro, y se han descrito casos en los que incluso favorece el crecimiento del patógeno como ocurre con el hongo necrotrofo Botrytis cinerea, que se aprovecha de la HR para ampliar la zona de necrosis celular y continuar con la infección (Govrin \& Levine, 2000). Además existen casos de resistencias mediadas por genes $R$ Avr que no implican HR como es el caso de la resistencia de la cebada a todas las razas de Erisiphe graminis sp hordei mediada por el gen Mlo (Freialdenhoven et al., 1996; Knogge, 1996) o el caso del gen de resistencia $R x$ de la patata al Virus X de la Patata (Köhm et al., 1993). 
En conclusión, las plantas se defienden de los patógenos que las atacan activando una serie de sistemas de defensa que pasan necesariamente por la percepción de éstos. La interacción de la planta con los diferentes tipos de patógenos genera señales distintas pero que convergen en rutas de transducción comunes que controlan respuestas defensivas similares (Talarczyk \& Hennig, 2001). Este reconocimiento mediado por MAMPs y genes $R$ conduce generalmente a la activación de dos rutas de señalización diferentes, una que lleva a la inducción de la muerte celular programada de las células próximas al lugar de infección y otra que consiste en la activación de mecanismos de resistencia tanto locales (en el lugar de infección) como sistémicos (en partes distales de la planta).

\section{Señalización hormonal}

En los últimos años mucho ha sido el progreso que se ha hecho en la identificación de componentes de la respuesta defensiva de las plantas frente a patógenos de todo tipo. Se ha demostrado que en esta respuesta están involucradas fundamentalmente tres fitohormonas que, al parecer, regulan dos rutas de señalización mayores: una dependiente de SA y otra independiente de SA pero dependiente de JA y ET. Estas rutas no funcionan completamente independientes, sino que la una influye en la otra a través de una compleja red de interacciones (Dong, 1998; Feys \& Parker, 2000a; Glazebrook, 2001; Kunkel \& Brooks, 2002; Pieterse \& van Loon, 1999; Thomma et al., 2001a). El conocimiento de estas interacciones es fundamental para establecer los finos mecanismos de activación y regulación de la respuesta defensiva, así como para conocer las estrategias que usan los patógenos para alterar, mediante evasión o supresión, las defensas de su hospedador, promoviendo así virulencia y enfermedad.

\section{$S A$}

El ácido salicílico está involucrado en multitud de procesos biológicos de las plantas. Por ejemplo, se ha comprobado que es un importante regulador del crecimiento celular (Vanacker et al., 2001), la floración (Martínez et al., 2004) o la termogénesis (revisado en Klessig \& Malamy, 1994; Malamy et al., 1992; Raskin, 1992; Shah et al., 1999). También son muchas las observaciones a lo largo del tiempo que han indicado un papel central del SA en defensa. Las primeras demostraciones claras vinieron del análisis de plantas transgénicas que sobreexpresan el gen bacteriano que codifica el enzima salicilato hidroxilasa (NahG), que impide la acumulación de SA convirtiéndolo en catecol (Lawton et al., 1995). Estos estudios demostraron que los niveles endógenos de SA aumentan en tejidos infectados, y aplicaciones exógenas de esta molécula incrementan la resistencia frente a gran cantidad de patógenos. Además, el SA es necesario para la rápida activación de las defensas mediadas por diferentes genes $R$, para la inducción de defensas locales que contienen el avance de las infecciones por patógenos virulentos y para el establecimiento de la llamada 
resistencia sistémica adquirida o SAR (Gaffney, 1993; Kunkel \& Brooks, 2002; Ryals et al., 1996). El fenómeno SAR es un estado de resistencia activado en la planta tras la infección de patógenos compatibles e incompatibles que causan lesiones necróticas. La SAR actúa como un potenciador o modulador de otros mecanismos de defensa de tal manera que si no llega a activarse, una interacción incompatible puede convertirse en compatible (Ryals et al., 1996). Algunos genes $P R$ cuya inducción es dependiente de SA son utilizados habitualmente como marcadores de SAR, como es el caso de PR1, PR2 y PR5. Otras evidencias que apoyan el papel del SA en la respuesta defensiva han sido aportadas tanto por el aislamiento de mutantes de Arabidopsis afectados en la producción de SA, como por ejemplo los mutantes eds (enhanced disease susceptibility. (Dewdney et al., 2000)), pad4 (phytoalexin deficient4. (Glazebrook et al., 1996)) o sid2 (SA induction deficient2. (Dewdney et al., 2000)). Estos mutantes exhiben una marcada susceptibilidad a varios patógenos como $P$. syringae, H. arabidopsidis o Erisyphe sp. (Cao et al., 1994; Cao et al., 1997; Delaney et al., 1994; Reuber et al., 1998). Por otro lado, la caracterización del mutante npr1 (nonexpressor of PR genes.(Cao et al., 1997)) arrojó algo de luz a la ruta de señalización dependiente de SA. Varios mutantes en Arabidopsis alélicos de npr1, también llamado nim1 (non inducible inmunity. (Ryals et al., 1997)) o sai1 (salicylic acid insensitive mutant (Shah et al., 1997)) han sido identificados en escrutinios realizados para identificar mutantes que fueran incapaces de activar la expresión de genes $P R$ o estuvieran alterados en la respuesta defensiva frente a patógenos en condiciones de activación de SAR. La sobreexpresión del gen NPR1 en Arabidopsis y en arroz conduce a un aumento en la resistencia de estas plantas frente a patógenos biotrofos como $P$. syringae o H. arabbidopsidis (Cao et al., 1998; Chern et al., 2001). Se ha comprobado que tanto la aplicación exógena de SA o de sus análogos, así como la inoculación de las plantas con uno de estos patógenos, produce un aumento en la translocación de NPR1 al núcleo y que esta translocación es requerida para la activación de la señalización aguas abajo y por tanto para la expresión de algunas proteínas PR (Kinkema et al., 2000; Zhang et al., 1999). Más aún, se ha demostrado que el SA afecta a la actividad de NPR1 en dos etapas: primero activa la expresión del gen y después estimula su translocación al núcleo donde NPR1 interacciona con factores transcripcionales que se unen específicamente a los elementos reguladores de respuesta a SA identificados en promotores de genes $P R$ (Fan \& Dong, 2002).

Sin embargo, a partir de diversos rastreos genéticos se han obtenido resultados que sugieren la existencia de una ruta dependiente de SA pero independiente de NPR-1. Es el caso del mutante dth9 (detachment 9(Mayda et al., 2000b)). En este mutante, permanece intacta la inducción de PRs tras la inoculación con P.syringae y sin embargo la planta es hipersusceptible a este patógeno, lo que podría indicar que DTH9 es requerido para el establecimiento de la SAR pero no para la expresión de genes habitualmente conocidos como indicadores de la SAR. Otro ejemplo es el del mutante sni1, identificado como supresor de npr1. En el doble mutante, la restauración de la expresión de genes $P R$ y del establecimiento de SAR indica que probablemente un factor de transcripción independiente de NPR1 y dependiente de SA puede estar implicado en la 
expresión de genes PR (Zhang et al., 1999). Recientemente, Desveaux y colegas han propuesto a Whirly1 (AtWhy1) como un serio candidato. Mutaciones que suprimen por completo la expresión de este gen son letales, lo que explicaría por qué este gen no ha sido identificado en otros rastreos. Dos líneas con mutaciones puntuales en este gen son viables y tienen comprometida la inducción de PRs dependiente de SA y la resistencia a $H$. arabidopsidis. Whirly1 se une a un motivo GTCAAAA/T presente en muchos promotores de genes PR. Además, el SA promueve la unión al ADN de Whirly1 de manera independiente de NPR1 (Desveaux et al., 2002; Dong, 2004).

Por otro lado, el estudio de las plantas NahG también ha permitido determinar la existencia de mecanismos defensivos independientes de SA. Así, muchos investigadores han descrito evidencias que apuntan hacia la existencia de respuestas defensivas específicas que están inalteradas por la ausencia de acumulación de SA en las plantas NahG. Además se han identificado mecanismos defensivos que pueden ser activados sin que ello implique un aumento en la síntesis de SA o en la expresión de genes marcadores regulados por esta hormona, sino que dependen de otras rutas de señalización mediadas por otros reguladores como el JA o el ET (Brederode et al., 1991; Penninckx et al., 1996; Schaffrath et al., 1997; Schweizer et al., 1997; Vidal et al., 1998; Vidal et al., 1997b; Zoubenko et al., 1997).

\section{$J A$}

El ácido jasmónico es un producto terminal de la ruta de los octodecanoides que ha sido implicado en varios aspectos de la biología de plantas que incluyen el desarrollo del polen y las semillas, o la defensa frente a herida, ozono, insectos y microoorganismos patógenos (Creelman \& Mullet, 1997; Ecker, 1995; Li et al., 2001; Reymond \& Farmer, 1998b). Mutantes de Arabidopsis afectados tanto en la producción de esta molécula (como el triple mutante fatty acid desaturase [fad3/fad7/fad8]) como en su percepción (como los mutantes jasmonic acid resistant1 [jar1] y coronatine insensitive [coi1]) exhiben una marcada susceptibilidad a patógenos tal y como los hongos Alternaria brassicicola, Botrytis cinerea, Plectosphaerella cucumerina o Phytium sp. o bacterias como Erwinia carotovora (Feys et al., 1994; Gibson et al., 1994; Penninckx et al., 1996; Staswick et al., 1992; Xie et al., 1998). Estos patógenos emplean una estrategia común de infección que implica la rápida muerte de las células del hospedador para obtener nutrientes, por lo que son denominados habitualmente como patógenos necrotrofos. La susceptibilidad de estos mutantes coincide con una disminución de los niveles de expresión de algunas proteínas codificadas por genes inducibles por JA como plant defensin1.2 (PDF1.2), thionin2.1 (THI2.1), hevein-like protein (HEL), vegetative storage protein (VSP) o chitinaseB (CHIB). JAR1 codifica una sintetasa de aminoácidos requerida para la conjugación de JA con el aminoácido isoleucina (JA-Ile), que al parecer es la forma activa para muchas señalizaciones incluida la defensiva (Staswick \& Tiryaki, 2004). Por su parte, COI1 codifica una proteína F-box con actividad E3 ubiquitin-ligasa involucrada en la degradación de proteínas a través del proteosoma 26S. Mutaciones que impiden la función de esta proteína 
afectan a la mayoría de los procesos biológicos regulados por el JA. Recientemente se ha demostrado que el JA-Ile induce la degradación mediada por COI1 de varios miembros de la familia JAZ (jasmonate ZIM-domain) de represores transcripcionales que tendrían como dianas genes de respuesta a JA como MYC2 (Chini et al., 2007; Thines et al., 2007). MYC2/JIN1 codifica un factor de transcripción del tipo basic helix-loop-helix-leucine zipper, cuya expresión es rápidamente inducida por JA de manera dependiente de COI1. Análisis de pérdida y ganancia de función han demostrado que este gen es un regulador transcripcional de la señalización mediada por JA, reprimiendo la respuesta defensiva frente a patógenos necrotrofos (regulando la expresión de PDF1.2), y activando la respuesta a estrés oxidativo, herida e insectos (regulando la expresión de VSP1 por ejemplo) en la que además está involucrado el ET (Chini et al., 2007; Dombrecht et al., 2007; Lorenzo et al., 2004; McGrath et al., 2005). También se ha documentado la implicación de la serín/treonín proteín quinasa BIK1 en la resistencia a necrotrofos mediada por JA. Este gen es inducido tanto por JA como tras la infección con B. cinerea, y su inactivación causa una atenuación de la inducción de PDF1.2 que lleva consigo un incremento en la susceptibilidad al hongo (Veronese et al., 2006).

Por otro lado, se han aislado más recientemente mutantes como cev1 (constitutive expressor of VSP) que posee expresión constitutiva de PDF1.2, THI2.1 y CHIB y que presenta una elevada resistencia a los patógenos Erisiphe cichoracearum y el áfido Myzus persicae. Dicha resistencia es reprimida en el doble mutante cev1/coi1. cev1 resultó estar afectado en una sintasa de celulosa, al igual que el mutante $r s w 1$, que también presenta inducción de VSP en condiciones no inductoras. Esto ha llevado a proponer que la pared celular puede estar implicada en la señalización defensiva en plantas (Ellis et al., 2002a; Ellis et al., 2002b; Ellis \& Turner, 2001). También se ha descrito la existencia de otros mutantes que sobreexpresan estos genes marcadores dependientes de JA (por ejemplo los mutantes constitutive expressor of thionin [cet]. (Hilpert et al., 2001)), o que acumulan elevados niveles de JA (como los mutantes jasmonate overexpressing [joe]. (Jensen et al., 2002)) y que presumiblemente tendrían una elevada resistencia a este tipo de patógenos aunque en la mayoría de los casos aún no ha sido publicada. Estos hallazgos sugieren que es la activación constitutiva de la ruta de señalización del JA la responsable de conferir a las plantas una mayor resistencia a patógenos necrotrofos. El aislamiento y caracterización del mutante bos1 (botrytis susceptible 1) puede constituir una excepción. BOS1 codifica un factor de transcripción de tipo R2R3 MYB que se induce tras la infección por B.cinerea y cuya disrupción provoca una inducción constitutiva del gen PDF1.2 y sin embargo presenta una elevada susceptibilidad a hongos necrotrofos (Mengiste et al., 2003). 
El papel del ET en la respuesta defensiva de la planta ha sido y es motivo de controversia en tanto en cuanto se ha visto que contribuye a la resistencia en algunas interacciones pero promueve la susceptibilidad en otras (Clarke et al., 2000; Norman-Setterblad et al., 2000; Thomma et al., 1999). Parece ser que la resistencia frente a Erwinia y Plectosphaerella requiere la participación del ET de forma que el mutante insensible a ET ein2.5 (ethylene insensitive2) es susceptible a estos patógenos, mientras que es más resistente que las plantas salvajes a la infección con P. syringae y X. campestris pv campestris (Bent et al., 1992). Esta ruta mediada por ET parece estar asociada con la del JA ya que el ET induce algunos genes relacionados con la defensa que también son dependientes de JA como los anteriormente mencionados PDF1.2, THI2.1, HEL y CHIB (Norman-Setterblad et al., 2000; Penninckx et al., 1998). Además se ha comprobado que tanto la ruta de señalización del JA como la del ET son requeridas para el establecimiento de la resistencia sistémica inducida (ISR del inglés induced systemic resistance), una forma de resistencia sistémica desencadenada por la infección de las raíces de algunas bacterias no patógenas del género Pseudomonas (Ahn et al., 2007; Pieterse \& Van Loon, 2004; Pieterse et al., 1996; Pieterse et al., 1998; Ton et al., 2001; van Loon et al., 1998). Todas estas observaciones han provocado la aparición de modelos que sitúan al JA y al ET en una misma ruta de señalización teniendo efectos sinérgicos, aunque probablemente la realidad no sea tan simple, ya que se tienen indicios que sugieren un papel regulatorio de cada ruta sobre la otra (Kunkel \& Brooks, 2002). A partir de los estudios realizados con A. brassicicola en Arabidopsis se propuso la idea de la existencia de dos grandes rutas defensivas, una mediada por SA y otra mediada por JA y ET. En estos trabajos se infectaban diferentes mutantes en las distintas rutas mediadas por cada una de las tres hormonas y se determinaba el grado de susceptibilidad. Así, mutantes en la ruta del SA como npr1 o la línea transgénica $N a h G$, no presentaban alteraciones en la respuesta defensiva frente a este hongo. Sin embargo, el mutante coi1 era extremamente susceptible, lo que demostraba una dependencia de la señalización mediada por JA pero no de la del SA (Thomma et al., 1998). Sin embargo, mutaciones en EIN2, un regulador de la respuesta a ET, no provocaban efecto alguno en la resistencia frente a $A$. brassicicola, mientras que aumentaban la susceptibilidad frente a B.cinerea, ambos hongos considerados como necrotrofos (Penninckx et al., 1996; Thomma et al., 1999). La idea más extendida hoy en día es la de que el ET podría regular el desarrollo de los síntomas de manera positiva o negativa dependiendo de la interacción planta patógeno estudiada (van Loon et al., 2006).

\section{Interacciones entre SA, JA y ET}

Las interacciones entre las rutas del SA y JA/ET parecen ser muy complejas, existiendo evidencias que sugieren efectos tanto positivos como negativos. Sin embargo, el modo de interacción principal entre estas dos grandes rutas parece ser el de antagonismo mutuo. El efecto inhibitorio del SA sobre la señalización mediada por JA en tomate ha sido demostrado en numerosos trabajos, donde la 
acción del SA bloquea la expresión de genes inducibles por JA (Doares et al., 1995; Penacortes et al., 1993). En Arabidopsis, también existen numerosos estudios genéticos que demuestran el efecto antagónico del SA sobre la ruta del JA/ET. Los mutantes eds4 y pad4, afectados en la acumulación de SA tras infecciones por patógenos biotrofos, muestran una mayor inducción de genes cuya expresión es dependiente de JA (Gupta et al., 2000). En un rastreo genético buscando mutantes que expresaran el marcador de SAR BGL2, se identificaron el mutante recesivo cpr 5 y el mutante dominante cpr6, que constitutivamente producen elevados niveles de SA y expresan genes marcadores de las rutas mediadas tanto por SA como JA/ET. Estos mutantes muestran una mayor resistencia frente a patógenos biotrofos. Todos estos fenotipos son dependientes de SA pero difieren en el requerimiento de NPR1. Además, introgresando la mutación eds 5 en un fondo genético cpr6 se disminuye el nivel de SA endógeno y la expresión de PDF1.2 se ve incrementada (Bowling et al., 1997; Clarke et al., 1998; Clarke et al., 2000). En otro rastreo buscando supresores de npr1, se identificó el mutante dominante ssi1 que expresa constitutivamente PDF1.2 de manera independiente de SA (Shah et al., 2001).

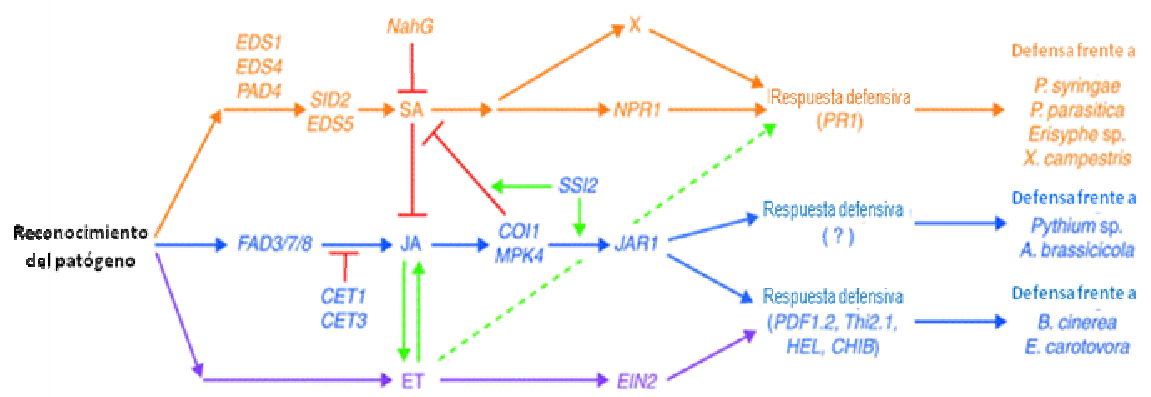

Figura 4. Modelo de interacción entre las rutas del SA, JA y ET en la respuesta defensiva de las plantas. Los genes SID2 y EDS5 parecen estar directamente involucrados en la biosíntesis de SA, mientras que EDS1, EDS4 y PAD4 estarían regulando este proceso. Los genes COI1 y MPK4 participan en la señalización temprana de la ruta del JA, mientras que $F A D 3 / 7 / 8$ y JAR1 intervendrían en la síntesis del JA o alguno de sus derivados. EIN2 y otros factores de transcripción serían los encargados de transducir la señal procedente de la ruta del ET. El modelo se ha simplificado y sólo se muestran algunos de los componentes conocidos. Las interacciones positivas entre las rutas se indican con flechas verdes, mientras que las líneas rojas muestran interacciones antagónicas. La línea verde discontinua indica una posible interacción positiva entre las rutas del SA y ET. Otras interacciones positivas y negativas entre las rutas del SA y JA se comentarán más adelante y no se muestran para simplificar el modelo (ver figura 6). Adaptado de Kunkel \& Brooks, 2002.

También existen datos acerca del papel de la ruta del JA/ET como represor de la señalización mediada por SA. En tabaco, el JA inhibe la expresión de genes dependientes de SA (Niki et al., 1998). Además, el tratamiento de plantas de tabaco con elicitores de E.carotovora, que activan las defensas dependientes de JA en Arabidopsis, es capaz de inhibir la expresión de genes dependientes de SA (Norman-Setterblad et al., 2000; Vidal et al., 1997a). Por otro lado, la caracterización de varios mutantes en la señalización por JA como $m p k 4$ 
(mitogen-activated protein kinase 4), ssi2 (supressor of SA insensitivity2) y coi1, también ha aportado evidencias acerca de que la señalización mediada por JA tiene un efecto antagónico sobre la ruta del SA en Arabidopsis (Kachroo et al., 2001; Kloek et al., 2001; Petersen et al., 2000). Además de tener afectada la señalización por JA, mpk4 y ssi2 muestran activación constitutiva de defensas reguladas por SA y un incremento en la resistencia frente a $P$. syringae e $H$. arabidopsidis (Kachroo et al., 2001; Petersen et al., 2000; Shah et al., 2001). El defecto en la inducción de genes dependientes de JA/ET no se debe a un efecto inhibitorio por una mayor acumulación de SA, dado que se mantiene al introgresar estas mutaciones en un fondo genético NahG. Esto hace indicar que, en estos mutantes, el defecto en la señalización mediada por JA/ET es el que provoca una activación constitutiva de la ruta del SA (Kachroo et al., 2001; Petersen et al., 2000). El mutante coi1 también exhibe una mayor resistencia frente a P.syringae acompañada de una mayor inducción de la expresión de genes de respuesta a SA cuando es infectado por esta bacteria (Feys et al., 1994; Kloek et al., 2001). Estos resultados podrían indicar que algunos patógenos como P.syringae activan la ruta de JA/ET para interferir en las defensas atenuando la señalización mediada por SA aprovechando el efecto antagónico.

Aunque son menos los casos descritos, también existen interacciones positivas entre las rutas del SA y JA/ET. Al parecer, tanto en tabaco como en Arabidopsis, la expresión de algunos genes de defensa precisa de la activación concomitante de ambas rutas (Schenk et al., 2000; Xu et al., 1994), sugiriendo que las dos señalizaciones regulan coordinadamente la expresión de, al menos, una parte de las defensas.

\section{Implicación de otras hormonas vegetales en la respuesta defensiva.}

Así, los mecanismos de defensa parecen estar controlados por dos grandes rutas hormonales. El SA promueve resistencia frente a patógenos biotrofos, mientras que la ruta del JA/ET promueve resistencia frente a patógenos necrotrofos. Estas dos rutas son habitualmente antagónicas, y la activación de una supone una atenuación de la otra. Sin embargo cada vez son más las evidencias de la impicación de otras hormonas en la respuesta inmune (revisado en: Feys \& Parker, 2000a; Kunkel \& Brooks, 2002; Robert-Seilaniantz et al., 2007).

Los mecanismos por los que las auxinas afectan la señalización defensiva no son bien conocidos. Sin embargo son muchas las evidencias que demuestran un papel importante. Se ha observado un efecto negativo de las auxinas en la defensa frente a patógenos biotrofos. Se ha demostrado por ejemplo que algunos patógenos inducen la síntesis de auxinas para suprimir la respuesta hipersensible contribuyendo así a un aumento de la susceptibilidad (Mayda et al., 2000a; Robinette \& Matthysse, 1990). Por otro lado, Navarro y colaboradores han demostrado que la supresión de la señalización mediada por auxinas forma parte de la respuesta inmune inducida por las plantas frente a patógenos biotrofos como Pseudomonas syringae pv. tomato DC3000 (en 
adelante Pst DC3000) (Navarro et al., 2004). También se ha demostrado un incremento en la expresión de genes involucrados en la biosíntesis de auxinas inducida por patógenos virulentos (O'Donnell et al., 2003; Schmelz et al., 2003). Otros efectos propuestos para las auxinas es el de incrementar la disponibilidad de nutrientes para el patógeno o incluso tener un efecto directo sobre la virulencia de estos, dado que muchos microbios utilizan auxinas como moléculas señalizadoras, y su producción se ve incrementada en condiciones de estrés (Fry, 1989; Lindow \& Brandl, 2003; Remans et al., 2006; Yang et al., 2007).

La habilidad de las citokininas de retardar la senescencia y de movilizar nutrientes hacia los sitios de aplicación hizo pensar a muchos investigadores que esta hormona podría estar involucrada en la aparición de "islas verdes" en las hojas de plantas inoculadas con hongos biotrofos. Existen evidencias de que la reducción en la fotosíntesis en hojas infectadas es causada por un rápido incremento en la actividad de las invertasas, llevando consigo un aumento en la acumulación de carbohidratos y un descenso en el metabolismo fotosintético. Es por esto que algunos autores han propuesto que los patógenos biotrofos utilizan las citokininas para generar ese aumento en la actividad de las invertasas e incrementar así la disponibilidad de nutrientes (Robert-Seilaniantz et al., 2007; Walters \& McRoberts, 2006). El papel de las citokininas en la respuesta defensiva de las plantas tiene algunas similitudes con el caso de las auxinas. Además de que ambas hormonas son sintetizadas y utilizadas en los procesos de infección por patógenos predominantemente biotrofos, ambos compuestos han sido asociados a la supresión de la HR (Murphy et al., 1997; Robinette \& Matthysse, 1990).

El ácido giberélico (GA) y sus distintas formas activas, por el contrario, parecen tener un efecto opuesto en la defensa de las plantas. Bien es conocida la promoción del crecimiento provocado por las GAs a través de la inducción de la degradación de las proteínas DELLA, reguladores negativos del crecimiento (Harberd, 2003). Recientemente se ha sabido que la pérdida de función de las DELLA hace a las plantas más resistentes a Pst DC3000 a través de la potenciación de las defensas dependientes de SA, pero incrementa drásticamente la susceptibilidad a necrotrofos. Esto estaría indicando que las proteínas DELLA funcionarían promoviendo resistencia a necrotrofos $\mathrm{y}$ susceptibilidad a biotrofos interviniendo en la modulación del balance entre las señalizaciones dependientes de SA y JA/ET (Robert-Seilaniantz et al., 2007).

El papel del ABA en la respuesta defensiva de las plantas no es muy conocido. Recientemente se ha observado que Pst DC3000 induce la producción de ABA durante su proceso de infección, indicando que el $A B A$ es un factor de susceptibilidad para esta bacteria. Este hecho encaja con algunos trabajos donde la aplicación exógena de ABA o los tipos de estrés abiótico como la sequía (que promueven la acumulación de $\mathrm{ABA}$ ) aumentan la susceptibilidad del arroz al patógeno Magnaporthe grisea (Koga et al., 2004; Mauch-Mani \& Mauch, 2005) o donde la concentración de ABA estaba correlacionada con la susceptibilidad de Arabidopsis a Pst DC3000 o H. arabidopsidis (Mohr \& Cahill, 
2003). Más recientemente Mohr y Cahill han demostrado que el ABA suprime la acumulación de SA y lignina en Arabidopsis infectadas con Pst DC3000 (Mohr \& Cahill, 2007). El ABA también interfiere con la señalización defensiva mediada por JA/ET. JIN1 es un factor de transcripción originariamente identificado por ser un regulador positivo de la señalización mediada por ABA (Abe et al., 2003). Mutaciones en este gen provocan además un aumento en la expresión de genes relacionados con la ruta del JA como PDF1.2 acompañada de un aumento en la resistencia a necrotrofos (Lorenzo et al., 2004). Otros estudios han demostrado que la aplicación exógena de ABA suprime la expresión de genes regulados por JA/ET (Anderson et al., 2004). Esto indica que el ABA estaría actuando como un regulador negativo tanto de la ruta del SA como de la ruta del JA, promoviendo susceptibilidad a patógenos biotrofos y necrotrofos.

Sin embargo el ABA ha sido también asociado con resistencia. Los mutantes deficientes en la síntesis de ABA son insensibles a la inducción de resistencia por ácido $\beta$-amino butírico (BABA). El BABA es un aminoácido no proteico, y su aplicación confiere resistencia de amplio espectro independiente de la activación de marcadores clásicos, no conociéndose los mecanismos por los cuales induce esa resistencia. Es por todo esto que se piensa que este químico puede tener un efecto de priming o potenciación de las rutas defensivas. Pues bien, la aplicación exógena de ABA es capaz de imitar ese efecto de priming del BABA (Mauch-Mani \& Mauch, 2005; Ton \& Mauch-Mani, 2004). Por otro lado también se ha descrito que el mutante aba3 (deficiente en la síntesis de ABA) es más susceptible a Pst DC3000, algo que choca con los resultados obtenidos por Zabala y colaboradores, en los que se demostraba que la ruta de biosíntesis del ABA era una diana de Pst DC3000 para promover virulencia (de Torres-Zabala et al., 2007). Una posible explicación a estos resultados aparentemente contradictorios podría buscarse en el papel del ABA como regulador positivo del cierre estomático. Los estomas son una de las principales vías de entrada a la planta de las bacterias, por lo que las bacterias podrían interferir en la síntesis del ABA impidiendo que se cierren. Sin embargo, una vez en los espacios intercelulares, las bacterias patógenas necesitan mantener un potencial hídrico elevado para el avance de su infección, por lo que un incremento en el contenido en ABA promovería que las plantas cerrasen los estomas, perdiesen menos agua, aumentando la virulencia (Wright \& Beattie, 2004).

El tratamiento con brasinoesteroides (BR) también tiene efecto en la inducción de defensas. Por ejemplo, la aplicación de BR a plantas de arroz y tabaco aumenta la resistencia frente a diversos patógenos biotrofos aunque de manera independiente de SA (Nakashita et al., 2003). La explicación podría residir en la compleja red de interacciones que existe entre los BR y otras hormonas vegetales (Krishna, 2003). Por ejemplo, algunos hongos producen toxinas como la zearalenona que se asemejan mucho a hormonas, y se ha observado que esta y otras moléculas interfieren en la señalización mediada por BRs en mamíferos (Kiessling, 1986), lo que podría sugerir que algunos patógenos pueden interferir en esta ruta de alguna manera para promover virulencia. 
En resumen, cada vez son más las evidencias que demuestran la implicación de múltiples reguladores hormonales en las interacciones planta-patógeno. A pesar de esto, el efecto de cada hormona en la resistencia parece seguir el modelo clásico con las rutas del JA/ET por un lado, y la del SA por el otro, ejerciendo un efecto antagónico mutuo. Así, auxinas y citokininas estarían promoviendo susceptibilidad a patógenos biotrofos al inducir resistencia frente a necrotrofos a través de la ruta de JA/ET. Por el contrario, las giberelinas inducirían susceptibilidad a necrotrofos debido a la activación de la ruta defensiva frente a biotrofos mediada por SA. El papel del ABA en la respuesta defensiva parece ser más complicado. El ABA ha sido asociado con susceptibilidad tanto a necrotrofos como a biotrofos y en general suele considerarse como un regulador negativo de la resistencia a patógenos. Además el ABA juega un papel crucial en los procesos adaptativos frente a estrés abiótico, y podría suceder que las plantas priorizasen la respuesta a estos tipos de estrés frente a los de tipo biótico. Sin embargo este modelo parece estar incompleto, debido a que también se ha asociado al ABA con resistencia a patógenos. Por último, los brasinoesteroides promueven resistencia frente a biotrofos a través de una ruta independiente de SA, no habiendo sido demostrado efecto alguno sobre la respuesta a necrotrofos (Robert-Seilaniantz et al., 2007).

Así pues, el impacto de las hormonas vegetales en las respuestas defensivas en una interacción planta-patógeno determinada no debe simplificarse a las relaciones existentes entre las rutas mediadas por SA y JA/ET. Parece claro que para el establecimiento de una adecuada respuesta defensiva, se produce una interacción coordinada entre componentes de las rutas mediadas por las distintas hormonas. La interferencia de una de las rutas por la infección de un patógeno debe entenderse como un desequilibrio en esa red en la cual cada cambio en un componente tiene su efecto sobre los otros (Nemhauser et al., 2006; Schenk et al., 2000).

El significado evolutivo de la existencia en las plantas de diferentes rutas defensivas que se regulan unas a otras se ha discutido en profundidad (Felton et al., 1999; Feys \& Parker, 2000a; Reymond \& Farmer, 1998a; Thomma et al., 2001a). La separación de las rutas de señalización ha podido proporcionar a las plantas un mecanismo de fina regulación de las respuestas defensivas más apropiadas para cada situación y cada patógeno, dependiendo de su estrategia de invasión. Las interacciones antagónicas de algunas de estas rutas podrían servir para impedir la activación de defensas inapropiadas en respuesta a según qué patógenos. Por ejemplo, se ha demostrado que la activación de la ruta del SA puede inducir la aparición de muerte celular para confinar el crecimiento de patógenos de tipo biotrofo (O'Donnell et al., 2001; Vanacker et al., 2001). Sin embargo, puede ser una ventaja suprimir la señalización mediada por SA a la hora de combatir una infección de patógenos necrotrofos, los cuales utilizan toxinas inductoras de muerte celular como factores de virulencia para macerar el tejido y generar un ambiente más apropiado para la colonización del hospedador (Kunkel \& Brooks, 2002). 


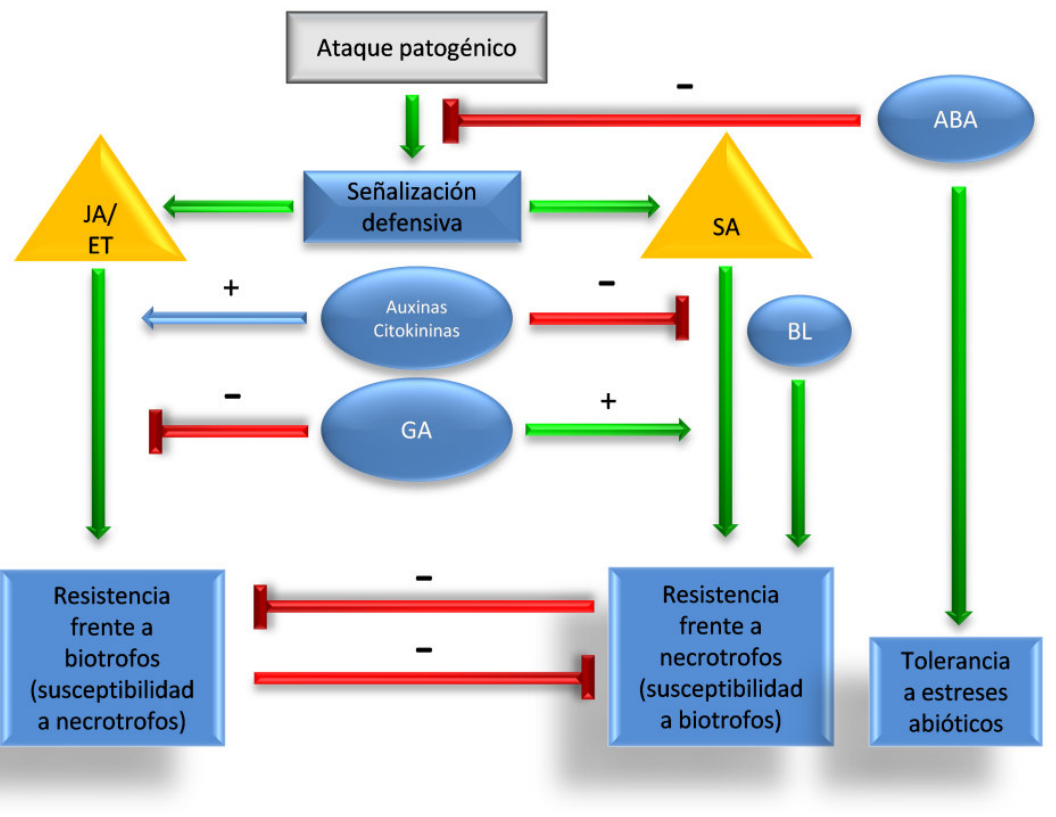

Figura 5. Modelo de interacción de las señalizaciones mediadas por las diferentes fitohormonas durante las interacciones planta-patógeno. El esquema divide las señalizaciones defensivas en dos grandes grupos. Por un lado la señalización dependiente de JA y ET que gobierna la resistencia frente a patógenos necrotrofos y por otro la señalización dependiente de SA que media la resistencia frente a patógenos biotrofos. Las interacciones de las diferentes fitohormonas con estas rutas se indican con flechas verdes (positivas) o líneas rojas (negativas). ABA, ácido abscísico; JA, ácido jasmónico; SA, ácido salicílico; ET, etileno; GA, ácido giberélico; BL, brasinólidos. Adaptado de RobertSeilaniantz et al., 2007.

Por otro lado, aunque esta compleja red de señalización altamente regulada puede proporcionar una ventaja evolutiva a las plantas, también ha podido contribuir a aumentar la vulnerabilidad a algunos patógenos. Como se ha ido comentando a lo largo de este apartado, muchos patógenos han desarrollado hábiles estrategias para incrementar su virulencia interfiriendo en las señalizaciones defensivas, sintetizando directamente hormonas como ET o auxinas u otras moléculas capaces de mimetizar su efecto como en el caso de la coronatina (Fukuda et al., 1993; Gross \& Cody, 1985; Kloek et al., 2001; Lambrecht et al., 2000). En algunos casos, el papel de la síntesis de estos compuestos no está claro, pero podría proporcionar a los patógenos un mecanismo para modificar los procesos fisiológicos y de señalización con el fin de hacer más apropiado el tejido de la planta para su colonización, crecimiento y producción de síntomas. 


\section{Respuestas sistémicas inducidas.}

Además de las respuestas defensivas locales, las plantas han desarrollado también respuestas sistémicas que establecen un incremento de la capacidad defensiva en tejidos distanciados del punto de infección primario. Estas respuestas sistémicas inducidas protegen a la planta frente a un amplio abanico de invasores posteriores. Son varias las respuestas defensivas sistémicas caracterizadas en detalle. Entre ellas cabe destacar la Respuesta Sistémica Adquirida (SAR), que es desencadenada por patógenos necrotizantes; la Respuesta Sistémica Inducida (ISR), activada tras la colonización de las raíces por algunas cepas de rizobacterias no patógenas; o la Resistencia Inducida por Herida (WIR), típicamente elicitada por el daño de los tejidos generado por insectos herbívoros al alimentarse (Pieterse \& Van Loon, 2004). Como ya se ha indicado, las respuestas sistémicas inducidas están reguladas por una red de rutas de transducción de señales interconectadas en las que las hormonas SA, JA y ET juegan un papel central, aunque, como se ha visto en apartados anteriores, otras hormonas como las auxinas, las citokininas, los brasinoesteroides o el ABA también están involucradas (Audenaert et al., 2002; Glazebrook, 2001; Nakashita et al., 2003; Pieterse \& van Loon, 1999; RobertSeilaniantz et al., 2007; Thomma et al., 2001b; Ton \& Mauch-Mani, 2004).

\section{SAR}

La Respuesta sistémica adquirida (SAR, (Ross, 1961)) es, de lejos, la más estudiada de las resistencias inducidas, y sin embargo, aún es mucho lo que nos queda por conocer. Por ejemplo, no se sabe con exactitud cuál es la señal que se transmite por la planta para inducir SAR en el tejido distal. En este sentido, aunque se ha observado que uno de los primeros eventos que acontecen en el establecimiento de SAR es un aumento local y sistémico de los niveles endógenos de SA y que esta molécula se mueve a través de la planta, se ha demostrado que no es la señal móvil en SAR (Sticher et al., 1997). DIR1 es un gen que codifica una proteína transportadora de lípidos localizada en el apoplasto y que es requerida para la inducción de la SAR. Análisis de una línea de inserción de T-DNA en DIR1 sugieren que esta proteína interacciona con un derivado lipídico, lo que permite la señalización a larga distancia durante SAR (Maldonado et al., 2002). Además, la proteína de unión a SA SABP2 de tabaco, que funciona como un receptor de SA en la interacción con el Virus del Mosaico del Tabaco (TMV) es una lipasa cuya actividad es estimulada por la unión de SA y podría generar esa señal lipídica en SAR (Kumar \& Klessig, 2003). Por otro lado, la proteína SFD1 (supressor of fatty acid desaturase deficiency1), que es requerida para la activación sistémica de SAR, también parece estar envuelta en el metabolismo de lípidos (Nandi et al., 2004). Juntos, estos resultados apuntan a que los derivados lipídicos son importantes componentes de la señalización a larga distancia en SAR, aunque no se conoce con exactitud cuál es la señal móvil que activa SAR en tejidos distales. 
Como se ha comentado en apartados anteriores, la señalización mediada por SA requiere de NPR1 para la expresión de genes $P R$. NPR1 es una proteína reguladora identificada en numerosos rastreos buscando mutantes afectados en SAR recibiendo diferentes nombres como NIM1 (non-inducible immunity1) o SAI1 (salicylic acid insensitive1) (Cao et al., 1994; Delaney et al., 1995; Glazebrook et al., 1996; Shah et al., 1997).

NPR1 codifica una proteína con repeticiones de ankirina. En condiciones no inductivas se encontraría inactiva formando multímeros en el citosol merced a la formación de puentes disulfuro inter e intramoleculares entre los residuos de cisteína. La inducción de SAR está asociada a su vez con un aumento de especies antioxidantes que modifican el estado redox de la célula, y que según el modelo propuesto, provocan la reducción de los puentes disulfuro generando monómeros activos de NPR1 (Mou et al., 2003). Estos monómeros serían capaces de entrar al núcleo donde se ha demostrado que se unen físicamente a miembros de una subfamilia de factores de transcripción de tipo basic leucine zipper (bZIP) denominada TGA, que regulan la transcripción de genes PR dependientes de SA uniéndose directamente a sus promotores (Kinkema et al., 2000; Zhang et al., 1999; Zhou et al., 2000). Se ha demostrado que NPR1 aumenta significativamente la unión de los factores TGA a estas secuencias promotoras, sugiriendo que la unión de los TGAs al ADN favorecida por NPR1 es importante para la expresión de los genes PR mediada por SA (Zhang et al., 1999). Así pues, los cambios en el estado redox de la célula causados por un incremento en los niveles de SA inducidos por el ataque de un patógeno, podrían estar modulando la función de NPR1 durante el establecimiento de SAR (Revisado en Dong, 2004; Pieterse \& Van Loon, 2004).

Además del papel de NPR1 como regulador central de la expresión de genes $P R$, se ha identificado una función citosólica de NPR1 como modulador de la interacción entre las señalizaciones defensivas mediadas por SA y ET. El establecimiento de SAR prioriza las defensas activadas por SA, reprimiendo la señalización mediada por JA de manera dependiente de NPR1. La localización nuclear de NPR1, que es necesaria para la expresión de PRs, parece no serlo para la supresión de la ruta del JA. Es por esto que recientemente se ha propuesto que esta supresión se lleva a cabo por parte del pool de monómeros activos de NPR1 presente en el citosol, que podría estar interfiriendo en la regulación de genes dependientes de JA (Pieterse \& Van Loon, 2004; Spoel et al., 2003). Sin embargo el modo de acción de NPR1 en el citosol es desconocido. Se ha especulado acerca de la posibilidad de que podría estar interfiriendo en la regulación de genes dependientes de JA a través del complejo de ubiquitinación SCFCol1, bloqueando el marcaje y posterior degradación vía proteosoma de un regulador negativo desconocido de la señalización mediada por JA (Spoel et al., 2003).

Se han identificado otros elementos importantes involucrados en estas interacciones. Es el caso de WRKY70, un factor de transcripción que funciona como activador de genes de respuesta a SA y represor de genes de respuesta a JA, integrando ambas señales antagónicas (Li et al., 2004). Se ha interpretado esto como que es el balance entre los niveles de SA y JA tras la infección 
patogénica, lo que determinaría los niveles de expresión de WRKY70 de forma que elevados niveles de este factor de transcripción activarían la expresión de genes de respuesta a SA, mientras que bajos niveles favorecerían la activación de genes dependientes de JA. Por otro lado, también se ha propuesto que otro factor de transcripción, ERF1 (ethylene response factor1), integra las señales provenientes de las rutas del JA y ET activando genes de defensa dependientes de ambas hormonas (Lorenzo et al., 2003). La expresión de este gen es rápidamente inducida tanto por JA como por ET, y la acción simultánea de las dos señales, incrementa su expresión. Sobreexpresando ERF1 en fondos mutantes ein2 o coi1 se activan una serie de genes cuya expresión está bloqueada en los mutantes, indicando que ERF1 actúa aguas abajo de COI1 y EIN2 activando genes co-regulados por JA y ET.

\section{ISR}

El estudio de la interacción entre Arabidopsis y la bacteria no patogénica Pseudomonas fluorescens WCS417 $\mathrm{r}$ ha permitido establecer las bases moleculares de la denominada Respuesta Sistémica Inducida o ISR (Pieterse et al., 1996). La colonización de las raíces por esta cepa de $P$. fluorescens induce resistencia en numerosas especies como clavel (Vanpeer et al., 1991), rábano (Leeman et al., 1995) o tomate (Duijff et al., 1998), protegiendo frente a infecciones por diferentes patógenos incluyendo Pst DC3000, X.campestris pv. Amoracia, Fusarium oxisporum f.sp. raphani o H.arabidopsidis (Pieterse et al., 1996; Van Wees et al., 1997). La inducción de ISR depende de la combinación de hospedador y rizobacteria. Así, se han descrito diferentes especies y cepas de Pseudomonas con efectividades distintas según la especie vegetal colonizada (Van Peer et al., 1991, 1992, Van Wees et al., 1997). En Arabidopsis se han observado diferencias en la elicitación de ISR según el ecotipo estudiado. Por ejemplo, Columbia o Landsberg erecta responden al tratamiento con WCS417r, mientras que los ecotipos RLD o Wassilewskija no (Ton et al., 1999; Van Wees et al., 1997). Estas observaciones llevaron a pensar que la ISR inducida por rizobacterias está genéticamente determinada.

Posteriores estudios han demostrado que la ISR mediada por WCS417r y otras rizobacterias en Arabidopsis es independiente de la acumulación de SA y la expresión de genes $P R$. Así, tanto las plantas transgénicas NahG como los mutantes sid1-1 y sid1-2, deficientes en la inducción de SA (Nawrath \& Metraux, 1999) desarrollan niveles normales de ISR (Pieterse et al., 2000). Por el contrario, mutantes defectivos en las rutas de señalización o síntesis de JA o ET, son incapaces de establecer eficazmente ISR, lo que sugiere que, de manera similar al SA en SAR, la ISR necesita de una correcta respuesta mediada por estas hormonas (Pieterse et al., 1998). Además, aplicaciones exógenas de JA y ACC (un precursor del ET), inducen resistencia frente a Pst DC3000 en plantas NahG. Sin embargo, mutantes como jar1-1 o etr1-1, alterados en la señalización mediada por JA y ET respectivamente, tienen bloqueada la inducción de resistencia por JA, mientras que para el caso del ACC, solo etr1-1 está afectado, pero no jar1-1. Estos resultados demuestran que, la cadena de eventos que lleva 
al establecimiento de esta respuesta defensiva, implica primero la activación de la señalización controlada por JA y a continuación la controlada por ET (Pieterse et al., 1998).

Aún así SAR e ISR tienen elementos reguladores en común, puesto que el establecimiento de ambos estados está bloqueado en el mutante npr1 que originariamente fue descubierto como regulador clave de SAR. La activación de NPR1 conduce a la expresión de genes $P R$ en SAR, algo que no sucede en ISR (Cao et al., 1994; Pieterse et al., 1998). Esto demuestra que NPR1 es capaz de regular diferencialmente tanto ISR como SAR dependiendo de la ruta activada.
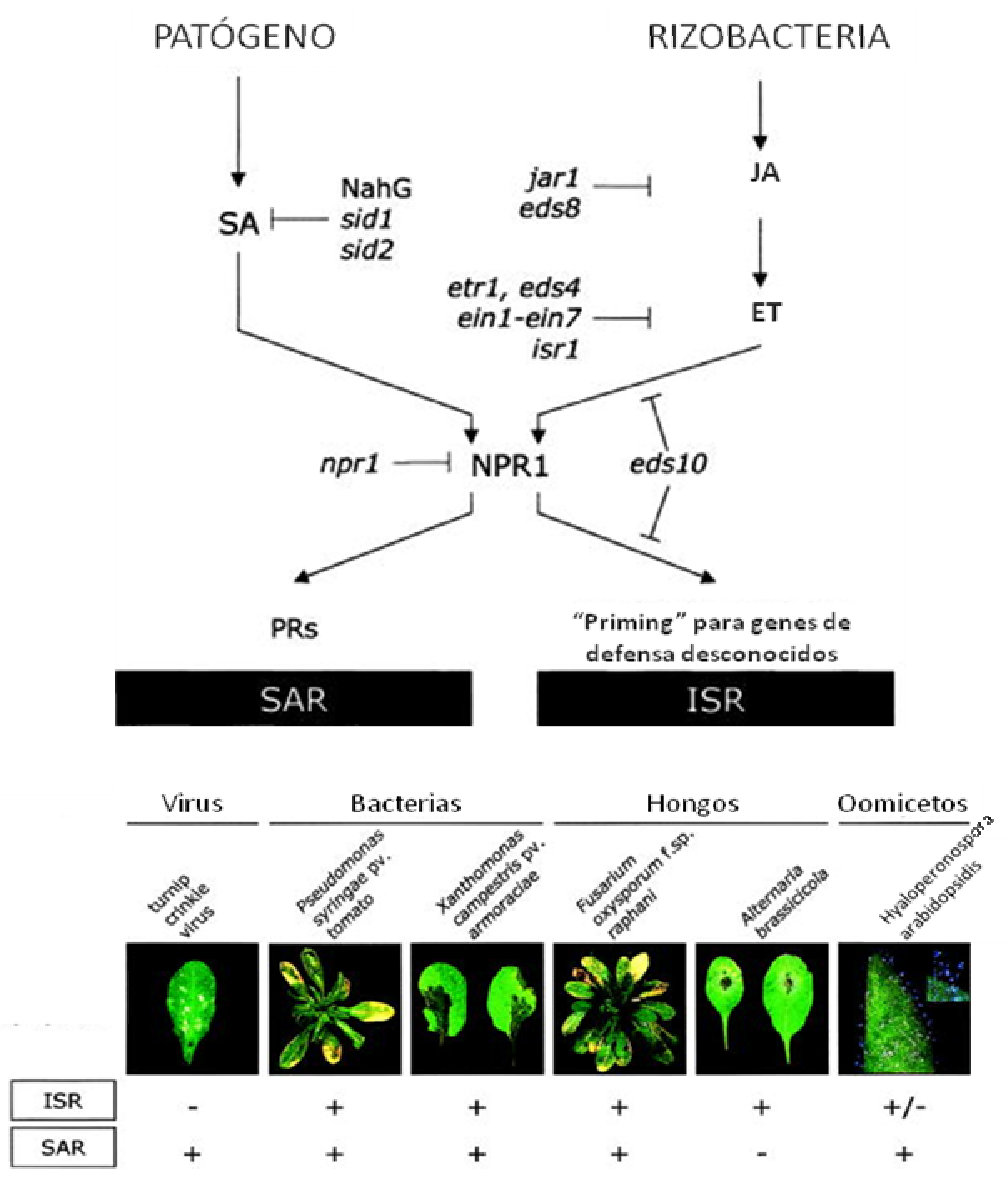

Figura 6. Modelo de integración de la Respuesta Sistémica Adquirida (SAR) y la Respuesta Sistémica Inducida (ISR) en el marco de las interacciones plantapatógeno. SAR e ISR se diferencian en que están mediadas por señalizaciones diferentes, controladas por SA y JA/ET respectivamente. Además SAR depende de la expresión de genes $P R$ inducibles por SA mientras que en el caso de ISR, se piensa que se produce un incremento en la sensibilidad o "priming" para la activación de las defensas dependientes de JA/ET. Sin embargo ambas respuestas tienen en común el papel de NPR1 como regulador central. En el panel inferior se muestra el rango de efectividades de ISR y SAR frente a diferentes tipos de patógenos.(Adaptado de Pieterse et al., 2002) 
Análisis de tejido tanto local como sistémico han revelado que el establecimiento de ISR no va acompañado de un aumento en los niveles de JA o ET, por lo que la inducción de resistencia debe estar basada en un aumento en la sensibilidad a estas hormonas más que en un aumento en su producción. Así, plantas en estado de ISR son capaces de reaccionar más rápido y de una manera más eficaz ante el ataque de un patógeno. Estudios transcriptómicos han determinado que la activación de ISR parece no inducir cambios de expresión de genes, al menos detectables a través de micromatrices. Se cree que de existir, estos cambios podrían darse en factores de transcripción con bajos niveles de expresión aunque es más probable que la base de la ISR se centre en un aumento de componentes celulares así como modificaciones de algunas proteínas, cambios que por sí solos no activarían la respuesta pero que amplificarían la señal en respuesta a una segunda señal como el ataque de un patógeno (Pieterse \& van Loon, 1999).

Van Wees y colaboradores monitorizaron los niveles de expresión de algunos genes dependientes de SA (PR-1, PR-2 y PR-5), JA (VSP, PDF1.2, LOX2, PAL1) y ET $(H E L$ y $C H I B)$. Mientras que el establecimiento de SAR potenciaba la expresión de todos los genes estudiados, solamente para VSP se observó un aumento de la expresión en plantas ISR comparado con las plantas control, sugiriendo que la ISR está asociada con la potenciación o priming (descrito más adelante) de un grupo específico de genes de respuesta a JA (Van Wees et al., 1997).

\section{BABA-IR}

El ácido $\beta$-aminobutírico (BABA) es un aminoácido no proteico que activa una respuesta defensiva inducida de otro tipo, denominada BABA-IR. El efecto protector del BABA frente a numerosas enfermedades de plantas está bien documentado, aunque las bases moleculares son poco conocidas (Cohen, 2001; Jakab et al., 2001). Al parecer, en el establecimiento de BABA-IR están involucrados mecanismos de defensa tanto dependientes de SA como de ABA, pero la importancia de estas defensas varía dependiendo de la naturaleza del patógeno. Así, frente a Pst DC3000 y B.cinerea, BABA-IR requiere de la acumulación de SA y de la proteína NPR1 intacta, aunque no frente a $H$. arabidopsidis o P.cucumerina. Sin embargo, mutantes afectados en la síntesis o sensibilidad al ABA están bloqueados en BABA-IR, sugiriendo la existencia de una ruta independiente de SA y NPR1 pero dependiente de ABA (Ton \& MauchMani, 2004; Zimmerli et al., 2000; Zimmerli et al., 2001).

Un aspecto interesante de la resistencia inducida por BABA es que confiere protección frente a una amplia gama de tipos de estrés tanto bióticos como abióticos (Cohen, 2001). En Arabidopsis, BABA-IR es efectiva frente a patógenos tanto biotrofos como necrotrofos, así como frente a sequía o salinidad (Jakab et al., 2001; Ton et al., 2005; Ton \& Mauch-Mani, 2004). Se ha propuesto que más que inducir directamente defensas, el BABA condiciona a la planta para una activación más rápida y fuerte de los mecanismos de defensa específicos bajo condiciones de estrés (Jakab et al., 2001; Ton \& Mauch-Mani, 2004; Zimmerli et 
al., 2001). Por analogía con un fenómeno similar en animales y humanos, este fenómeno fue denominado sensibilización, potenciación o priming (Conrath et al., 2002). Los mecanismos fisiológicos y moleculares del priming son poco conocidos y los primeros estudios fueron básicamente descriptivos. Algunas plantas estresadas respondían de manera más eficiente ante el ataque de un patógeno a través de una acumulación de calosa más rápida y abundante, mayores niveles de lignificación de las paredes celulares o una más rápida cinética de inducción de genes de defensa (Dean \& Kuc, 1987; Kovats et al., 1991; Silverman et al., 1995; Skipp \& Deverall, 1973). En Arabidopsis, el tratamiento con BABA provoca un priming para diversos mecanismos de defensa. Por ejemplo, induce una mayor expresión de PRs dependientes de SA en respuesta a la infección por Pst DC3000 o B. cinerea (Zimmerli et al., 2000; Zimmerli et al., 2001). También potencia la deposición de papillae ricas en calosa bajo los apresorios de hongos y oomicetos patógenos (Ton \& MauchMani, 2004) o la expresión de genes como $R A B-18$ y $R D 29 A$ en respuesta a sequía y salinidad (Jakab et al., 2005).

\section{Antecedentes}

El mutante ocp3 (overexpressor of cationic peroxidase 3) se identificó recientemente durante un escrutinio genético que pretendía aislar mutantes desregulados en el patrón de expresión del promotor del gen de tomate Ep5C (Coego et al., 2005a). Ep5C codifica un enzima de tipo peroxidasa, cuya transcripción se induce de forma muy rápida tras la aplicación de $\mathrm{H}_{2} \mathrm{O}_{2}$ así como a las pocas horas tras la inoculación tanto con los hongos $B$. cinerea y $P$. cucumerina como con bacteria compatible (Pseudomonas syringae pv. tomato DC3000) e incompatible (Pseudomonas syringae pv. tomato DC3000 AvrRpm1) (Coego et al., 2005a; Coego et al., 2005b). Es de resaltar el patrón de expresión del gen Ep5C, ya que ninguno de los tratamientos con moléculas que clásicamente están involucradas en la respuesta defensiva en las plantas, tales como la aplicación exógena de SA, JA, ET o tratamientos asociados con herida, son capaces de inducir la expresión de dicho gen (Coego et al., 2005a). Mientras que la sobreexpresión de Ep5C en plantas de tomate no altera los niveles de crecimiento de la bacteria Pst DC3000, plantas antisentido muestran una elevada resistencia, indicando que Ep5C podría ser utilizado por este tipo de patógenos como un factor de pro-virulencia (Coego et al., 2005a).

El aislamiento de ocp3 se realizó a partir de la mutagénesis con EMS de una población de semillas procedentes de una línea transgénica de Arabidopsis en la que el promotor del gen Ep5C de Solanum lycopersicon dirigía la expresión del gen uidA (GUS), que codifica la enzima $\beta$-glucuronidasa (Jefferson et al., 1987). En este escrutinio se aislaron varios mutantes ocp (overexpressor of cationic peroxidase). En concreto, el mutante recesivo ocp3 presenta una expresión constitutiva del gen GUS. La caracterización molecular del mutante desveló que ocp3 posee expresión constitutiva de los genes PDF1.2 y GST-6, ambos relacionados con defensa. 
Las plantas ocp3 exhiben una mayor resistencia frente a hongos necrotrofos como B. cinerea y P. cucumerina, mientras que el crecimiento de patógenos con un estilo de vida biotrofo como Pst DC3000 o H.arabidopsidis, no se ve alterado. Mediante la generación y caracterización de una extensa batería de dobles mutantes entre ocp3 y mutantes alterados en diferentes rutas de señalización, se concluyó que la resistencia asociada a ocp3 es independiente de SA y ET, y sin embargo es dependiente de JA (Coego et al., 2005b).

El gen OCP3 codifica un factor de transcripción de la familia Homeobox, y su expresión se ve reprimida tanto por la aplicación exógena de JA como por la infección con hongos necrotrofos (Coego et al., 2005b). Así pues, según todos estos datos, se ha propuesto que OCP3 estaría actuando como un regulador negativo de la resistencia a patógenos necrotrofos controlada por la ruta de señalización dependiente de JA.

La caracterización previa del mutante ocp3 justifica un estudio en profundidad de los mecanismos celulares y moleculares que operan tras la resistencia a patógenos necrotrofos en estas plantas. Además parece necesario un completo estudio fenotípico para determinar posibles nuevas funciones para el gen $O C P 3$, a través del impacto de su pérdida y/o ganancia de función sobre otros procesos biológicos de las plantas. 
Introducción general

40 
OBJETIVOS 


\section{Objetivos}

Con el fin de profundizar en el estudio de las funciones del gen $O C P 3$, en la regulación de los procesos adaptativos de las plantas frente a situaciones de estrés tales como la sequía o infecciones por patógenos necrotrofos, se establecieron los siguientes objetivos:

1- Estudio de la implicación de $O C P 3$ en la interacción de las rutas de señalización mediadas por SA y JA/ET. Análisis en profundidad del efecto de la mutación ocp3 en la resistencia/susceptibilidad a Pst DC3000 de diferentes fondos genéticos alterados en la señalización defensiva regulada por SA. Estudio de la función de OCP3 como regulador de la Respuesta Sistémica Inducida (ISR).

2- Estudio de la participación de OCP3 en la regulación del mecanismo de señalización mediada por la fitohormona ABA. Identificación de proteínas interactoras de OCP3 mediante el sistema de doble híbrido en levadura. Determinación del dominio concreto de interacción. Caracterización genética y funcional de la interacción OCP3-ABI1 dentro del marco de la resistencia a sequía mediada por $A B A$ y su conexión con la resistencia a hongos necrotrofos controlada por JA. 


\section{RESULTADOS Y DISCUSIÓN}


CAPÍTULO I.

OCP3, un nuevo componente de la Resistencia

Sistémica Inducida (ISR) 


\section{OCP3, un nuevo componente de la Resistencia Sistémica Inducida (ISR)}

En el apartado de Antecedentes se han resumido las evidencias que han llevado a situar a $O C P 3$ en el panorama de la respuesta defensiva de las plantas como un regulador negativo de la ruta de transducción de señales dependiente del JA y efectiva frente a patógenos de tipo necrotrofo. Además las plantas ocp3 presentan una expresión constitutiva de la defensina PDF1.2 que es drásticamente suprimida tras la aplicación de SA (Coego et al., 2005b). En anteriores trabajos se ha demostrado que los niveles de crecimiento de algunos patógenos biotrofos como $H$. arabidopsidis o Pst DC3000 no son diferentes entre ocp3 y Col-0 (Coego et al., 2005b). Como se ha comentado en el apartado de Introducción, aunque la respuesta defensiva frente a este tipo de patógenos está mediada fundamentalmente por la señalización dependiente de SA, existen numerosas evidencias que apuntan a la existencia de una compleja red de interrelaciones entre ésta y la ruta del JA. Se han dedicado muchos esfuerzos a identificar y caracterizar componentes de cada una de las rutas por separado, que posteriormente han sido relacionados con la otra (Clarke et al., 2000; He et al., 2004; Jirage et al., 2001; Kachroo et al., 2003; Nandi et al., 2003; Veronese et al., 2004). Aún así, el conocimiento de las comunicaciones entre las señalizaciones mediadas por SA y JA es limitado.

\section{La mutación ocp3 revierte la susceptibilidad a Pst DC3000 en algunos mutantes de la ruta de señalización mediada por SA.}

Con el fin de profundizar en las posibles relaciones entre la regulación defensiva mediada por OCP3 y las interconexiones existentes entre las rutas del JA y SA decidimos generar una batería de dobles mutantes introgresando la mutación oсp3 en fondos genéticos que presentan defectos en la ruta del SA, bien en la inducción de la síntesis de esta hormona, bien en su percepción, o bien en la acumulación. Por un lado seleccionamos mutantes hipersusceptibles frente a Pst DC3000 como son pad4, eds1 y npr1 además de la línea transgénica $N a h G$. Se ha descrito que el gen PAD4 participa en un bucle de regulación positiva que incrementa los niveles de SA activando así la expresión de múltiples genes de defensa como $P R-1$ o la síntesis de camalexina en respuesta a la infección por Pst DC3000 (Jirage et al., 1999). EDS1 es un enzima con elevada similitud de secuencia con lipasas eucarióticas, que podría participar en la hidrólisis de lípidos durante la HR. Mutaciones en este gen bloquean la activación de la ruta del SA con el consiguiente aumento en la susceptibilidad de las plantas frente a patógenos biotrofos (Aarts et al., 1998; Ochsenbein et al., 2006; Wiermer et al., 2005). NPR1 es un regulador central en la resistencia mediada por SA. Las plantas npr1 son más susceptibles a patógenos biotrofos que las plantas wt ya que son incapaces de activar la expresión de diferentes genes $P R$, en respuesta tanto a la aplicación exógena de SA como a la infección por Pst DC3000 (Dong, 2004; Pieterse \& Van Loon, 2004). Las plantas transgénicas NahG expresan el enzima SA-hidroxilasa y no son capaces de 
acumular SA ya que lo convierten en catecol, por lo que son muy susceptibles a Pst DC3000 (Delaney et al., 1994; Gaffney, 1993; Lawton et al., 1995; Reuber, 1998).

Por otro lado introgresamos también la mutación ocp3 en dos fondos mutantes que presentan una mayor resistencia frente a Pst DC3000, como son $c p r-1 \mathrm{y}$ cpr-5. Estos mutantes expresan constitutivamente $P R-1, P R-2$, y $P R-5$ y presentan mayores niveles de acumulación de SA (Clarke et al., 2000).

La caracterización de la respuesta de todos estos dobles mutantes frente a Pst DC3000 nos permitió determinar el efecto de la mutación ocp3 en los diferentes fondos genéticos y por tanto descubrir la implicación de OCP3 en este tipo de señalización defensiva.

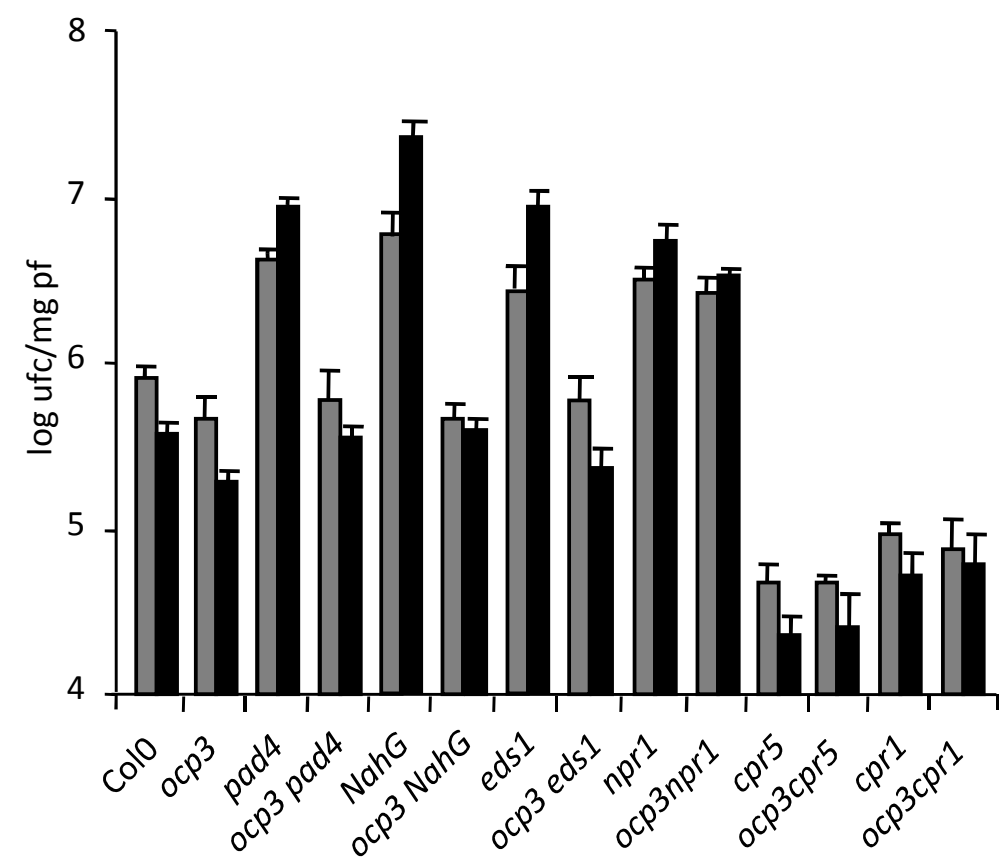

Figura 1. La mutación ocp3 restablece hasta niveles wt la susceptibilidad de los genotipos pad4, eds1 y NahG, pero no de npr1. Gráfica de crecimiento de Pst DC3000. Plántulas de dos semanas de edad inoculadas por inmersión en una suspensión bacteriana a una D.O. de 0,1. El crecimiento logarítmico fue determinado a los 3 días (barras grises) y 5 días (barras negras) según la media de las unidades formadoras de colonias por peso fresco en cuatro réplicas independientes. Las barras de error representan el error estándar de la media de las cuatro réplicas. El experimento fue repetido al menos cuatro veces con resultados similares.

La figura 1 muestra el crecimiento de Pst DC3000 en los diferentes genotipos. Sorprendentemente la mutación ocp3 es capaz de suprimir la susceptibilidad asociada tanto a las mutaciones pad4 y eds1 como a la línea $N a h G$ dado que el nivel de crecimiento de la bacteria en las plantas ocp3 pad4, ocp3 eds1 y ocp3 NahG es comparable al de las plantas ocp3 y el control Col-0. Sin embargo, el doble mutante ocp3 npr1 se comporta de la misma manera que npr1 en 
términos de susceptibilidad. Por otro lado, los niveles de resistencia de los dobles mutantes ocp3 cpr-1 y ocp3 cpr-5 no son diferentes a los de los simples mutantes $c p r-1$ y $c p r-5$. Conjuntamente estos resultados sugieren que la pérdida de función de ocp3 podría estar activando una señalización defensiva independiente de la ruta del SA aunque dependiente de NPR1 que podría complementar la incapacidad de pad4, eds1 y NahG en la activación de las defensas frente a Pst DC3000. El hecho de que no se detecte un efecto aditivo en la resistencia de los dobles mutantes ocp 3 cpr-1 y ocp 3 cpr-5 puede explicarse bien porque los niveles de resistencia se encuentran cercanos al máximo en los mutantes cpr-1 y cpr-5 y no es posible detectar una resistencia aditiva en los dobles mutantes con ocp3, o bien porque ambas respuestas no son compatibles, en otras palabras, que la activación constitutiva de la señalización dependiente del SA debida a las mutaciones cpr, bloquee la resistencia aportada por la mutación ocp3. Esta última posibilidad explicaría por qué las plantas ocp3 no son más resistentes que Col-0 a pesar de sobreactivar esa respuesta defensiva independiente de SA, ya que este efecto sólo es posible apreciarlo en un escenario donde la inducción de la acumulación de SA como consecuencia de la infección por Pst DC3000 permanece bloqueada (como sucede en los fondos genéticos pad4, NahG o eds1).

\section{La resistencia aportada por ocp3 es independiente de la expresión de genes $P R$ dependientes de SA.}

Según se desprende de los resultados mostrados en la figura 1, la pérdida de función de OCP3 revierte la susceptibilidad a Pst DC3000 debida a la incapacidad de activar correctamente la ruta defensiva mediada por SA. Habitualmente, la inducción de la transcripción de algunos genes como $P R-1$, $P R-2$ o $P R-5$ se emplea como marcador de esta ruta, correlacionándose en muchos casos con el grado de resistencia/susceptibilidad de las plantas. Así, mutantes parcialmente bloqueados en la inducción de la expresión de estos genes son más susceptibles a patógenos biotrofos, mientras que mutantes que los expresan de manera constitutiva o con mayor intensidad son más resistentes (Feys \& Parker, 2000a; Glazebrook, 2005).

Siguiendo esta lógica, nos propusimos analizar la expresión de los genes $P R-1$, $P R-2$ y $P R-5$ durante el proceso de infección por Pst DC3000 en los fondos genéticos anteriormente descritos, determinando el grado de requerimiento de la expresión de estos genes en la reversión observada del fenotipo de hipersusceptibilidad en ocp3 pad4, ocp3 eds1 y ocp3 NahG. Si observamos con detenimiento la figura 2, podemos comprobar como efectivamente, los parentales pad4, npr1, esd1 y NahG están alterados, aunque en diferente medida, en la expresión de estos genes. ocp3, por el contrario, no muestra defecto alguno en la inducción de ninguno de los marcadores evaluados si lo comparamos con el control Col-0. Los dobles mutantes se comportan de manera muy similar a sus parentales hipersusceptibles, manteniendo intactos los defectos atribuibles al bloqueo en la señalización mediada por SA. Estos resultados por un lado demuestran que la mutación ocp3 no causa una alteración en la expresión de genes $P R$ dependientes de SA, y por otro lado, 
refuerzan la idea de que el efecto compensatorio de la hipersusceptibilidad observada en los fondos genéticos deficientes en la activación de defensas mediadas por SA no incluye el reestablecimiento de la expresión de genes marcadores de esta ruta. Esto concuerda con los resultados anteriores en los que se indicaba la independencia de la ruta del SA. Así pues, la ruta defensiva en la que participa $O C P 3$, funcionaría a través de la activación de genes de defensa diferentes de los habitualmente asociados a la ruta del SA como son $P R-1, P R-2$ y $P R-5$.

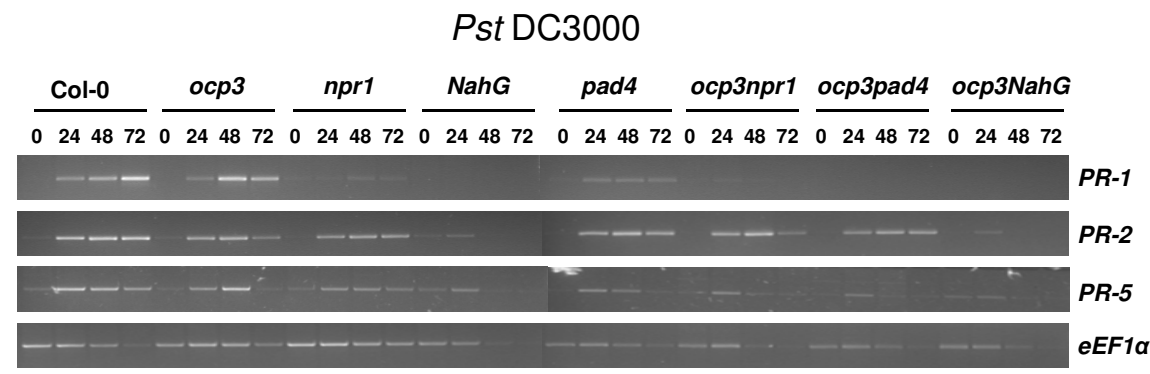

Figura 2. Análisis mediante RT-PCR de la expresión de los genes $P R-1, P R-2$ y $P R-5$ en respuesta a la infección de Pst DC3000. Los ADNc utilizados como molde para las PCRs se obtuvieron de plantas de los diferentes genotipos, a las $0,24,48$ y 72 horas después de la inoculación con Pst DC3000 según lo descrito en la figura 1. hpi, horas post-inoculación.

\section{La inducción de resistencia frente a Pst DC3000 mediada por JA está alterada en el mutante ocp3.}

Las plantas ocp3 muestran una gran resistencia frente a hongos necrotrofos como $B$. cinerea o $P$. cucumerina, patógenos cuya resistencia depende fundamentalmente de las señalizaciones dependientes de JA. Coherentemente, esa resistencia a necrotrofos asociada a la mutación ocp3 es dependiente de JA e independiente de ET y SA (Coego et al., 2005b). Como ya se ha discutido en profundidad, en el caso de los patógenos biotrofos no es bien conocido el papel del JA, aunque parece asumido que el principal efecto es el de antagonizar la ruta del SA (Kachroo et al., 2001; Kloek et al., 2001; Petersen et al., 2000). Sin embargo, la aplicación exógena tanto de JA como de ACC (un precursor de la síntesis de ET) consigue un efecto protector frente a una gran variedad de patógenos, entre los que se incluye Pst DC3000, hecho que ocurre de manera independiente de la expresión de genes $P R$ dependientes de SA aunque dependiente de NPR1 (Pieterse et al., 1998; Ton et al., 2002; van Wees et al., 1999). A tenor de los resultados obtenidos nos planteamos indagar en la naturaleza del incremento de resistencia atribuible a la mutación ocp3 en los fondos genéticos ocp3 pad4, ocp3 eds1 y ocp3 NahG. Dado que, como demostraban los resultados anteriores, el efecto de dicha mutación parecía ser independiente de la señalización defensiva mediada por SA, quisimos ver si la ruta del JA jugaba algún papel. 
Con ese fin, analizamos la inducción de resistencia frente a Pst DC3000 tras la aplicación exógena de JA o ACC en el mutante ocp3. Para ello comparamos el crecimiento de la bacteria en plantas tratadas previamente con una solución $100 \mu \mathrm{M}$ de MeJA por un lado y $500 \mu \mathrm{M}$ de ACC por otro, frente a plantas control sin tratar. Utilizamos como controles el mutante npr1 y el ecotipo Wassilevskaja (Ws-0), que son incapaz de responder a ambos tratamientos (Pieterse et al., 1996; Ton et al., 1999); el mutante ein2.5, defectuoso en la percepción de ET (Alonso et al., 1999); el mutante jar1, insensible a JA (Staswick et al., 1992). Como puede verse en la figura 3, al igual que en el mutante npr1, todos los tratamientos fueron ineficaces a la hora de inducir resistencia en las plantas ocp3, mientras que el crecimiento de Pst DC3000 en las plantas control Col-0 a los 3 y 5 días se vio disminuido considerablemente en el caso tanto del JA como del MeJA y, aunque en menor medida, para el caso del ACC.

A

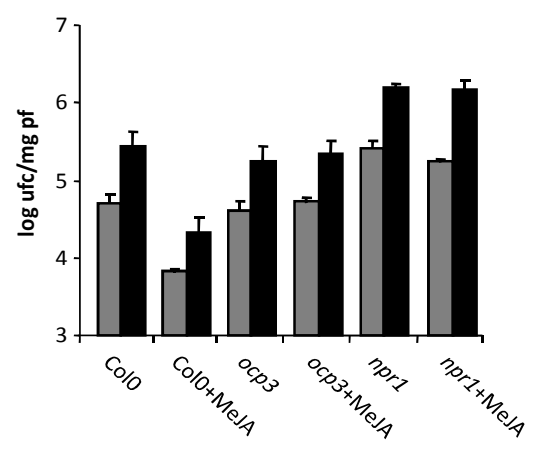

C

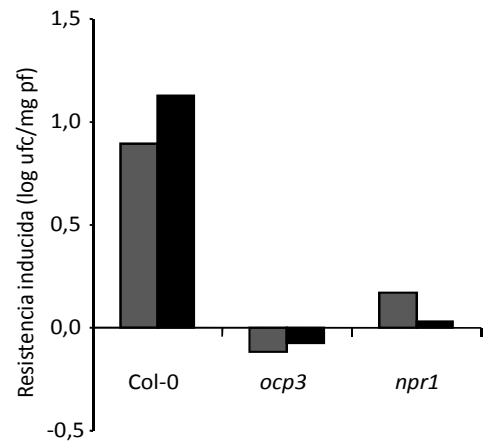

B

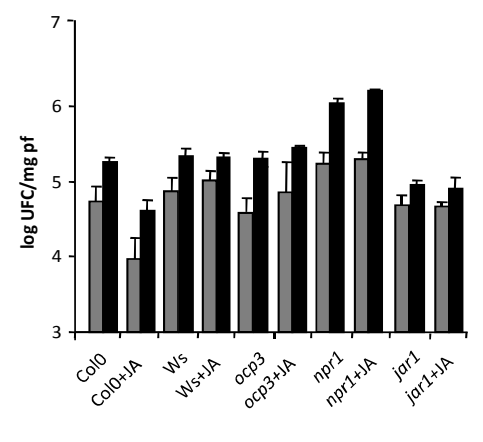

D

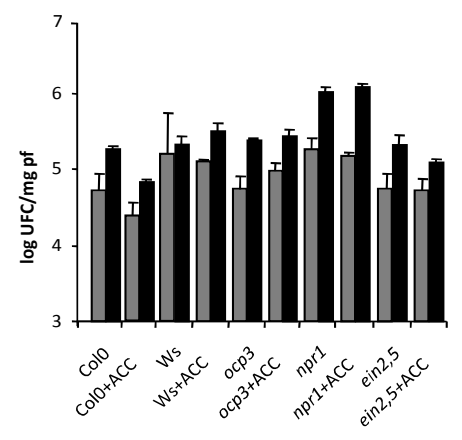

Figura 3. Indución de resistencia contra Pst DC3000 mediante aplicación exógena de JA, MeJA o ACC en plantas Col-0, ocp3 y npr1. Dos días antes de la inoculación con Pst DC3000 se trataron las plántulas por inmersión con una solución control de $\mathrm{MgSO}_{4}, \mathrm{MeJA} 100 \mu \mathrm{M}, \mathrm{JA}$ $20 \mu \mathrm{M}$ o ACC $500 \mu \mathrm{M}$. La inoculación se realizó según lo descrito para la figura 1 . Crecimiento bacteriano a los 3 y 5 días en plantas control y tratadas con MeJA (A), JA (B) o ACC (D). C) Inducción de resistencia por la aplicación de MeJA. 
Conjuntamente, los datos presentados hasta el momento indican que la mutación ocp3 provoca la activación de una ruta de señalización defensiva eficaz contra Pst DC3000, que es capaz de compensar un déficit en la señalización mediada por SA como la presente en los fondos genéticos eds1, pad4 o NahG. Esta respuesta es independiente de la expresión de genes $P R$ inducidos por la ruta del SA y, al parecer, dependiente tanto de JA como de NPR1. Además, el hecho de que el mutante ocp3 tenga bloqueada la inducción de resistencia por la aplicación de MeJA y ACC indicaría que puede ser un elemento clave en la ruta de transducción de señales que media este tipo de respuesta defensiva. De esta forma OCP3 constituiría un nuevo componente en esta respuesta defensiva que podría estar actuando como nexo de unión entre la activación de la cascada de señalización del JA y el regulador NPR1.

\section{El mutante ocp3 esta alterado en el establecimiento de ISR.}

Como se ha descrito en el apartado de Introducción, la ISR es una respuesta defensiva inducida en las plantas por algunas rizobacterias no patógenas. Así, plantas cuyas raíces han sido colonizadas por este tipo de rizobacterias, como es el caso de $P$. fluorescens WCS417r, resisten mejor que las plantas control ante infecciones en la parte aérea con patógenos como Pst DC3000 o $H$. arabidopsidis. A través del estudio de este efecto en mutantes de las distintas rutas de señalización hormonal se ha propuesto que la ISR es una respuesta independiente de la activación de defensas mediada por SA pero que requiere una correcta percepción y señalización de JA y ET además de NPR1 (Pieterse et al., 1998; Ton et al., 2002; van Wees et al., 1999).

A tenor de los resultados anteriores, decidimos estudiar si existía alguna alteración en el establecimiento de ISR en el mutante ocp3. Para esto analizamos el crecimiento tanto del oomiceto $H$. arabidopsidis como de la bacteria Pst DC3000 en plantas control y plantas cuyas raíces habían sido preinoculadas con la bacteria inductora de ISR $P$. fluorescens WCS417r, comparando Col-0 frente al mutante ocp3. Los resultados se muestran en la figura 4. Como se puede observar, en el caso de los dos patógenos conseguimos inducir una resistencia significativa en las plantas Col-0 pretratadas, mientras que en el caso de ocp3 vemos como claramente el tratamiento es incapaz de inducir resistencia. Estos resultados coinciden plenamente con los anteriormente descritos para la inducción de resistencia mediante aplicación exógena de MeJA. Sorprendentemente, en el caso de Pst DC3000, no solo no conseguimos inducir resistencia, sino que claramente puede apreciarse el efecto contrario, posiblemente debido a algún tipo de interacción negativa alterada en ocp3. 


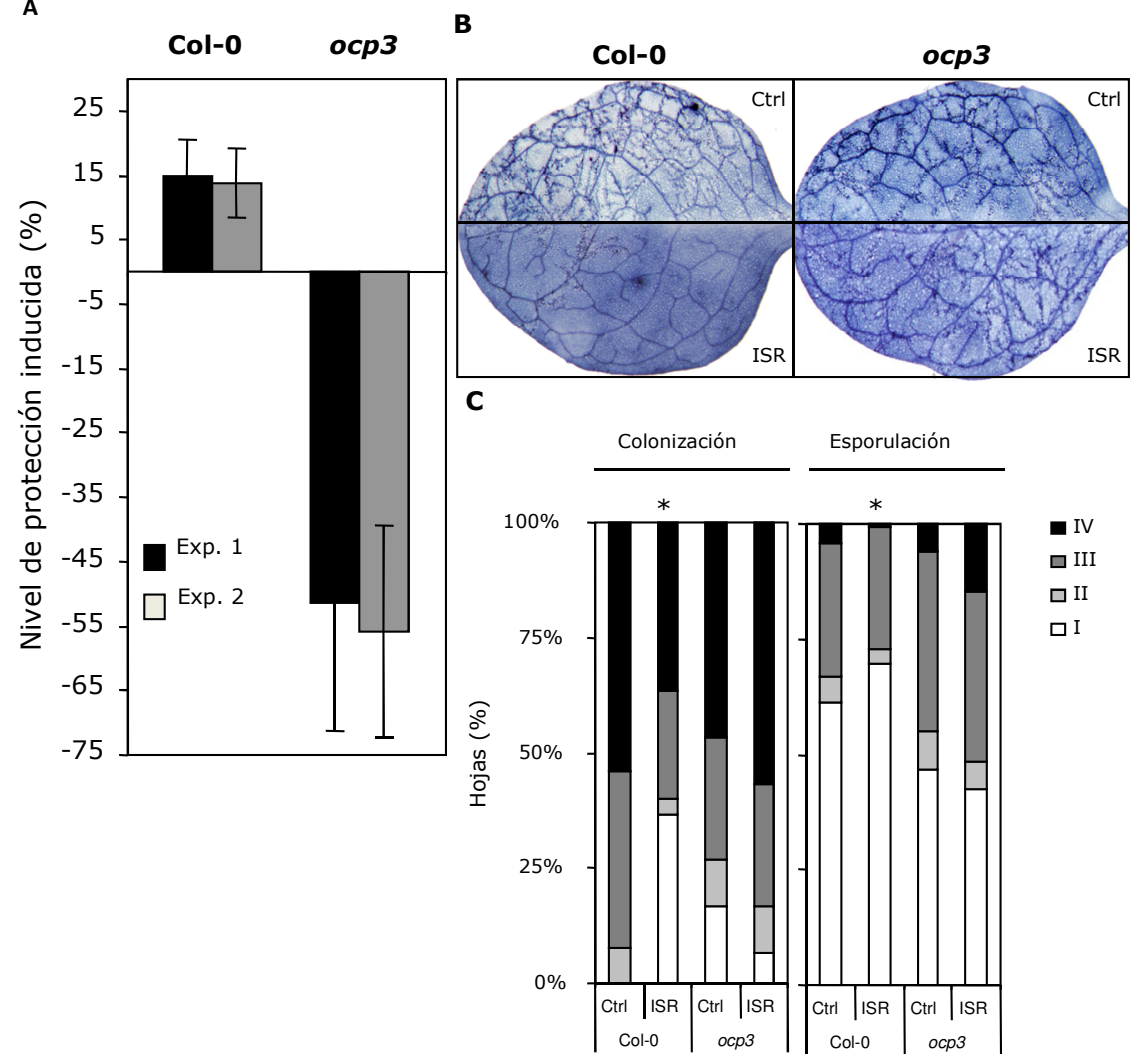

Figura 3. Cuantificación de la ISR mediada por $P$. fluorescens $W C S 417 r$ frente a Pst DC3000 (A) o H. arabidopsidis (B y C) en plantas Col-0 y ocp3.

En ambos casos la ISR se indujo creciendo las plantas durante 3 semanas en sustrato que contenía $5 \times 10^{7}$ ufc/g de $P$. fluorescens WCS417r o una solución de $\mathrm{MgSO}_{4} 10 \mathrm{mM}$ como control. (A) Plantas de cinco semanas de edad fueron inoculadas con una suspensión de Pst DC3000 de 2,5 x $10^{7}$ ufc/mL. Cuatro días después de la inoculación, se midió el porcentaje de hojas con síntomas así como la inducción de protección, calculada sobre la base de la reducción de síntomas relativa a las plantas control no inducidas pero inoculadas con Pst DC3000. Los asteriscos indican niveles de protección significativos comparando las plantas inducidas y las plantas control (Prueba t de Students: $\alpha=0.05 ; n=20$ ). Las barras de error representan los errores estándar de la media). (B) Tinción con azul de tripano de plantas Col-0 y oсp3 preinoculadas con $P$. fluorescens WCS417r (ISR) y sin preinocular (Ctrl), a los 8 días después de infectar con $H$. arabidopsidis. Para determinar la colonización las hojas infectadas y teñidas con azul de tripano, se examinaron al microscopio y se valoró el proceso de infección (C) según los siguientes parámetros: I, ausencia de colonización; II, baja colonización ( $<25 \%$ del área foliar colonizada); III, colonización media $(25-50 \%$ del área foliar colonizada); IV, colonización elevada $(>50 \%$ del área colonizada). La esporulación se expresó como intensidad de la esporulación del patógeno en cada hoja: I esporulación ausente; II, $<50 \%$ del área foliar cubierta por esporangióforos; III, 50\% del área foliar cubierta por esporangióforos; y IV, altamente cubierta por esporangióforos, con clorosis adicional y colapso del tejido. Los asteriscos indican distribuciones estadísticamente significativas de las clases de severidad de la enfermedad comparado con el control de tratamiento no inducido (Chi- cuadrado, $\mathrm{P}<0,05$ ). Los datos mostrados son de experimentos repetidos tres veces con similares resultados. 
El gen NPR1 parece regular exquisitamente las respuestas defensivas así como la capacidad de inducir SAR e ISR (Dong, 2004; Pieterse \& Van Loon, 2004). El hecho de que mutaciones en este gen afecten a su capacidad de activar ISR efectivamente, y no a otras respuestas controladas por JA y/o ET, indica la importancia y especificidad que NPR1 tiene en este proceso. Hasta el momento, además de NPR1, son muy escasos los genes involucrados directamente en el establecimiento de ISR. De hecho, la mayoría de ellos se han identificado porque su pérdida de función impacta en la señalización mediada bien por JA o bien por ET, de forma que los mutantes son insensibles a estas hormonas, estando afectados además de en ISR, en otros procesos controlados por estos reguladores. En este trabajo se ha demostrado que el gen OCP3 posee un papel determinante en la respuesta ISR frente a, al menos, dos patógenos diferentes como son Pst DC3000 y $H$. arabidopsidis, anotándolo como un nuevo componente de esta respuesta defensiva.

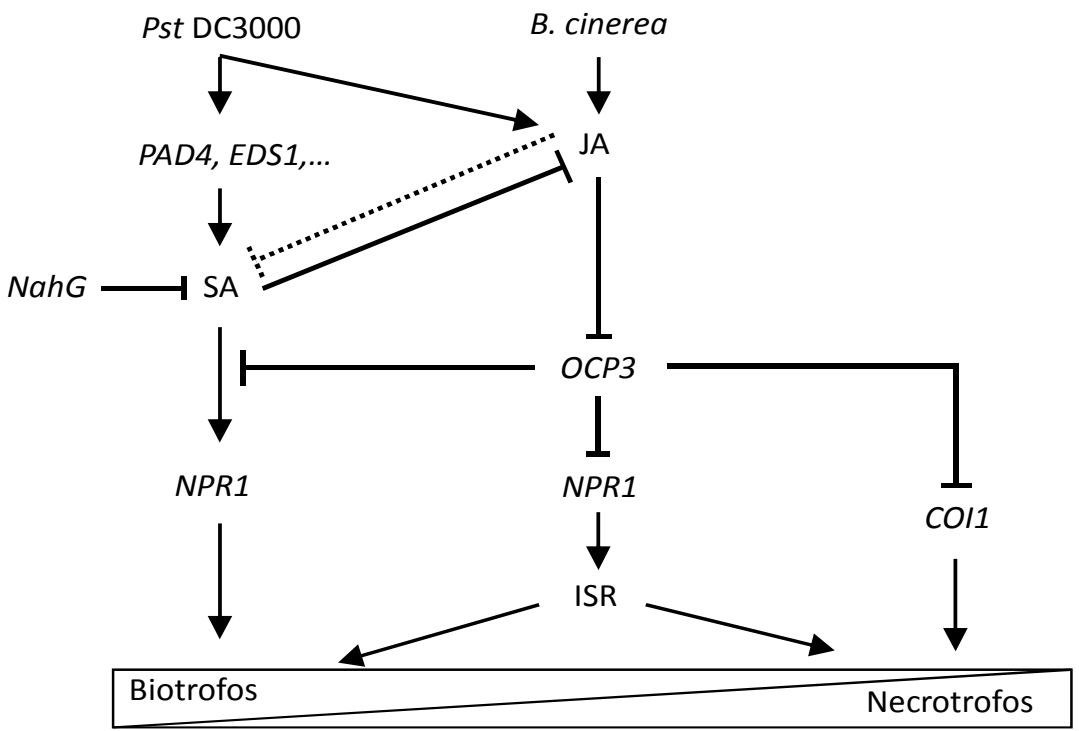

RESISTENCIA

Figura 5. Modelo de integración de los resultados.

El reconocimiento de Pst DC3000 activa la señalización defensiva de la planta mediada por SA a través de $P A D 4$, se produce un aumento de la concentración de SA en la planta lo que activa a NPR1 y dispara la síntesis de proteinas de defensa como PR1. Además ese aumento de SA bloquea la señalización mediada por JA. En el mutante ocp3 hay una mayor activación de la ruta mediada por JA, pero al estar intacta la señalización mediada por SA, el aumento provocado por la percepción del patógeno es capaz de bloquearla, por lo que la respuesta del mutante es similar al de las plantas Col-0. Sin embargo, cuando está bloqueado el aumento endógeno de SA inducido por la infección de Pst DC3000 como en los fondos genéticos pad4, eds1 o NahG, la activación de la ruta defensiva mediada por JA asociada a la mutación ocp3 es capaz de compensar la resistencia y llevar los niveles de crecimiento bacteriano hasta valores comparables a los de las plantas Col-0. 


\section{Discusión general del capítulo}

Las plantas, al contrario que los animales, carecen de células móviles especializadas en defensa. Es por esto que se defienden frente a las infecciones de los diferentes tipos de patógenos sirviéndose de la inmunidad innata de cada célula y de mecanismos inducibles que incluyen señales sistémicas generadas en los sitios de infección (Glazebrook \& Ton, 2007; Jones \& Dangl, 2006). En los últimos años se ha avanzado mucho en el conocimiento de los componentes que participan en estas respuestas defensivas y de cómo las plantas integran las diferentes señales tras el reconocimiento del patógeno. En la actualidad, parece claro que existen, en esencia, dos grandes ramas que integran el sistema inmune de las plantas. La primera de ellas utiliza receptores transmembrana de patrones moleculares asociados a los microbios (denominados PRRs) para monitorizar la presencia de patógenos potenciales. La segunda actúa fundamentalmente dentro de la célula y utiliza proteínas NB-LRR altamente polimórficas que son codificadas por muchos genes $R$ (Bittel \& Robatzek, 2007; Dangl \& Jones, 2001a; Jones \& Dangl, 2006). En todo caso, tras el reconocimiento del patógeno se desencadenan una serie de respuestas que convergen en la activación de mecanismos defensivos inducibles regulados fundamentalmente por las fitohormonas SA, JA y ET. Todo se complica aún más por el hecho de que la importancia relativa de las señalizaciones mediadas por cada una de estas moléculas varía dependiendo del patógeno en cuestión y de su modo de invasión. Clásicamente se ha venido aceptando que las defensas inducibles dependientes del SA son efectivas frente a patógenos que necesitan células del hospedador vivas para completar su ciclo vital (biotrofos), mientras que las dependientes de JA y ET se han asociado a la resistencia frente a patógenos que matan las células del hospedador para alimentarse (necrotrofos) (Dong, 1998; Feys \& Parker, 2000a; Glazebrook, 2001; Kunkel \& Brooks, 2002; Thomma et al., 2001a).

Gracias a la gran cantidad de rastreos genéticos realizados para encontrar reguladores de la resistencia frente a un amplio abanico de patógenos, se han identificado multitud de componentes involucrados en estas rutas. La caracterización de algunos de estos mutantes ha permitido detectar interferencias entre distintas rutas de señalización (ver Introducción). Así, los mecanismos de defensa inducibles están regulados por una compleja red de interconexiones en las que SA, JA y ET juegan un papel central, pero cada vez son más las evidencias de la implicación de otros reguladores hormonales como el ABA o las auxinas (Mauch-Mani \& Mauch, 2005; Mayda et al., 2000a; RobertSeilaniantz et al., 2007). Así, parece más y más clara la necesidad de ampliar nuestro conocimiento de la naturaleza de estas relaciones encontrando nexos de unión y determinando su modo de acción.

En trabajos anteriores se ha descrito a $O C P 3$, un factor de transcripción de la familia Homeobox, como un regulador central de la resistencia frente a hongos necrotrofos. Al parecer, dicha resistencia podría estar relacionada con una hiperactivación de la ruta defensiva mediada por JA. Así, el mutante de pérdida 
de función ocp3 presenta una expresión constitutiva de la expresión de PDF1.2 acompañada de un notable incremento en la resistencia frente a los hongos necrotrofos B. cinerea y P. cucumerina (Coego et al., 2005b).

En el presente trabajo se han presentado resultados que apuntan a la implicación de OCP3 como un importante eslabón en el diálogo entre las señalizaciones controladas por las rutas del SA y JA en el establecimiento de la respuesta defensiva en Arabidopsis frente a la bacteria fitopatógena Pst DC3000. Según los resultados presentados, el gen OCP3 regularía negativamente una ruta defensiva dependiente del regulador NPR1 y de la señalización mediada por JA, siendo independiente de la ruta del SA y las defensas activadas por la acumulación de esta hormona. Además, OCP3 sería un regulador clave de la ISR, efectiva frente a un amplio abanico de patógenos.

Parece una contradicción el hecho de que las plantas ocp3 no presentan diferencias respecto al control Col-0 en el nivel de crecimiento de patógenos biotrofos tales como Pst DC3000 (Coego et al., 2005b). La explicación podría estar en el modo de infección de esta bacteria. Se ha demostrado en numerosos trabajos que algunos patógenos, incluido Pst DC3000, han desarrollado un mecanismo para interferir en la respuesta inmune de las plantas que incluye la activación de la señalización mediada por JA aprovechando el efecto antagónico que esta ruta tiene sobre la del SA. Así, por un lado, Pst DC3000 aumentaría su virulencia activando algún aspecto específico de la señalización mediada por JA para ralentizar el establecimiento de la batería de defensas mediado por SA. Por otro lado, la planta respondería a la detección del patógeno incrementando los niveles endógenos de SA y activando la señalización mediada por esta fitohormona y bloqueando además la ruta del JA. Esta interferencia en las relaciones entre SA y JA proporcionaría a la bacteria una ventana de oportunidad suficiente para ser capaz de multiplicarse y producir enfermedad. (Block et al., 2005; de Torres-Zabala et al., 2007; Kloek et al., 2001; Melotto et al., 2006; Pieterse \& van Loon, 1999; Pieterse et al., 2002).

Sin embargo, también se ha demostrado la existencia de una ruta de señalización defensiva independiente del SA y eficaz frente a algunos patógenos biotrofos entre los que se encuentra Pst DC3000 (Pieterse \& van Loon, 1999; Pieterse et al., 2002). Aunque son escasos los componentes conocidos de esta ruta defensiva, se sabe que tanto NPR1 como una correcta percepción/señalización de JA y ET son necesarios. Así, es posible inducir resistencia frente a Pst DC3000 mediante la activación de la ruta del JA. Esta aparente contradicción podría tener su explicación en el hecho de que el balance entre las diferentes señalizaciones hormonales es precisamente el que otorga especificidad a los sistemas defensivos inducibles.

Es posible, por tanto, que la sobreactivación de la ruta del JA en el mutante ocp3 se vea anulada por la acumulación de SA y/o posterior estimulación de defensas en respuesta a la detección de Pst DC3000 por parte de la planta. Esto explicaría por qué la mutación ocp3 únicamente provoca diferencias en la susceptibilidad a este patógeno cuando es analizada en un fondo genético que 
impide la acumulación de SA como es el caso de los dobles mutantes ocp3 pad4, ocp3 NahG u ocp3 eds1. Esto encajaría con el hecho de que la expresión constitutiva de PDF1.2 en el mutante ocp3 es drásticamente reprimida por la aplicación exógena de SA (Coego et al., 2005b). Además, la expresión de OCP3 es reprimida en etapas tempranas de la infección por Pst DC3000, lo que sería consistente con la función de $O C P 3$ como regulador negativo de la ruta de JA y con el papel de esta hormona en el proceso de infección de Pst DC3000.

Se conoce la importancia de NPR1 como regulador central en todos estos procesos de señalización defensiva frente a Pst DC3000, tanto dependientes de SA como independientes de SA y dependientes de JA. Así, la inducción de resistencia debida a la aplicación de JA observada en plantas Col-0, queda bloqueada en las plantas npr1. Sin embargo, se ha demostrado que, tras el reconocimiento del patógeno, la inducción de la acumulación de SA en el mutante npr1 no está afectada. Consistentemente con esto, la pérdida de función de $O C P 3$, con la activación de la ruta del JA que conlleva, no consigue suprimir la susceptibilidad atribuible a la mutación $n p r 1$.

Como se ha comentado en la Introducción, se ha propuesto que el estado redox de la célula es alterado en respuesta a la percepción del patógeno, posiblemente debido al incremento en la acumulación de SA. Este cambio en el estado redox favorecería la formación de monómeros activos de NPR1 que entrarían al núcleo donde se uniría a los factores de transcripción de la familia TGA para regular la expresión de genes $P R$ y promover así resistencia. Esta cascada de eventos y la localización nuclear serían fundamentales para el establecimiento de una respuesta defensiva dependiente de SA frente a Pst DC3000. Sin embargo se ha observado que la localización nuclear de NPR1 no es necesaria para el establecimiento de la ISR, una respuesta defensiva inducible, independiente de SA y dependiente de JA y NPR1. Por tanto, NPR1 debe tener una función citosólica aún desconocida como regulador de la ruta de señalización dependiente de JA (Dong, 2004; Pieterse \& Van Loon, 2004; Spoel et al., 2003).

Por otro lado, se ha descrito que el mutante ocp3 presenta una mayor acumulación de $\mathrm{H}_{2} \mathrm{O}_{2}$ en condiciones normales, por lo que OCP3 podría estar actuando como un regulador del estrés oxidativo (Coego et al., 2005b). Así pues, podría darse el caso de que OCP3 actuase sobre la función citosólica de NPR1 a través de una modulación del estado redox de la célula, regulando negativamente el establecimiento de la ISR. OCP3, por tanto, constituiría un nexo de unión entre las señalizaciones defensivas mediadas por SA y JA, posiblemente actuando como modulador de la función del regulador central NPR1. Aunque son necesarios futuros experimentos encaminados a esclarecer el mecanismo de acción de OCP3 en ISR, la posibilidad de que esté actuando como modulador de la función de NPR1 parece plausible. Actualmente se están generando algunas herramientas genéticas que pueden permitirnos arrojar algo de luz sobre esta cuestión. Entre ellas cabe destacar la obtención de líneas transgénicas de sobreexpresión de NPR1 fusionado a GFP (del inglés green fluorescent protein), para analizar posibles cambios en la localización subcelular de NPR1 debidos a la pérdida de función de OCP3. 
OCP3, un nuevo componente de la ISR 56 


\section{CAPÍTULO II.}

OCP3, un regulador negativo de la resistencia a hongos necrotrofos y a sequía. 


\section{OCP3, un regulador negativo de la resistencia a hongos necrotrofos y a sequía.}

\section{Introducción.}

La sequía es, probablemente, el problema más importante de la agricultura moderna, siendo la causante de cuantiosas pérdidas año tras año. Exposiciones prolongadas a una escasez de agua provocan en la planta daños devastadores e irreversibles que derivan a menudo en mermas en la productividad de los cultivos y en ocasiones en la muerte de los mismos. Durante la sequía se produce un aumento de la concentración de solutos debido a un una pérdida de agua que a su vez hace caer el potencial hídrico de la planta. Esto provoca, en sus etapas iniciales, una desestabilización del conjunto del sistema de membranas (incluida la membrana plasmática), y a su vez la disrupción de procesos fisiológicos y bioquímicos de gran importancia para la homeostasis celular entre los cuales cabe resaltar a la fotosíntesis por su especial relevancia en los organismos vegetales (Holmberg \& Bulow, 1998). De hecho, en condiciones de sequía o ante situaciones de riego limitado la tasa fotosintética puede caer a niveles tan bajos que incluso puede llegar a comprometer la síntesis de la cantidad de ATP suficiente necesaria para mantener un metabolismo celular equilibrado y ello puede conllevar a la muerte de la célula. Adicionalmente a la caída en la tasa fotosintética durante el proceso de sequía, la luz sigue incidiendo y excitando los cloroplastos. Ello deriva, por tanto, en un aumento en la síntesis y acumulación de especies de oxígeno reactivas que inevitablemente participan en la generación del daño celular mencionado anteriormente y conducen así a un deterioro celular acelerado (Holmberg \& Bulow, 1998).

Las plantas han desarrollado sofisticadas estrategias de defensa y adaptación para hacer frente a todos estos complejos procesos fisiológicos y bioquímicos que se inducen o están asociados a la sequía. Una de las estrategias más tempranas es la de evitar la pérdida excesiva de agua a través de la activación de unas cascadas de señalización que rinden un aumento en los niveles de ácido abscísico (ABA) y el correspondiente cierre de los estomas; todo ello mediado por un aumento en los niveles del $\mathrm{Ca} 2+$ citosólico en las células guarda (McAinsh et al., 1990). Además de este mecanismo celular, y en el caso de que el periodo de sequía se prolongue en el tiempo, la planta pone en marcha otros mecanismos de adaptación y protección con el fin de mantener su metabolismo en unos límites sostenibles. Esto implica la activación de diferentes rutas de señalización que resultan en la expresión de una batería de genes que codifican proteínas que podrían funcionar como antioxidantes y osmoprotectores con el fin de proteger y/o reparar el daño celular producido por la disminución del potencial hídrico (Courtois et al., 2000).

El ABA es la principal hormona que regula todos estos procesos de adaptación y protección orquestados en respuesta al estrés hídrico. Fundamentalmente es la 
encargada de mantener un balance hídrico en las células guarda de los estomas y de aumentar la tolerancia al estrés osmótico a través de la regulación de gran número de genes. Así, mutantes deficientes en la síntesis o percepción de ABA muestran una drástica disminución de la tolerancia a estrés hídrico siendo incapaces de responder de manera efectiva a periodos de escasez de agua relativamente cortos (Xiong et al., 2001). Por otro lado, gran parte de estos genes regulados por $\mathrm{ABA}$ poseen en sus regiones promotoras una secuencia reguladora común denominada caja o elemento ABRE (ABA-responsive element). Se han identificado proteínas que muestran capacidad de unión a estas secuencias ABRE y a dichas proteínas se les denomina factores AREB (ABA-responsive element binding) o $\mathrm{ABF}$ ( $A B R E$ - binding factors). Estos son factores de transcripción de tipo bZIP (Basic leucine zipper) que funcionan como activadores transcripcionales en respuesta a ABA (Choi et al., 2000; Uno et al., 2000). La sobreexpresión de algunos de estos elementos, tal y como ocurre con el factor ABF3 o el factor ABF4, confieren a las plantas transgénicas un aumento de la tolerancia a la sequía que se ve acompañada de una alteración en la expresión de genes de respuesta a estrés tales como los genes $R D 29 B$, $R D 22$, $R A B 18, A B I 1$ y $A B I 2$ (Kang et al., 2002). Por otro lado, las proteínas de tipo MYB y MYC son reguladores transcripcionales de gran importancia que también participan como activadores en los sistemas de regulación dependientes de ABA (Abe et al., 2003).

Existe, sin embargo, otro grupo de genes tal y como es el caso del gen $R D 29 A$ (responsive to dehydration29A), cuya expresión se induce en respuesta a sequía aunque de una manera independiente de ABA (Shinozaki et al., 2003). Estos genes habitualmente presentan en su región promotora una secuencia o elemento cis conservado al cual se unen proteínas reguladoras denominadas DRE (Dehydration-responsive element) o CRT (C-repeat) (Baker et al., 1994; Yamaguchi-Shinozaki \& Shinozaki, 1994). Estas proteínas son factores de transcripción pertenecientes a la familia ERF/AP2 (Ethylene-responsive element binding factor/Apetala2) (Dubouzet et al., 2003; Weigel, 1995). Existen dos grupos de proteínas DRE/CRT: el grupo DREB2, implicado en la respuesta a sequía, y el grupo DREB1, implicado además en la respuesta a frío (Liu et al., 1998). Se ha demostrado que sobreexpresando tanto DREB1A como una versión modificada de DREB2A se consigue un gran aumento en la tolerancia de las plantas transgénicas a la sequía, atribuible a un aumento en la inducción de la expresión de genes de respuesta a estrés, tales como el gen RD29A mencionado con anterioridad (Gilmour et al., 2000; Liu et al., 1998; Sakuma et al., 2006). Sin embargo estas plantas presentan un fenotipo pleiotrópico en el que aún siendo resistentes al estrés impuesto, sufren serios transtornos en su pauta de desarrollo; son enanas y de morfología foliar aberrante. En posteriores trabajos se ha mostrado una alternativa tecnológica para paliar este aspecto pleiotrópico de dicha sobreexpresión mediante el uso de un sistema inducible para sobreexpresar este tipo de genes obteniendo plantas más resistentes a sequía sin mermar su crecimiento (Kasuga et al., 1999; Sakuma et al., 2006). 
Adicionalmente a esta casacada de regulación transcripcional, las denominadas ROS, juegan un papel preponderante en los mecanismos de percepción y adaptación a la sequía (Sanders et al., 1999). Así, la acumulación de ROS es inducida por ABA y se propone que podrían actuar como intermediarios de la señalización promovida por esta hormona en respuesta a la sequía (Pei et al., 2000).

Recientes evidencias que implican a la fitohormona ABA en la defensa de las plantas frente a microorganismos patógenos (Mauch-Mani \& Mauch, 2005) han conducido a que emerja con fuerza la importancia del estudio de las interacciones entre respuestas a estrés de tipo biótico y abiótico (Anderson et al., 2004; Fujita et al., 2006) más que simplificar las complejas redes de señalizaciones a rutas lineales controladas por una sola hormona. Ya se ha comentado anteriormente la importancia ampliamente estudiada del ABA como regulador en la respuesta de las plantas frente a estré abiótico como la sequía. Por otro lado, las hormonas SA, JA y ET juegan un papel central en la defensa ante microorganismos patógenos. Sin embargo, son pocos los datos que se conocen acerca de los puntos de convergencia molecular entre las rutas de señalización genéticamente determinadas frente a estos dos tipos de estrés.

Las ROS han sido propuestas como segundos mensajeros implicados en la señalización frente a ambos tipos de estrés por separado y pueden constituir un buen punto de partida para el estudio de esta compleja red regulatoria. En respuesta a un déficit hídrico se produce un aumento transitorio de la producción de $\mathrm{H}_{2} \mathrm{O}_{2}$ mediado por $\mathrm{ABA}$ que es necesario para el cierre estomático a través de la activación de canales de $\mathrm{Ca}^{2+}$ que promueven un incremento de $\mathrm{Ca}^{2+}$ en las células guarda lo que se traduce en última instancia en un cierre de los estomas (Kwak et al., 2003; Pei et al., 2000). Por otro lado, la generación de ROS es uno de los primeros eventos que se producen tras el reconocimiento planta-patógeno estando implicados tanto en la respuesta hipersensible (HR) como en el establecimiento de señalizaciones defensivas posteriores (Levine et al., 1994).

Como se ha comentado en el capítulo de Antecedentes, recientemente se ha identificado en Arabidopsis a OCP3, un factor de transcripción con una posible función como regulador negativo del estrés oxidativo y de la respuesta defensiva frente a hongos necrotrofos. Así pues, el mutante de pérdida de función ocp3 presenta una gran resistencia frente a este tipo de patógenos mediada por JA y elevados niveles de $\mathrm{H}_{2} \mathrm{O}_{2}$ en condiciones no inductoras (Coego et al., 2005b).

\section{La fosfatasa 2C ABI1.}

El papel de ABI1 como regulador negativo de la señalización mediada por ABA fue descubierto gracias a la identificación del mutante abi1-1 (Allen et al., 1999) y de sus supresores intragénicos denominados abi1-1R (Merlot et al., 2001). La mutación dominante abi1-1 hace a las plantas insensibles a ABA, por lo que, en 
respuesta a estrés hídrico, estas son incapaces de cerrar los estomas e inducir una batería de proteínas con diferentes funciones que permiten establecer una respuesta adaptativa eficaz. Además, el mutante está afectado en otros procesos regulados por ABA como la dormancia de las semillas o el desarrollo vegetativo. Es por todo ello que se propuso para la proteína ABI1 una función como regulador negativo de la ruta del ABA. El aislamiento de varias mutaciones recesivas en la secuencia codificante de ABI1 que suprimen esta insensibilidad fortalece esta idea además de proporcionar información muy valiosa en términos de la relación estructura/función de la proteína. También se han identificado diversas proteínas que interaccionan "in vivo" con esta fosfatasa teóricamente para regular diferentes aspectos de la señalización por ABA. Es el caso de $A T H B 6$, un factor de transcripción del tipo Homeobox, que podría estar regulando la transcripción de genes y la respuesta a ABA dependiente de ABI1 (Himmelbach et al., 2002). Por otro lado, ABI1 interacciona con el dominio regulador de SRK2E/OST1/SnRK2.6, una proteinquinasa que actúa como un regulador positivo del cierre estomático inducido por ABA, regulando así su función (Yoshida et al., 2006). Además de estos componentes de la señalización mediada por $\mathrm{ABA}, \mathrm{ABI} 1$, pero no $A B I 1-1$, se une directamente al ácido fosfatídico (PA, por phosphatidic acid). Un aumento en la concentración del ABA endógeno promueve el incremento de PA libre a partir de la hidrólisis de fosfatidil-colina por la acción de fosfolipasas D (PLD). Se ha propuesto que esa unión PA-ABI1 inhibe la función como regulador negativo de ABI1 al afectar su actividad fosfatasa, promoviendo así la señalización mediada por ABA (Mishra et al., 2006a).

\section{OCP3 interacciona físicamente con varios componentes de la cascada de señalización dependiente de $A B A$ que regulan la respuesta adaptativa de las plantas frente al estrés hídrico.}

Con el fin de identificar nuevos componentes que nos ayudasen a desglosar la función de OCP3 realizamos un rastreo por doble híbrido en levadura. Con esta técnica, la expresión de un gen que permite la supervivencia de las levaduras en un medio de cultivo deficiente en algún nutriente, queda bajo el control de un promotor o región reguladora de un gen que únicamente se activa con la formación de un complejo proteico estable entre las dos proteínas en estudio. En este caso fusionamos la proteína OCP3 al dominio de unión al promotor del gen GAL4, y utilizamos esta fusión (BD-OCP3) como cebo para una librería de proteínas de Arabidopsis fusionadas al dominio activador de GAL4 (AD-X). Expresamos estas fusiones en una levadura en la que un promotor regulado por GAL4 dirige la expresión del gen marcador HIS3, de tal forma que únicamente cuando existiera interacción entre OCP3 y una proteína X, se restauraría el crecimiento de esta levadura en un medio sin histidina. Además, para aumentar la especificidad, utilizamos un inhibidor competitivo de HIS3 como es el 3-AT (3-amino triazol). Mediante este sistema conseguimos identificar clones de levadura que eran capaces de crecer en este medio selectivo. Tras secuenciar y 
comprobar dichos clones positivos, determinamos que correspondían a levaduras que contenían los ADNc por un lado de la fosfatasa 2C ABI1, y por otro lado los de otras tres proteínas: FAC1, FAC2 Y FAC3. En la figura 7 puede verse como la expresión de la proteína de fusión BD-OCP3 junto con cada uno de los interactores por separado (AD-ABI, AD-FAC1, AD-FAC2 y AD-FAC3) es capaz de restaurar el crecimiento de la levadura en un medio carente de histidina, mientras que cualquier combinación por separado, o los vectores vacíos, no lo consiguen. Así pues, podemos concluir que ABI1, FAC1, FAC2 Y FAC3 interaccionan con OCP3 en el sistema de doble híbrido de levadura.

A Proteína OCP3

MIKAMALSSAGVVSHLHPPSFSSSSGLSVNRVLFRNRNASPCGLSLPILNPSRSVLVFAR GKNRKGEVSSSSSSPKKNKKKSLDGADNGGGEEEEDPFEALFNILIEFDIKNDNSDDEEIS EEELEALADELARALGVGDDVDDIDLFGSVTGDVDVDVDNDDDDNDDDDNDDDDDDSEED ERP TKLKNWQLKRLAYALKAGRRKTS I KNLAAEVCLDRAYVLELLRDP P P KLLMLSATLP DEKPPVAAP ENSSPDP SPVESLSAEDVVVEPKEKVKDEAVHVMQQRWSAQKRVKKAHIET 1 LEKVYRRSKRPTNAVVSSIVQVTNLPRKRVLKWFEDKRAEDGVPDKRAPYQAPV

B

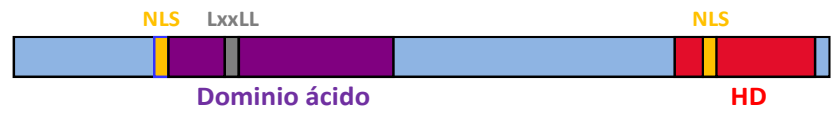

C

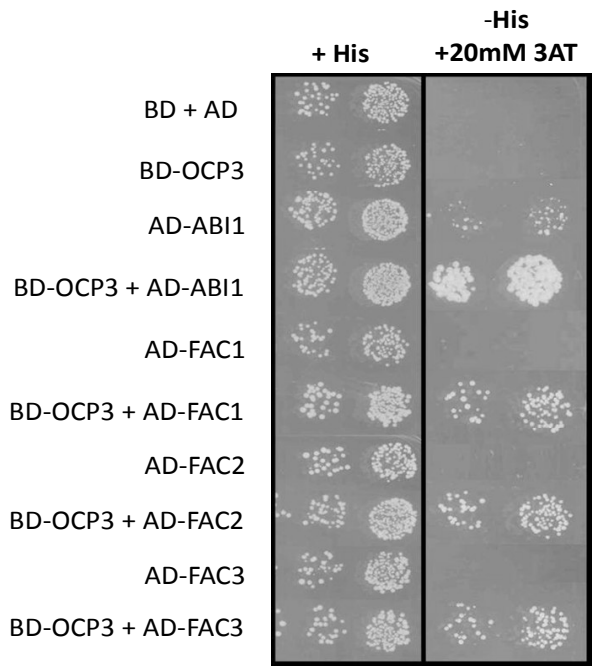

Figura 7. OCP3 interacciona con ABI1, FAC1, FAC2 Y FAC3.

(A) Secuencia de la proteína OCP3. (B) Esquematización de la estructura lineal de la proteína OCP3. NLS: dominio de localización nuclear; HD: homeodominio (dominio de unión a ADN de alrededor de 60 aminoácidos característico de los factores Homeobox). (C) Análisis de la interacción entre las proteínas mediante el sistema de doble híbrido en levadura. Se comprobó el crecimiento de las levaduras portando las diferentes combinaciones de vectores, en un medio con histidina por un lado (panel izquierdo) y sin histidina suplementado con $20 \mathrm{mM}$ de 3-AT. Se colocó una gota de un cultivo de DO 0,1 y una dilución $1 / 5$ de éste para cada levadura. El crecimiento sin Histidina y con 3-AT marca la interacción entre BD-OCP3 y las distintas fusiones AD. Como control se utilizaron cada uno de los vectores por separado así como combinaciones de los vectores vacíos. 
Ensayando diferentes versiones modificadas de OCP3 se consiguió limitar el sitio de interacción entre OCP3 y cada uno de los interactores identificados a una región acídica que envuelve a un dominio típico de interacción proteínaproteína descrito para factores de transcripción de tipo Homeobox. Curiosamente, esta región de interacción es la misma para las cuatro proteínas, hecho que podría tener gran importancia en lo que respecta al significado biológico de estas interacciones. En la figura 8 se muestran los resultados para ABI1 como ejemplo.

A
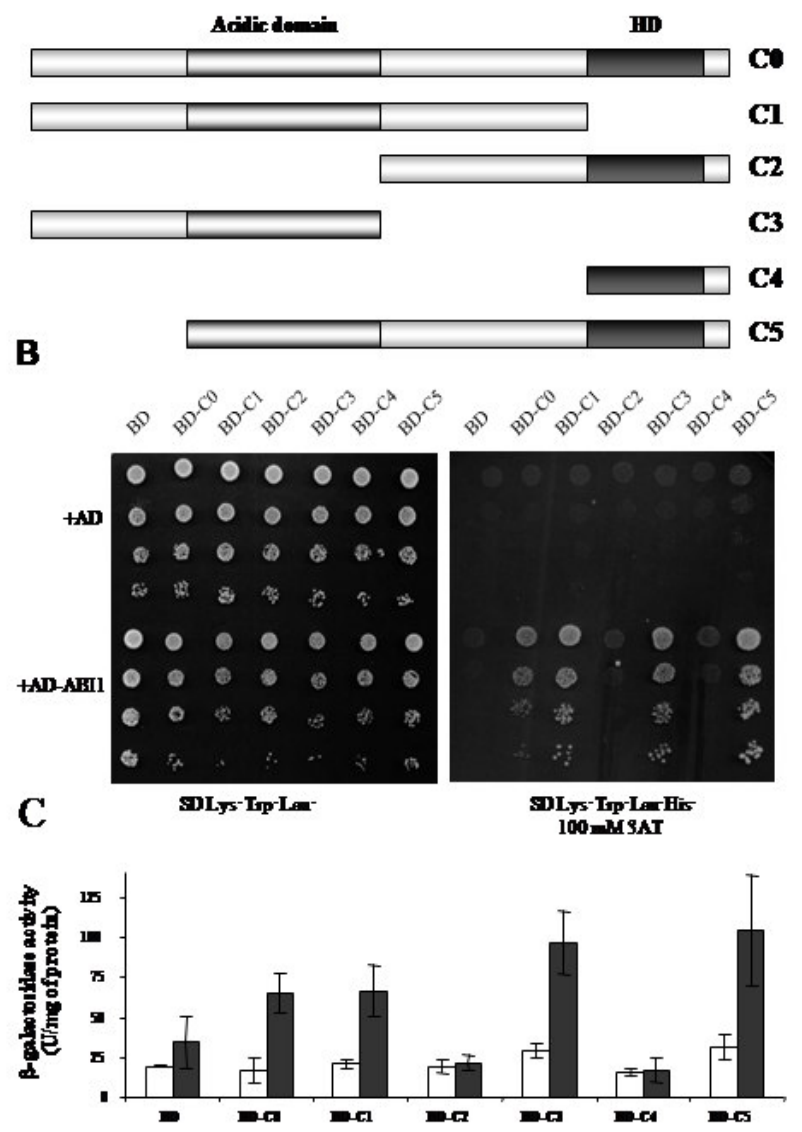

Figura 8. OCP3 interacciona con ABI1 a través de su dominio ácido.

El sitio de interacción de la proteína OCP3 con ABI1 se identificó comprobando la interacción entre diferentes formas truncadas de la proteína fusionadas a DB y AD-ABI1. (A) Esquema de las diferentes formas truncadas de OCP3 utilizadas. (B) Crecimiento de las levaduras portadoras de las construcciones indicadas en medio con histidina (panel izquierdo) y con $100 \mathrm{mM}$ de $3-\mathrm{AT}$ y sin histidina (panel derecho). (C) Determinación de la actividad $\beta$-Galactosidasa de las levaduras con las distintas combinaciones de plásmidos. 
La implicación de la fostatasa 2C ABI1 en la ruta de señalización dependiente de ABA es clara y ha sido muy estudiada. De hecho, la mayor parte de los fenotipos dependientes de esta hormona quedan reflejados en el mutante dominante abi1-1. Estas plantas son hipersensibles a sequía y a deshidratación ya que son incapaces de cerrar los estomas por tener reprimida de manera constitutiva la señalización mediada por ABA. Además, el mutante abi1-1 presenta insensibilidad a ABA y está drásticamente afectado en la inducción de la expresión de genes como $R D 29 A, R D 29 B, R D 22$, etc..., habitualmente utilizados como marcadores en condiciones de deshidratación así como en respuesta a la aplicación exógena de ABA (Allen et al., 1999; Koornneef et al., 1989; Koornneef et al., 1984; Leung et al., 1997; Merlot et al., 2001; Mishra et al., 2006a). Por otro lado, análisis de los patrones de expresión de FAC1, FAC2 y FAC3 en la base de datos Genevestigator (https://www.genevestigator.ethz.ch/) indican que sus niveles de ARNm se acumulan rápidamete en respuesta a ABA y sequía.

En resumen todos los interactores de OCP3 identificados en el rastreo están directamente relacionados con la señalización controlada por ABA. OCP3, como factor de transcripción, podría estar modulando la transcripción de genes de respuesta a $A B A$. Teniendo en cuenta todo esto decidimos estudiar los posibles fenotipos del mutante ocp3 en algunos procesos regulados por ABA.

NOTA: Los resultados derivados de la interacción OCP3-ABI1 y la función de OCP3 como regulador de la respuesta a sequía forman parte de la patente P200700128. Los resultados referentes a la implicación de OCP3 en la resistencia a hongos necrotrofos forman parte de la patente PCT/ES2006/070050. Los resultados e información acerca de los interactores FAC1, FAC2 y FAC3 están sujetos actualmente a proceso de patente.

\section{El mutante ocp3 es hipersensible a ABA.}

Uno de los efectos que desencadena la aplicación exógena de ABA a plantas de Arabidopsis es la disminución en la capacidad de elongación de la raíz, aspecto que además se ve reflejado en un menor porte de la parte aérea de las plantas. Así, los mutantes insensibles a ABA, tales como abi1 y abi2, muestran una menor inhibición del desarrollo radicular comparado a la sufrida por los controles Col-0 y Ler (Koornneef et al., 1984).

Para estudiar el efecto de la aplicación exógena de ABA en el desarrollo de las plantas ocp3 sembramos semillas de dicho mutante en placas de MS-Agar, así como en placas de MS-Agar suplementadas con una concentración de ABA de $0,8 \mu \mathrm{M}$, y siempre utilizando como plantas control en estos experimentos al genotipo Col-0. Como se muestra en la figura 10, aunque la tasa de geminación y la emergencia de la radícula del mutante ocp3 no se ve afectada por la presencia de ABA en el medio, su desarrollo post-germinativo está seriamente afectado. De ello cabría deducir, por tanto, que la pérdida de función atribuible a la mutación ocp3 rinde una hipersensibilidad a la hormona ABA y por tanto la 
función normal del gen OCP3 sería compatible con la de regular negativamente la ruta de transducción de la hormona ABA en el desarrollo vegetativo.
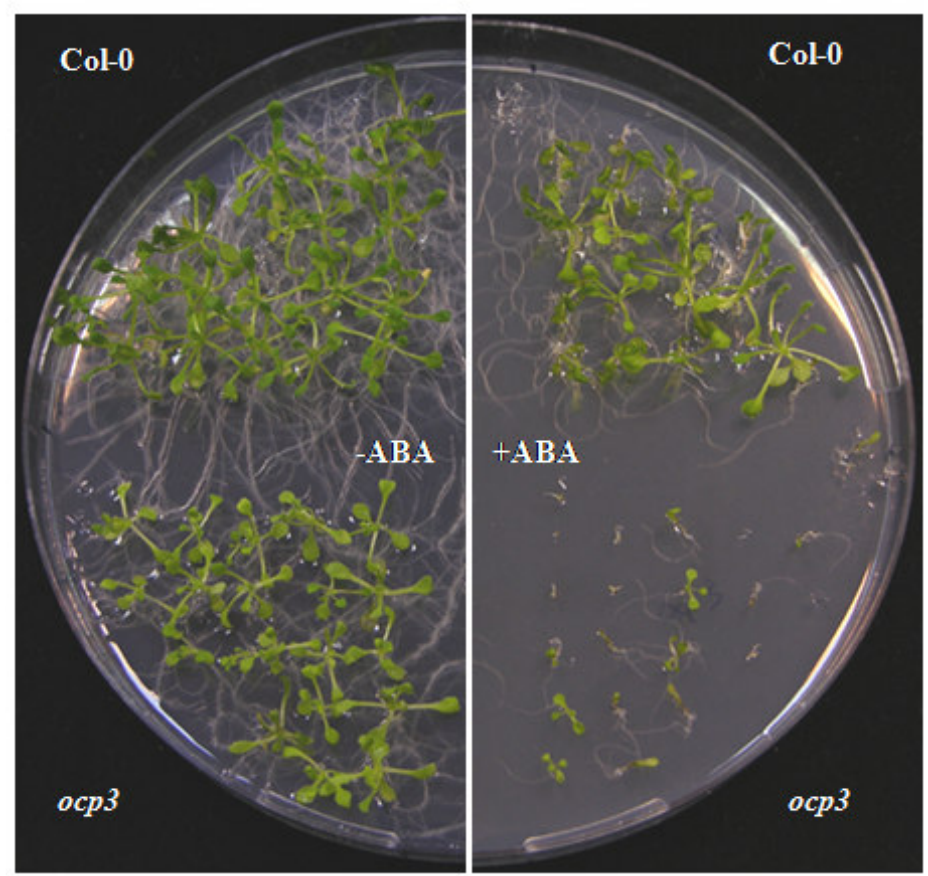

Figura 10. Efecto del ABA en el crecimiento de las plantas Col-0 y ocp3.

Plantas de 2 semanas de edad de los genotipos Col-0 (arriba) y ocp3 (abajo) crecidas en medio MS (izquierda) o MS suplementado con ABA 0,8 $\mu \mathrm{M}$ (derecha).

\section{Las plantas ocp3 presentan una mayor tolerancia a la sequía.}

Son muchas las evidencias de la implicación del ABA en la respuesta de las plantas al estrés hídrico (Hetherington, 2001; Koornneef et al., 1998; Schroeder et al., 2001b; Zeevaart \& Creelman, 1988). Así, por ejemplo, plantas mutantes afectadas en la correcta percepción o la síntesis de ABA, tal y como es el caso de los mutantes abi (abscisic acid insensitive) o aba (abscisic acid-deficient), son incapaces de responder de manera efectiva a un régimen de ausencia de agua, $\mathrm{y}$ dichas plantas mutantes se marchitan y mueren en periodos relativamente cortos de tiempo.

Comparamos la respuesta del mutante ocp3 y el control Col-0 frente a exposiciones prolongadas a ausencia de agua o riego. La figura 11 muestra plantas representativas de cada genotipo días después de dejar de regarlas, crecidas bien en macetas independientes (12 días sin riego) o bien agrupadas en la misma maceta (18 días sin riego) dependiendo del estadio de desarrollo. Como se aprecia, las plantas Col-0 presentan un acusado marchitamiento llegando incluso a morir, mientras que las plantas mutantes ocp3 permanecen aparentemente sanas e inalteradas tras el periodo prolongado de sequía. Aún 
reponiendo el régimen de riego tras dicho periodo prolongado de sequía, las plantas Col-0 no se recuperaron, mientras que las plantas ocp3 continuaron su desarrollo normal (Figura 11). Estos resultados demuestran que la pérdida de función del gen $O C P 3$, a través de la mutación recesiva ocp3, es suficiente para conferir a las plantas de Arabidopsis una evidente resistencia a la sequía y argumenta a favor de que la proteína OCP3 podría funcionar como un regulador negativo de un mecanismo existente de adaptación de las plantas para la supervivencia ante amplios periodos de escasez de agua o sequía.
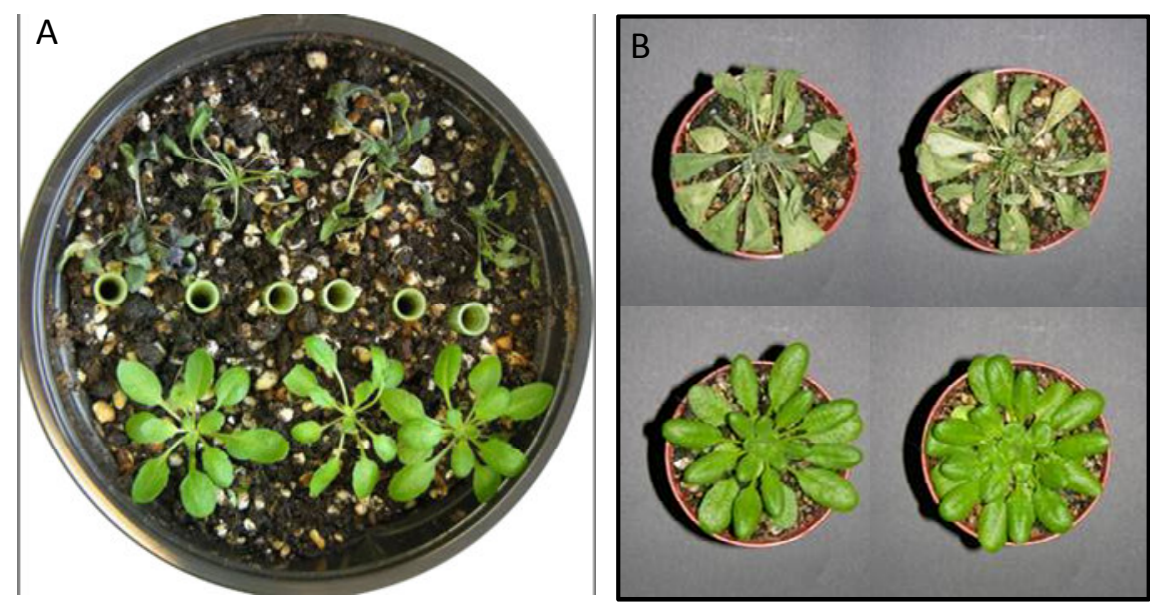

Figura 11. Las plantas ocp3 presentan una tolerancia a la sequía incrementada.

(A) Plantas de 3 semanas de edad de los genotipos Col-0 (arriba) y ocp3 (abajo), se dejaron de regar durante 18 días. Para el experimento se evaluaron diez macetas como la representada en la figura. (B) Plantas de 5 semanas de edad se dejaron de regar durante 12 días (izquierda). Se repuso el régimen de riego normal y a los tres días se fotografiaron (derecha). Para el experimento se analizó el comportamiento de 20 plantas por genotipo distribuidas al azar. La figura muestra imágenes representativas de cada genotipo.

\section{La expresión del gen $O C P 3$ se reprime en respuesta tanto a la aplicación exógena de ABA como a la deshidratación.}

En condiciones tanto de sequía como de deshidratación las plantas responden aumentando los niveles de ABA endógenos (Koornneef et al., 1998), lo que conlleva la activación de una cascada de señalización que tiene como resultado una serie de cambios a nivel transcriptómico. Para estudiar el posible efecto que el ABA pudiera tener en la regulación transcripcional de OCP3 en plantas Col-0, medimos por RT-PCR cuantitativa (q-RT-PCR) los niveles relativos del ARNm correspondientes al gen OCP3 a diferentes tiempos tras la aplicación de ABA, así como tras someter a las plántulas a estrés por deshidratación. Como control se utilizó en dichos experimentos el gen $A B I 1$, cuya expresión se sabe que se induce en respuesta tanto a ABA como a deshidratación (Merlot et al., 2001). 
Como se puede observar en la figura 12, como consecuencia tanto de la aplicación de ABA $100 \mu \mathrm{M}$ como tras imponer un estrés hídrico a las plántulas, se observa una fuerte caída de los niveles de acumulación del transcrito correspondiente al gen OCP3. Dicha represión en la expresión del gen OCP3 como consecuencia del tratamiento con ABA o de la deshidratación se hace patente ya a tiempos muy cortos y de manera inversa a la activación observada para el gen $A B I 1$ (Figura 12). Esto indica, por tanto, que el gen OCP3 podría estar implicado en una señalización temprana en respuesta al aumento en los niveles de $\mathrm{ABA}$, de manera que su represión sea necesaria, aunque no necesariamente suficiente, para promover la activación del programa transcripcional demostrado para los genes de referencia arriba indicados, incluyendo el propio gen $A B I 1$. Por otra parte, la inducción de la proteína ABI1, la cual funciona como un regulador negativo de la respuesta a ABA, serviría para modular esta fuerte demanda transcripcional activada por las condiciones inductivas empleadas.

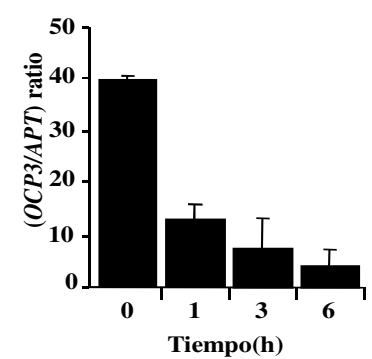

C

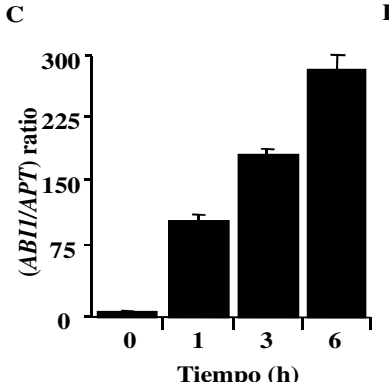

B

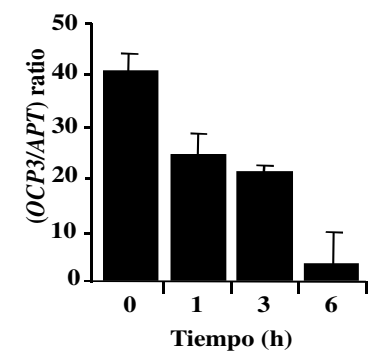

D

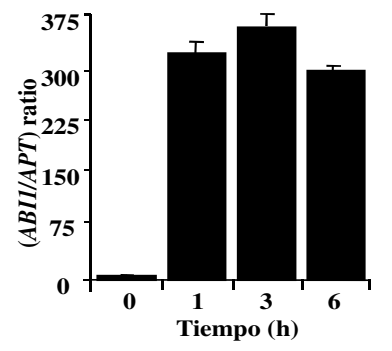

Figura 12. OCP3 se reprime en respuesta a ABA y deshidratación.

Análisis por q-RT-PCR de la expresión de los genes OCP3 (A y B) y ABI1 (C y D) en respuesta a la aplicación exógena de ABA $100 \mu \mathrm{M}$ (A y C) y a deshidratación (B y D). La expresión de estos genes está referida a $A P T$.

\section{El mutante ocp3 no presenta alteraciones en los niveles de expresión de genes de respuesta a deshidratación.}


Una posibilidad que explicaría la mayor sensibilidad a ABA del mutante ocp3 así como el aumento en la resistencia a la sequía, podría ser que la mutación en dicho gen hubiera causado una mayor o más rápida activación de la ruta de señalización dependiente de ABA y que tendría como última consecuencia una mayor expresión de genes de respuesta a deshidratación que aumentasen los niveles de protección contra el daño producido por el estrés hídrico. Con el fin de estudiar esta posibilidad se realizó un análisis molecular determinando los niveles de expresión (medido como acumulación del ARNm correspondiente por RT-PCR) de algunos genes marcadores de la señalización en respuesta a deshidratación o ABA. Se analizaron los niveles de los transcritos de RD29A, RD29B y RD22 a diferentes tiempos $(0,1 \mathrm{~h}, 3 \mathrm{~h}$ y $6 \mathrm{~h})$ tras la incubación de las plantas en un medio líquido con $100 \mu \mathrm{M}$ de ABA. Como se muestra en la figura 13A, no existen diferencias observables en los niveles de inducción y acumulación de los transcritos correspondientes a los marcadores utilizados cuando se comparan las poblaciones de ARN obtenidas de plantas Col-0 y plantas ocp3 tratadas de manera similar. Ello indica que no existe defecto observable en la ruta de señalización que media la inducción de la expresión de estos genes por ABA y elimina la consideración de que la mutación ocp3 esté afectando dicha vía de activación génica.

Para complementar la caracterización molecular se compararon los niveles de los transcritos de estos mismos genes marcadores en respuesta a deshidratación (Figura 13B). Los experimentos se realizaron tal y como se describe en Sakuma et al.,2006. Se crecieron in vitro plántulas Col-0 y ocp3 en placas MS-Agar y a las 2 semanas se trasladaron las plántulas a placas Petri sin medio de cultivo para provocar así su deshidratación. Se analizaron los niveles de acumulación de los transcritos correspondientes a los genes marcadores reseñados anteriormente a las 0, 1, 3 y 6 horas de deshidratación. Los resultados (Figura 13B) demuestran que tanto $R D 29 B$ y $R D 22$ como $R D 29 A$ muestran una acumulación acusada en condiciones inductivas de deshidratación pero, a su vez, no se observan diferencias entre los niveles de inducción y acumulación de los transcritos correspondientes cuando se comparan las poblaciones de ARN obtenidas de plantas Col-0 y plantas ocp3 tratadas de manera similar. Todo ello indica, por tanto, que el mutante ocp3 tampoco muestra defecto en cuanto a la activación de las cascadas de señalización que inducen estos genes marcadores en respuesta a la deshidratación. 

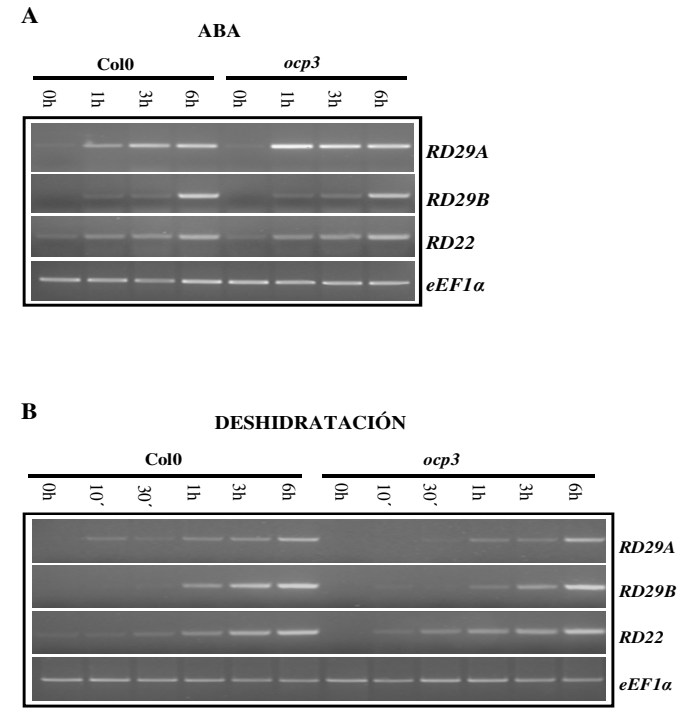

Figura 13. Análisis por RT-PCR de los niveles de expresión de RD29A, RD29B y RD22 en plantas Col-0 y ocp3 sometidas a la aplicación exógena de ABA (A) y deshidratación (B).

Las muestras se recolectaron de plántulas de 2 semanas de edad crecidas en medio MS en condiciones estériles a los diferentes tiempos indicados tras la aplicación de ABA $100 \mu \mathrm{M}$ (A) o la deshidratación forzada (B). Como control se utilizó el gen $e E F 1 \alpha$.

Así pues los resultados indican que pese a que las plantas ocp3 muestran una marcada sensibilidad frente al ABA comparada con las plantas Col-0 en términos de inhibición de desarrollo, no existen diferencias en la inducción de la expresión de genes marcadores dependientes de ABA (como RD29B, RD22 o $R D 29 A$ ). Por tanto la resistencia a la sequía mostrada por el mutante ocp3 parece ser independiente de la expresión de estos genes.

\section{El mutante ocp3 no muestra alteraciones en respuesta a la desecación.}

Uno de los primeros eventos característicos que acontecen en las plantas tras la percepción de un aumento en los niveles de ABA endógeno como consecuencia de periodos prolongados de sequía es el cierre de los estomas, ya que el ABA promueve el cierre de los mismos así como inhibe la apertura de los estomas cerrados (Schroeder et al., 2001b). Por tanto, una medida indirecta de la capacidad de las plantas para cerrar los estomas consiste en determinar la pérdida de peso fresco a lo largo del tiempo en hojas escindidas de la planta y colocadas bajo condiciones controladas de temperatura y humedad ambiental. Así, algunos mutantes alterados en la síntesis, percepción y/o respuesta al ABA son incapaces de cerrar los estomas de una manera efectiva, y por tanto en dichos mutantes se produce un descenso más rápido del peso fresco en 
respuesta a este proceso de desecación (Allen et al., 1999; Finkelstein \& Somerville, 1990; Koornneef et al., 1984; Leung et al., 1997).

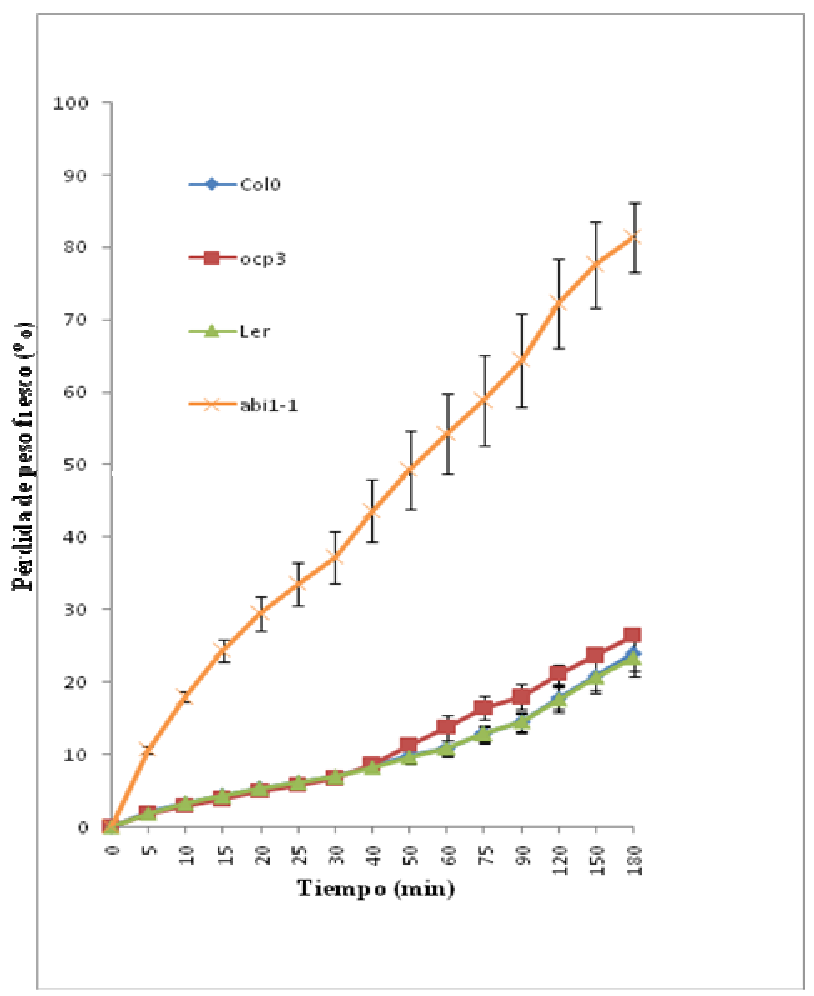

Figura 14. Evaluación de la pérdida de agua.

La pérdida de agua se determinó indirectamente mediante la determinación de la pérdida de peso fresco en hojas cortadas de los diferentes genotipos sometidas a desecación a lo largo del tiempo. Los datos representan la media de cinco réplicas para cada genotipo, compuestas por hojas de 3 plantas cada una. Las barras de error representan la desviación estándar.

Con el fin de observar el comportamiento de las plantas ocp3 en referencia a este aspecto fisiológico, realizamos este tipo de ensayo de medición de la velocidad de deshidratación y referenciamos los datos a los obtenidos con plantas abi-1 y las plantas control correspondientes; Col-0 como parental del mutante ocp3 y Ler como parental del mutante abi1-1. Para ello cortamos hojas de roseta de plantas de cada uno de los genotipos, las dividimos en tres réplicas y las colocamos en placas Petri en una cabina de flujo laminar para provocar su desecación, realizando medidas de la pérdida de peso fresco a diferentes tiempos. Como puede observarse en la Figura 14, el mutante abi1-1 tiene una pérdida de peso fresco abrupta con pérdidas cercanas al $80 \%$ de su peso fresco a las tres horas de iniciarse la desecación. Por el contrario, los controles Ler y 
Col-0 solo han perdido el $20 \%$ de su peso fresco original, al igual que ocurre con las muestras procedentes del mutante ocp3. Así pues, a pesar de las acusadas diferencias observadas en respuesta a sequía entre el mutante ocp3 y las plantas Col-0, no existen diferencias significativas en la respuesta a desecación entre dichas plantas. Esta diferencia en el comportamiento, alta resistencia a sequía en plantas crecidas en macetas pero normal comportamiento a la desecación rápida por parte de las plantas ocp3, podría deberse a que los dos tipos de estrés ensayados (sequía y desecación) tienen un mecanismo de señalización diferente y precisamente el mutante ocp3 revela dicha diferencia.

\section{El mutante ocp3 no presenta alteraciones en la disposición y número de estomas}

En resumen, los resultados descritos hasta el momento apuntan a que OCP3 estaría funcionando como un regulador negativo en etapas tempranas de los procesos de adaptación frente al estrés hídrico mediados por ABA. Según los resultados, la pérdida de función de OCP3 no estaría alterando los niveles de inducción de genes clásicamente asociados con estos procesos sin tener repercusión en la respuesta de las plantas frente al estrés por deshidratación, pero sí en condiciones de sequía o la inhibición del crecimiento en presencia de ABA.

Ante la pregunta de qué mecanismos estarían detrás de la extraordinaria tolerancia a la sequía de ocp3, y dado que el número de estomas, su disposición, y también el grado de apertura/cierre de los mismos pueden jugar un papel fundamental en la respuesta de las plantas frente al estrés hídrico, nos planteamos la posibilidad de que el mutante pudiera mostrar alguna alteración a este nivel. Tras un análisis con microscopía de barrido (Figura 15A), no se observaron diferencias entre las plantas ocp3 y las plantas Col-0 ni en la disposición ni en la cantidad de estomas a lo largo de la lámina foliar. Tampoco se encontraron diferencias significativas en el grado de apertura de los estomas entre las plantas ocp 3 y las plantas Col-0 cuando son crecidas en condiciones de normal temperatura, iluminación y riego, aunque ambos si se diferenciaban drásticamente de lo observado para el mutante abi1 que muestra apertura estomática permanente y que explica el comportamiento observado de las plantas abi1 frente a deshidratación.

\section{Las plantas ocp3 son más sensibles al cierre estomático promovido por ABA.}

Aunque ocp3 muestra una mayor tolerancia a la sequía, parece no estar afectado en la respuesta a deshidratación. Los experimentos de deshidratación que determinan la pérdida de agua en las hojas, miden la capacida de las plantas de resistir caídas en el potencial hídrico y pueden no ser los mejores para investigar los mecanismos de tolerancia a la sequía (Levitt, 1972; Verslues et al., 2006). De hecho, mientras que los mutantes deficientes en ABA, presentan alteraciones en este fenotipo, no todos los mutantes afectados en la 
sensibilidad a ABA los presentan (Verslues et al., 2006). Estas indicaciones encajan con la aparente contradicción en los resultados presentados para el mutante ocp3. La tasa de pérdida de agua durante la sequía es mayoritariamente determinada por la apertura y cierre de los estomas. Existen diferentes estímulos que modifican la velocidad así como el grado de apertura/cierre de los estomas y entre ellos cabría resaltar la sequía y la privación de luz. Ambas señalizaciones están directamente relacionadas con un aumento de los niveles endógenos de ABA, hormona que determina el cierre de estomas bajo condiciones inductivas o de estrés. Con el fin de indagar en la naturaleza del mecanismo que opera detrás de la resistencia a la sequía mostrada por ocp3, decidimos comparar la velocidad de cierre de los estomas entre plantas ocp3 y plantas Col-0 que acontece tras la aplicación directa de $\mathrm{ABA}$ en muestras epidérmicas (peelings) obtenidas de hojas de roseta. Como puede verse en la Figura 15B, la presencia de ABA provoca un cierre acelerado de los estomas en las plantas ocp3 que ya es observable de manera significativa a los 30 minutos tras la aplicación de ABA y en situaciones donde el control Col0 aún no ha iniciado el proceso de cierre de sus estomas. Sin embargo estas diferencias desaparecen a las 2 horas posteriores a la aplicación de ABA, tiempo en el que los estomas de las plantas ocp3 y las plantas Col-0 están prácticamente cerrados. Por tanto, se desprende de estos experimentos que el mutante ocp3 es más sensible a la hormona ABA y ello se traduce en una pronta respuesta a esta hormona que se manifiesta con un cierre estomático acelerado. De la misma forma comparamos entre los dos genotipos el cierre de los estomas inducido por diferentes concentraciones de ABA. Así, al cabo de 2,5 horas, los estomas de las plantas ocp3 están sensiblemente más cerrados en todas las concentraciones, no existiendo diferencias en el control sin ABA (Figura 15C). El ABA, además de inducir cierre estomático, tiene también un efecto inhibitorio sobre la inducción de la apertura estomática promovida por la luz. Incubamos hojas de plantas Col-0 y ocp3 en oscuridad durante 2,5 horas y a continuación añadimos diferentes concentraciones de ABA al medio y encendimos las luces. Al cabo de 2,5 horas medimos la apertura estomática. La figura 15D demuestra como, de nuevo, los estomas de las plantas ocp3 están más cerrados en todas las concentraciones utilizadas. Esto demuestra que las plantas ocp3 sienten más rápido y en concentraciones menores, el efecto inhibitorio del ABA sobre la apertura estomática inducida por la luz.

Así pues, las plantas ocp3 presentan una mayor sensibilidad al ABA referido tanto a la inducción del cierre estomático, como al efecto inhibitorio que la hormona tiene sobre la inducción de la apertura estomática promovida por la luz (Fig. 15, B, C y D). Esa mayor sensibilidad de las plantas ocp3 ante la regulación de la apertura/cierre estomático mediado por ABA podría explicar el fenotipo de resistencia a la sequía, dado que implicaría una mayor rapidez en la señalización del cierre de estomas ante una situación de estrés hídrico, lo que conduciría a una menor pérdida de agua de las plantas ocp3 o un mejor aprovechamiento de esta. El arresto del crecimiento del mutante ocp3 en placas de MS-Agar suplementadas con ABA concordaría con esto, ya que la inducción continua de esta ruta podría estar reduciendo la transpiración de las plantas y por tanto la disponibilidad de fotoasimilados hasta prácticamente detener su crecimiento. 
A

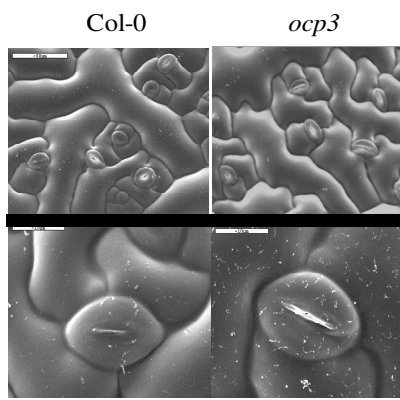

C

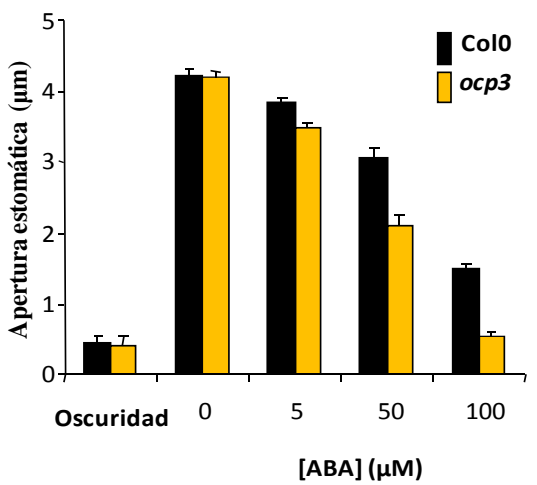

B

abil-1

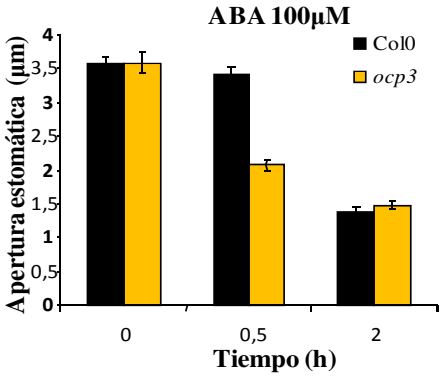

D

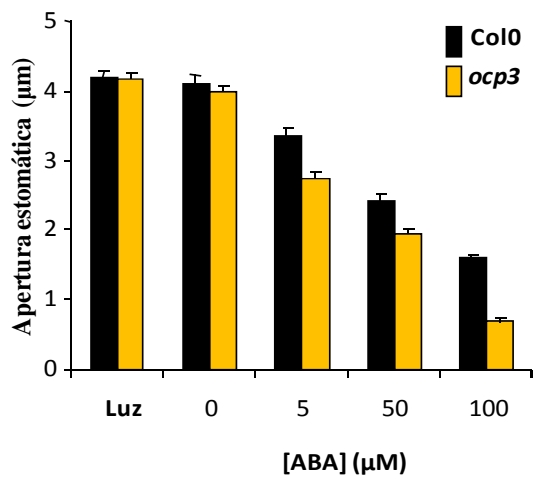

Figura 15. Comparación del número, disposición y movimiento de los estomas en plantas Col-0 y ocp3.

(A) Análisis de superficie foliar por microscopía de barrido de hojas procedentes de plantas Col-0, ocp3 y abi1. El panel inferior es una magnificación donde se muestran estomas representativos para cada genotipo seleccionado y el que la apertura estomática correspondiente a las muestras foliares de plantas abi1 es evidente. Las barras representan 100 micras (panel superior) o 10 micras (panel inferior). No se observan diferencias ni entre el grado de apertura/cierre ni en el número de estomas entre las muestras Col-0 y ocp3. (B) Medida del cierre estomático inducido por ABA $(100 \mu \mathrm{M})$ en plantas ocp3 y wt. Se escindieron hojas de roseta de plantas de 6 semanas de edad de los genotipos ocp3 y Col-0 y se incubaron en una solución (Mes-KOH $10 \mathrm{mM} \mathrm{pH} \mathrm{6,15} \mathrm{y} \mathrm{KCl} 30 \mathrm{mM}$ ) durante 2 horas para inducir la apertura de los estomas. A continuación se añadió ABA $100 \mu \mathrm{M}$ para inducir el cierre de los estomas. Se midió la apertura del ostiolo a los diferentes tiempos indicados en peelings epidérmicos de las hojas de los diferentes fondos genéticos. A los 30 minutos de la aplicación de ABA es evidente y estadísticamente significativo (según un análisis t-Student $\mathrm{p}<0,001$ ) un mayor cierre de los estomas en el mutante ocp3. (C) Efecto de la mutación ocp3 en el cierre estomático inducido por ABA. Se partió de hojas tratadas como en B y tras 2,5 horas se incubaron con luz en las concentraciones de ABA indicadas. Las medidas fueron tomadas a las 2,5 horas. (D) Efecto de la mutación ocp3 en la inhibición por ABA de la apertura estomática inducida por luz. Los estomas se cerraron incubándo las muestras en oscuridad durante 2,5 horas. A continuación fueron incubados con luz en las diferentes concentraciones de ABA tomando las medidas al cabo de 2,5 horas. Los datos representados corresponden a las medias \pm error estándar de la media $(n \geq 90)$. 
La mutación abi1-1 suprime la susceptibilidad a ABA del mutante ocp3 y su resistencia a sequía.

Para caracterizar el significado funcional de la interacción OCP3-ABI1 introgresamos la mutación ocp3 en un fondo mutante abi1-1, generando así el doble mutante ocp3 abi1-1 y analizamos la respuesta de estas plantas en diferentes situaciones.

Por un lado estudiamos el crecimiento del doble mutante ocp3 abi1-1 en placas de MS suplementadas con $0,8 \mu \mathrm{M}$ de ABA y comparamos el efecto que ejercía sobre el crecimiento de plántulas de manera comparativa con los genotipos Col0, Ler, ocp3 y abi1-1. Como se puede observar en la figura 16A el doble mutante ocp3 abi1-1 se comporta como abi1-1, y por tanto muestra supresión de la hipersensibilidad a ABA atribuible a la mutación ocp3.

Por otro lado, analizando los niveles de los ARNm de los genes marcadores de la ruta de ABA anteriormente utilizados se observó que las plantas portadoras de la mutación doble ocp3 abi1-1 tienen mermada la inducción de la expresión de dichos genes marcadores en contraposición con lo observado con las plantas Col-0 u ocp3. El doble mutante ocp3 abi1-1 se comporta igual que el mutante abi1-1, el cual tiene también mermada la activación de la expresión de los genes de referencia en respuesta a ABA (Figura 16B). Como puede verse tanto en el caso de abi1-1 como del doble mutante ocp3 abi1-1, la inducción de la expresión del gen $R D 29 A$ queda muy mermada, mientras que en el caso de los genes $R D 29 B$ y $R D 22$ la misma queda prácticamente anulada. Estos resultados concuerdan con los obtenidos en anteriores trabajos donde la inducción de la expresión de estos genes marcadores, se ve disminuida en el mutante abi1-1 (Nordin et al., 1993; Shinozaki et al., 2000; Umezawa et al., 2006). En estos experimentos, como control interno para verificar que la aplicación y dosis de ABA utilizadas has sido efectivas, utilizamos el mutante aba2-1. El mutante aba2-1 no sintetiza ABA (Leon-Kloosterziel et al., 1996) y por tanto cualquier inducción de expresión de los genes dependientes de ABA utilizados anteriormente es atribuible solamente al ABA exógeno aplicado y no a cualquier otra perturbación interna que pueda resultar de los diferentes fondos genéticos o condiciones experimentales empleadas.

Por último estudiamos si la mutación abi1-1 es capaz también de suprimir la resistencia a sequía asociada a la mutación ocp3. Para ello se analizó el comportamiento de las plantas Col-0, Ler, ocp3, abi1-1 y ocp3 abi1-1 en respuesta a sequía. En la figura 17 se muestran plantas representativas de cada genotipo privadas de riego durante 7 días. Como puede comprobarse en esta figura, las plantas control (Col-0 y Ler) presentan síntomas de marchitamiento y estrés característicos de la privación de riego y que preceden al completo colapso de las mismas si el periodo de estrés se alarga en el tiempo. El mutante abi1-1 muestra una susceptibilidad incrementada al estrés hídrico impuesto (con una manifestación más temprana y acusada de la sintomatología característica) denotando la importancia de esta hormona en este tipo de 
respuesta. Por el contrario, el mutante ocp3, como era de esperar, presenta un comportamiento de resistencia evidente a dicho estrés. Sin embargo, el doble mutante ocp3 abi1-1 muestra un comportamiento similar al del simple mutante abi1-1 con un acusado marchitamiento que resulta ser, de nuevo, superior al observado en las plantas Col-0 (Figura15). La pérdida de la resistencia a la sequía demostrada por las plantas ocp3 abi1-1 indica, por tanto, que para la manifestación del fenotipo de resistencia atribuible a ocp3 es absolutamente imprescindible mantener intacta la ruta del ABA a través del regulador ABI1. De ello se puede derivar, además, que en condiciones salvajes la proteína OCP3 y ABI1 pueden estar interactuando para mediar un comportamiento tal y como el observado en las plantas Col-0 de cara a la percepción y respuesta a la sequía.

A
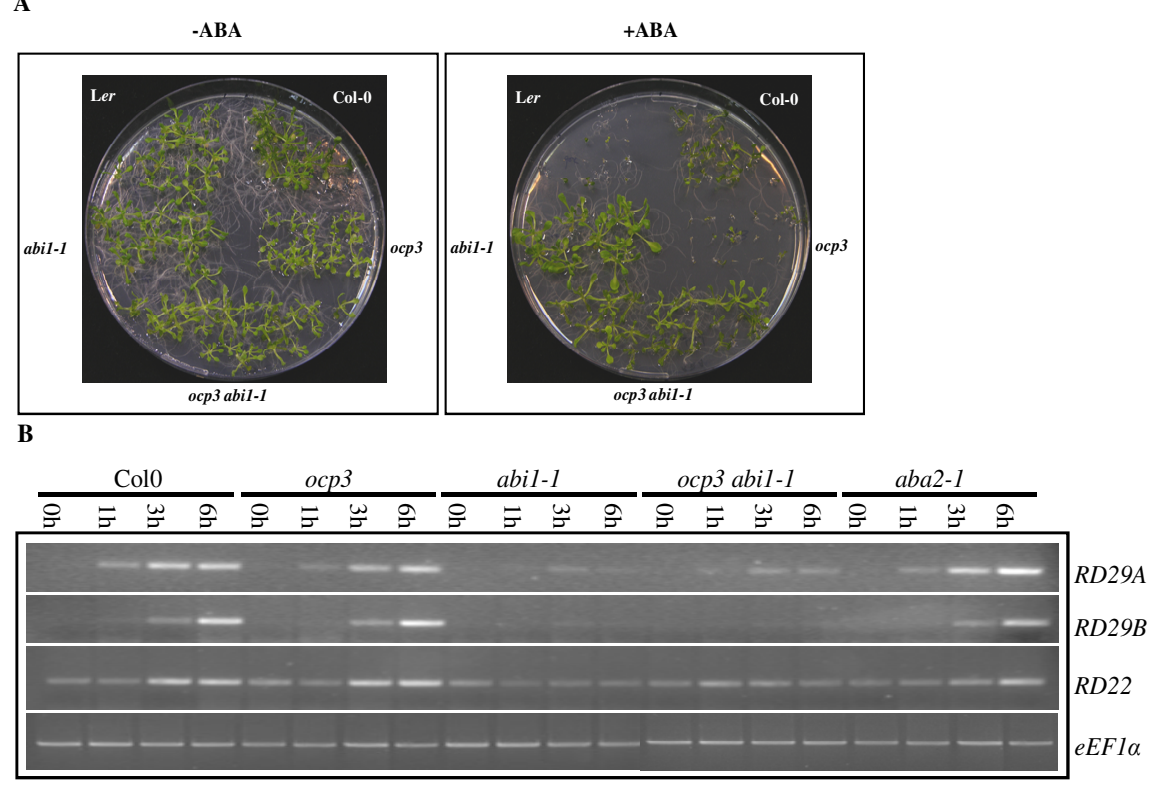

Figura 16. La mutación abi1-1 suprime la hipersensibilidad a ABA de ocp3 así como la inducción de la expresión de genes dependientes de ABA.

(A) Efecto del ABA en el desarrollo del doble mutante ocp3 abi1-1. Se utilizaron como controles los parentales ocp3 y abi1-1 además de Col-0 y Ler. Las semillas fueron tratadas de igual forma que la descrita para la figura 8.

(B) Comparativa de la inducción por ABA de la expresión por RT-PCR de genes marcadores de estrés hídrico RD29A, RD29B y RD22 en plantas Col-0, ocp3, aba2-1, abi1-1 y ocp3 abi1-1, utilizando como control el gen $e E F 1 \alpha$. Se procedió de igual manera que la descrita para la figura 11. La inducción de la expresión de los genes marcadores se ve claramente disminuida tanto en el mutante abi1-1 como en el doble mutante ocp3 abi1-1 si la comparamos con los niveles obtenidos para ocp3 o Col-0.

Visto que la mutación abi1-1 suprimía la resistencia a sequía asociada a ocp3 quisimos comprobar si otras mutaciones en la ruta de señalización del ABA 
también tenían algún efecto. Para ello generamos los dobles mutantes ocp3 aba2-1, ocp3 abi5-3 y ocp3 abi1-1R1 y ensayamos su respuesta a la sequía en las condiciones descritas anteriormente. La mutación aba2-1 inactiva una de las enzimas implicados en la síntesis de ABA, por lo que en estas plantas la cantidad de hormona es prácticamente nula. Por otro lado $A B I 5$ es un factor de transcripción bZIP implicado en la señalización mediada por ABA, de manera que el mutante de pérdida de función abi5-3 es insensible a ABA. Por su parte el mutante recesivo abi1-1R1 es un supresor intragénico de abi1-1, de tal manera que estas plantas han perdido insensibilidad a ABA aunque tienen comprometida la función de la proteína ABI1. La figura 17 resume los resultados de estos ensayos de resistencia a sequía. En ella puede apreciarse cómo ocp3 pierde su resistencia característica en presencia de cada una de las tres mutaciones. Este hecho queda patente si comparamos el grado de marchitamiento de las plantas ocp3 aba2-1, ocp3 abi5-3 y ocp3 abi1-1R1 donde se observa claramente que se comportan de manera idéntica a sus parentales aba2-1, abi5-3 y abi1-1R1 respectivamente. El periodo de sequía para este experimento se redujo para poder observar las diferencias entre genotipos más sensibles. Nótese que el comportamiento del supresor abi1-1R1 en respuesta a sequía es comparable con el de las plantas control Col-0, y dista mucho del comportamiento como hipersensible del genotipo abi1-1. El hecho de que el doble mutante ocp3 abi1-1R1 pierda la resistencia hasta niveles Col-0 refuerza por tanto la idea del requerimiento de una proteína ABI1 funcional para la resistencia a sequía observada en el mutante ocp3. Por tanto puede desprenderse de estos resultados que para la función como regulador de la respuesta a sequía, OCP3 precisa de la existencia de una ruta intacta tanto de síntesis como de correcta percepción y señalización de ABA.

ABI1 podría regular finamente el grado de apertura de los estomas promoviendo el cierre o inhibiéndolo dependiendo de múltiples interacciones con componentes de la señalización mediada por ABA (Himmelbach et al., 2002; Mishra et al., 2006a; Yoshida et al., 2006). Se ha demostrado que en el mutante abi1-1, la proteína modificada pierde la capacidad de interacción con uno de esos componentes bloqueando la inducción del cierre estomático aunque manteniendo intacta la inhibición del cierre (Mishra et al., 2006a). Nosotros proponemos que OCP3 estaría funcionando como regulador negativo del cierre estomático promovido por el ABA regulando de alguna manera la función de $\mathrm{ABI} 1$, muy posiblemente a través de una interacción directa. Consistentemente con esto la mutación abi1-1 suprime la resistencia a sequía inherente al mutante ocp3 de forma que el doble mutante ocp3 abi1-1 es incapaz de cerrar los estomas en respuesta a un incremento de ABA ya que permanece activa la señalización de inhibición del cierre estomático y está bloqueada la promoción del cierre. 


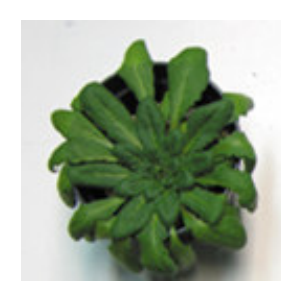

Col0

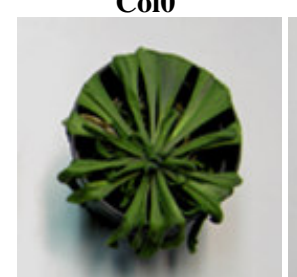

abil-1

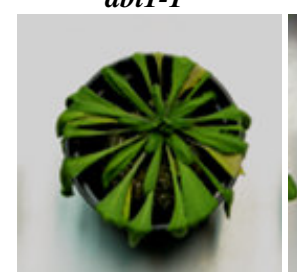

ocp3 abi1-1

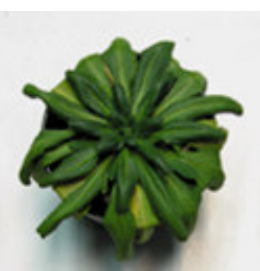

Ler

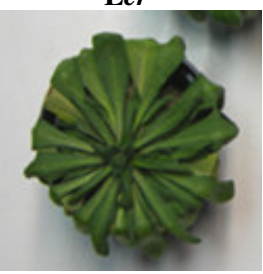

abi5-1

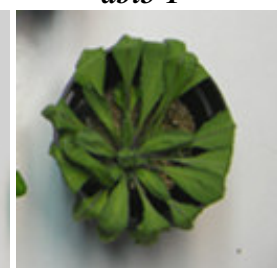

ocp3 abi5-1

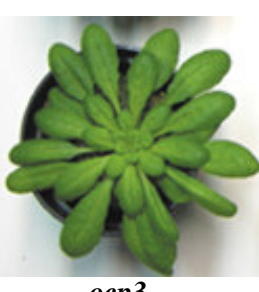

ocp3

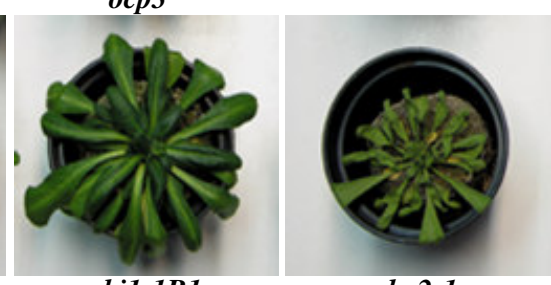

$a b a 2-1$

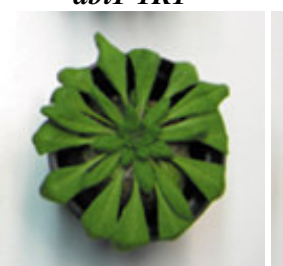

ocp3 abi1-1R1

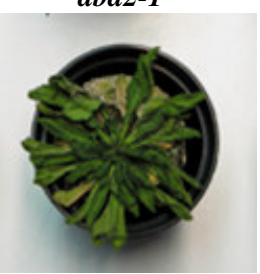

ocp3 aba2-1

Figura 17. La resistencia asociada a la mutación ocp3 requiere de una síntesis y percepción de $\mathrm{ABA}$ intactas.

Ensayo de resistencia a sequía de plantas Col-0, Ler, ocp3, abi1-1, abi5-1, aba2-1, abi1-1R1 y los respectivos dobles mutantes. Plantas de 5 semanas de edad se dejaron de regar durante 7 días. Los dobles mutantes ocp3 abi1-1, ocp3 abi5-1 y ocp3 aba2-1 muestran un comportamiento hipersensible similar al observado en los simples mutantes abi1-1, abi5-1 y aba2-1, que contrasta claramente con la resistencia exhibida por las plantas ocp3. En el caso del doble mutante ocp3 abi1-1R1 las plantas tienen un comportamiento similar al salvaje, como el simple mutante abi1-1R1. El periodo de sequía al que se sometieron las plantas fue menor de lo descrito para otros experimentos debido a que se pretendían observar diferencias entre los fenotipos hipersensible y salvaje.

\section{La resistencia a sequía asociada a ocp3 es independiente de JA y dependiente de $A B A$, mientras que la resistencia a patógenos necrotrofos es independiente de ABA y dependiente de JA.}

Como ya se ha mencionado, ocp3 exhibe una incontestable resistencia frente a patógenos de tipo necrotrofo como son $B$. cinerea o P. cucumerina. Esa resistencia requiere de una proteína COI1 funcional (Coego et al., 2005b). COI1 es una proteína F-box con actividad ubiquitin-ligasa implicada en la ruta de degradación mediada por el proteasoma $26 \mathrm{~S}$ y requerida para la mayoría de los procesos regulados por la hormona JA incluidos la inhibición del crecimiento de la raíz, la esterilidad masculina o la expresión de genes de defensa (Xie et al., 1998). Consistentemente, la resistencia frente a patógenos necrotrofos 
conferida por la mutación ocp3 se ve suprimida en el doble mutante ocp3 coi1-1 (Coego et al., 2005b).

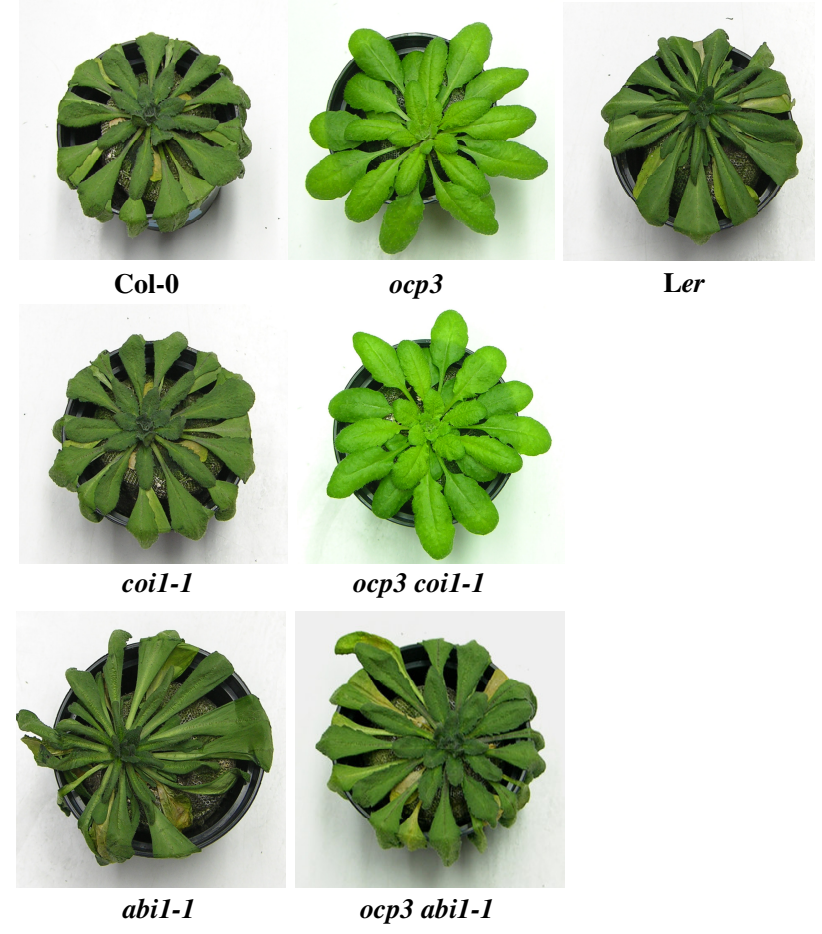

Figura 18. La resistencia a sequía asociada a ocp3 es dependiente de $A B I 1$ e independiente de COI1.

Ensayo de resistencia a la sequía de plantas ocp3, abi1-1, coi1-1 y los dobles mutantes ocp3 abi1-1 y ocp3 coi1-1. Como controles se emplearon Col-0 y Ler como fondos genéticos de los respectivos mutantes. Plantas de 5 semanas de edad se dejaron de regar durante 9 días. Mientras que el doble mutante ocp3 abi1-1 ha perdido el fenotipo de resistencia asociado a ocp3, el doble mutante ocp3 coi1-1 lo mantiene intacto.

Se ha propuesto la existencia de componentes comunes a las rutas de cierre estomático inducido tanto por ABA como por JA, como son por ejemplo las ROS, el NO o la alcanización del citosol (Bright et al., 2006; Desikan et al., 2002; Neill et al., 2002; Suhita et al., 2004). Además, el JA induce cierre estomático de manera similar al ABA, promoviendo la generación de ROS y NO en las células guarda de los estomas y activando canales de $\mathrm{Ca}^{2+}$ en sus membranas plasmáticas (Gehring et al., 1997; Suhita et al., 2003; Suhita et al., 2004). Así, el mutante coi1 es incapaz de cerrar los estomas en respuesta a la aplicación exógena de JA, pero sí lo hace inducido por la acción del ABA. De manera que se ha sugerido que probablemente la inducción del cierre estomático promovida por el JA se da a través de un receptor o receptores diferentes a los del ABA (Munemasa et al., 2007). Estos componentes comunes a ambas rutas han sido relacionados además con la señalización defensiva mediada por JA (Huang et al., 2004; Orozco-Cardenas \& Ryan, 2002). 
B

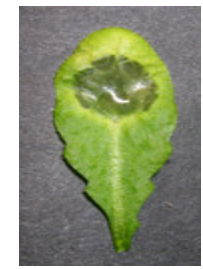

Col0

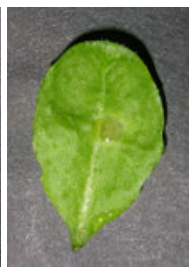

ocp3

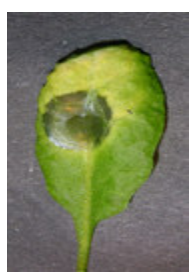

abi1-1

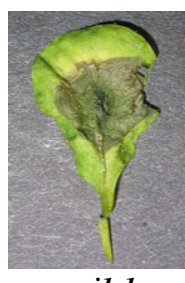

coil-1

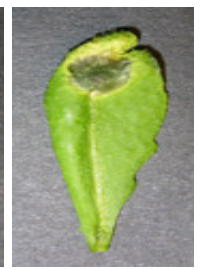

Ler

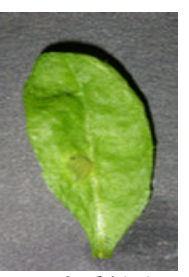

ocp3 abil-1

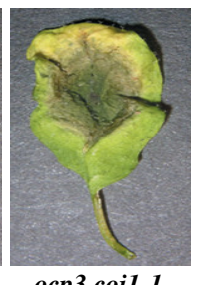

ocp3 coil-1

Figura 19. La resistencia a $B$. cinerea asociada a la mutación ocp3 es dependiente de COI1 pero independiente de $A B I 1$.

Ensayo de resistencia frente a $B$. cinerea de plantas Col-0, ocp3, Ler, abi1-1, coi1-1, ocp3abi1-1 y ocp3 coi1-1. (A) Fotografías representativas de la lesión desarrollada por el hongo a las 72 horas de la infección en los diferentes genotipos. (B) Medida del diámetro de la necrosis producida por B.cinerea en los diferentes genotipos. En la gráfica se representa la media de las medidas. Las barras de error representan el error estándar de la media.

Por todo ello decidimos estudiar las más que posibles conexiones entre ambas rutas en los fenotipos de resistencia a patógenos necrotrofos y sequía caracterizados en el mutante ocp3. Así pues ensayamos la resistencia a sequía del doble mutante ocp 3 coi1 y la resistencia a necrotrofos de ocp3 abi1. Como se demuestra en la figura 18, la mutación coi1 no es capaz de suprimir la resistencia a sequía asociada a la mutación ocp3. Como estaba descrito en otros trabajos anteriormente comentados, el mutante coi1 no tiene alterada la señalización mediada por ABA y por tanto sus niveles de resistencia a sequía son comparables a los de las plantas Col-0. Esto indica que OCP3 no precisa de una correcta señalización dependiente de COI1 y mediada por JA para su función reguladora de la resistencia a sequía mediada por ABA y dependiente de ABI1 como se demostró anteriormente. Por otro lado, el doble mutante ocp3 
abi1 se comporta en términos de resistencia a $B$. cinerea de forma similar a ocp3 como puede apreciarse en la figura 19. En ella, es evidente que la resistencia característica que acompaña a la mutación ocp3 queda intacta en el doble mutante ocp3 abi1-1, mientras que el diámetro de la lesión producida por el hongo en las plantas ocp3 coi1 alcanza niveles muy superiores al de las plantas ocp3, Col-0, o abi1-1 comportándose de manera comparable a coi1. Esto indica que la resistencia a patógenos necrotrofos a través de OCP3 no requiere de la señalización mediada por ABA ni probablemente de la interacción con ABI1, sino que la totalidad del fenotipo de resistencia es dependiente de COI1, un regulador central de la ruta del JA.

Estos resultados indican que las plantas responden al estrés de tipos tan diferentes como la sequía o las infecciones por hongos necrotrofos a través de señalizaciones paralelas que confluyen en la regulación de la función de OCP3. Es por esto que, provocando la pérdida de función de este gen, como en el mutante ocp3, conferimos resistencia frente a estos dos tipos de estrés, aunque de manera dependiente de la presencia de copias funcionales de COI1 para la resistencia a necrotrofos, y ABI1 para la resistencia a sequía. Un modelo que podría explicar los resultados obtenidos podría ser el representado en la figura 20. La pérdida de función de $O C P 3$ provoca un incremento en la resistencia frente a estrés de naturaleza tanto abiótica -sequía-, como biótica -infección por hongos necrotrofos-, controlados por los reguladores hormonales ABA y JA respectivamente. Las rutas de señalización reguladas por estas hormonas utilizan componentes centrales a través de los que se transduce la señal (ABI1 y COI1), y la pérdida de función de estos componentes se traduce en un bloqueo absoluto de la percepción de estos tipos de estrés con el consiguiente incremento en los daños producidos en la planta. Así pues, OCP3 serviría como un modulador común de las funciones tanto de ABI1 como de COI1, controlando en última instancia las respuestas finales desencadenadas en la planta. Aparentemente la respuesta frente a estos tipos de estrés podría parecer inconexa. Sin embargo son muchas las evidencias de la existencia de conexiones. Además de las ya comentadas conexiones entre las rutas de señalización mediadas por las dos hormonas, han sido constantes las observaciones en campo de la relación entre los dos tipos de estrés. Así, se ha venido describiendo desde hace mucho tiempo la circunstancia de que plantas sometidas a un estrés hídrico resisten mejor las infecciones causadas por patógenos (Conrath et al., 2002). A pesar de esto, los componentes que sirven de nexo regulador de estas relaciones se desconocen. En el presente trabajo, se ha descrito como la disrupción de un único gen, el factor de transcripción $O C P 3$, provoca un aumento en la resistencia frente a sequía y a infecciones por hongos necrotrofos. Además se ha demostrado una dependencia de la señalización mediada por $A B A$ y su regulador $A B I 1$ para el caso del fenotipo de resistencia a sequía así como una dependencia de la señalización mediada por JA y su regulador COI1 para el caso de la resistencia a infecciones por hongos necrotrofos. Por todo ello creemos acertado proponer a OCP3 como ese nexo regulador, abriendo un amplio abanico de posibilidades para su manipulación biotecnológica con el fin de mejorar la adaptación de cultivos a tipos de estrés tan limitantes para la producción. 


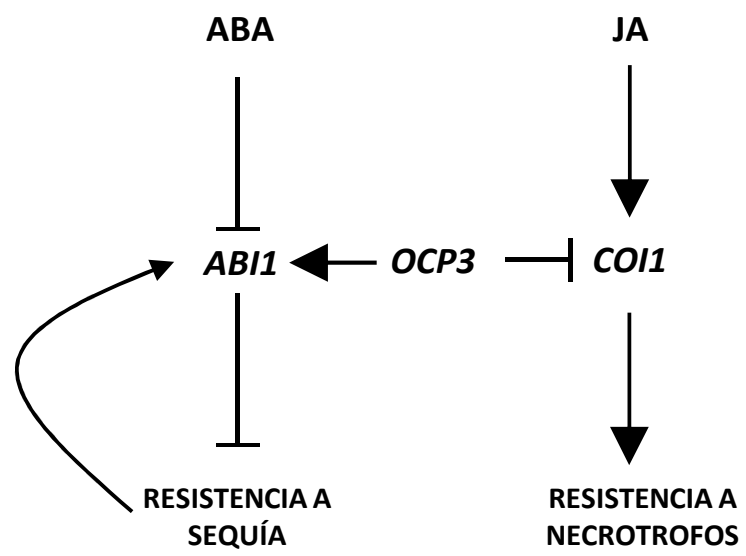

Figura 20. Un modelo de regulación común de la respuesta defensiva frente a hongos necrotrofos y a sequía a través de OCP3.

Las respuestas adaptativas de las plantas frente a la infección por hongos necrotrofos y sequía están reguladas por las fitohormonas JA y ABA respectivamente. OCP3 actúa como regulador negativo de ambos procesos. La función de COI1, un regulador positivo de la señalización mediada por JA, es reprimida por OCP3. En respuesta a la infección se produce un aumento de la biosíntesis de JA que reprime a OCP3 impidiendo su función como regulador negativo, activando así la resistencia. OCP3 y ABI1 interaccionan físicamente para regular negativamente la señalización mediada por $\mathrm{ABA}$ manteniendo los estomas abiertos. En periodos de sequía, la concentración endógena de ABA aumenta, los niveles de OCP3 disminuyen y ABI1 deja de reprimir la respuesta, los estomas se cierran y la planta es capaz de resistir mejor el estrés hídrico evitando la pérdida de agua. La propia respuesta activa un mecanismo de retroalimentación que activa de nuevo la regulación negativa por parte de ABI1, volviéndose a la situación de partida. 


\section{Discusión general del capítulo}

La sequía y las infecciones fúngicas son dos de los factores más limitantes en la productividad de los cultivos. Las respuestas de las plantas frente a estos dos tipos de estrés están mediadas por las fitohormonas ABA y JA respectivamente. En este capítulo, se ha caracterizado funcionalmente al factor de transcripción OCP3 implicándolo en la regulación de ambos procesos. El mutante de pérdida de función ocp3, presenta una mayor tolerancia frente a periodos prolongados de sequía así como frente a infecciones por hongos necrotrofos. Según indican los resultados expuestos, OCP3 juega un importante papel funcionando como regulador negativo en estas respuestas adaptativas. Al parecer OCP3 estaría modulando aspectos específicos de las señalizaciones controladas por ABA y JA a través de ABI1 y COI1, componentes centrales que transducen la señal en cada una de estas dos rutas.

EL ABA regula la respuesta al déficit hídrico modulando, entre otros, los procesos de apertura y cierre estomático (Schroeder et al., 2001a). Por otro lado, se ha demostrado que el JA, una hormona implicada en el control de diversas respuestas defensivas frente a infecciones patogénicas, también induce el cierre de los estomas (Munemasa et al., 2007; Suhita et al., 2003). Además son muchas las evidencias que implican al ABA en la respuesta frente a patógenos. Estas observaciones indicarían que los procesos mediados por ABA y JA podrían estar interrelacionados utilizando componentes comunes a ambas señalizaciones para regular la resistencia a sequía y a patógenos (Anderson et al., 2004; Fujita et al., 2006; Mauch-Mani \& Mauch, 2005). Pese a esto, son escasos los datos disponibles acerca de las interrelaciones existentes entre estas dos presiones medioambientales.

OCP3 es un miembro de la familia Homeobox de factores de transcripción. En Arabidopsis, OCP3 funciona como un regulador negativo de la respuesta defensiva ante infecciones por hongos necrotrofos como P. cucumerina o $B$. cinerea (Coego et al., 2005b). Así, las plantas ocp3 muestran una mayor resistencia frente e este tipo de patógenos, manteniendo intacta la respuesta frente a biotrofos como Pst DC3000 o H. arabidopsidis. Evidencias genéticas indican que la función de OCP3 como regulador de la respuesta frente a necrotrofos requiere COI1, una proteína F-Box que forma parte de un complejo de ubiquitinación implicado en la degradación de proteínas via proteosoma 26S, actuando como un integrador central de las respuestas mediadas por la fitohormona JA (Xie et al., 1998; Xu et al., 2002).

A partir de un escrutinio de doble híbrido en levadura se identificó a la fosfatasa 2C ABI1, un regulador central de las respuestas mediadas por ABA, como una proteína interactora de OCP3 (Allen et al., 1999; Leung et al., 1997; Merlot et al., 2001). Además se identificaron otras tres proteínas interactoras, denominadas FAC1, FAC2 y FAC3, cuya expresión es inducida rápidamente por ABA y sequía. En este capítulo también hemos descrito algunos resultados que demuestran que OCP3 juega también un papel crucial en la ruta de señalización controlada por ABA que determina la respuesta a sequía. Parte de esta respuesta incluye una fina regulación del grado de apertura/cierre de los 
estomas a través de ABI1, que interaccionaría con distintos componentes de la ruta de señalización del ABA ya sea para promover el cierre o inhibir la apertura en respuesta a un déficit hídrico (Himmelbach et al., 2002; Mishra et al., 2006a; Yoshida et al., 2006). El mutante ocp3, además de ser hipersensible al efecto inhibitorio del ABA en el crecimiento vegetativo, es más eficiente en el cierre estomático promovido por esta hormona, hecho que explicaría su mayor resistencia a sequía. La mutación dominante abi1-1 es capaz, además, de suprimir estos efectos, por lo que proponemos que ABI1 es necesario para la función de OCP3 como regulador negativo de la resistencia a sequía mediada por $\mathrm{ABA}$. Este requerimiento de ABI1 se ha comprobado además mediante el análisis del efecto de la mutación de reducción de función de ABI1 abi1-1R1. Así, el doble mutante ocp3 abi1-1R1 pierde la resistencia a sequía asociada a la mutación ocp3. Siguiendo el mismo razonamiento se ha demostrado que tanto la síntesis de ABA como la correcta transducción de señal, son necesarias para dicho fenotipo, como demuestra la supresión de la resistencia a sequía conferida por la pérdida de función de OCP3 en los dobles mutantes ocp3 aba21 у ocp3 abi5-1.

Así pues, para funcionar como un represor de la respuesta a sequía, OCP3 requiere de la participación de la fosfatasa $2 \mathrm{C}$ ABI1 y presumiblemente de la interacción física entre las dos proteínas. Los datos genéticos aportados sitúan a $A B I 1$ aguas abajo de $O C P 3$, al contrario de lo que parecería más intuitivo. No está totalmente dilucidado cómo la interacción OCP3-ABI1 contribuye a la represión de la señalización mediada por $\mathrm{ABA}$, y en última instancia al establecimiento de una respuesta eficaz frente a un déficit hídrico. Sin embargo, a raíz de los resultados se propone un modelo en el que OCP3 no sólo estaría funcionando como un represor transcripcional, sino como un vehículo para aproximar la función enzimática de ABI1 a otros factores de trascripción que estarían regulando la expresión de genes de respuesta a ABA. Una vez allí, ABI1 podría modular el estado de fosforilación/ desfosforilación de estos factores de transcripción controlando la expresión de dichos genes. Un posible candidato a ser regulado de esta forma podría ser ATHB6, un factor de transcripción cuya activación es modulada a través de desfosforilación por ABI1 (Himmelbach et al., 2002). Esta propuesta asume que ABI1 podría estar funcionando como un regulador transcripcional que indirectamente modularía la expresión génica a través de la desfosforilación de proteínas de unión a ADN. Esto podría tener algún paralelismo con el modo de funcionamiento de DBP1, otra fosfatasa también de tipo 2C, localizada predominantemente en el núcleo, y que se une específicamente a ciertos promotores de genes de respuesta a patógenos regulando su expresión, no sólo directamente actuando como un factor de transcripción propiamente dicho, sino también indirectamente defosforilando a otros factores de transcripción (Carrasco et al., 2005; Carrasco et al., 2003; Carrasco et al., 2006).

Así pues, OCP3 estaría funcionando como un facilitador de la función de ABI1, interaccionando con él y acercándolo a los promotores de genes de respuesta a ABA para que defosforile a otros factores de transcripción modulando así la respuesta de la planta a sequía. 
En resumen, los datos presentados indican que las plantas responden a la infección por patógenos necrotrofos y a la sequía a través de señalizaciones paralelas en las que OCP3 desempeña un papel regulador. El mutante ocp3 muestra una mayor resistencia frente ambos tipos de estrés. Las señalizaciones reguladas por ABA y JA y mediadas por la fosfatasa 2C ABI1 y la proteína F-Box COI1 respectivamente, parecen ser independientes pero comúnmente moduladas por OCP3. Este modo de regulación genética proporcionaría flexibilidad a la hora de regular finamente las respuestas de la planta frente a diferentes tipos de estrés ambiental. Además, este mecanismo podría estar detrás de por qué ciertos estímulos son capaces de predisponer a la planta para responder con mayor eficacia ante otros insultos aparentemente no relacionados. 
Conclusiones 


\section{Conclusiones}

1- La mutación ocp3 revierte la susceptibilidad a Pst DC3000 en mutantes de la ruta de señalización mediada por SA tales como eds1, pad4 o $N a h G$. Esa supresión es dependiente de NPR1 pero independiente de la expresión de $P R-1, P R-2$ y $P R-5$.

2- Tanto la inducción de resistencia frente a Pst DC3000 mediada por JA como el establecimiento de la Resistencia Sistémica Inducida (ISR) frente a Pst DC3000 e H. arabidopsidis están alterados en el mutante ocp3.

3- OCP3 podría, por tanto, estar involucrado en el diálogo entre las señalizaciones mediadas por SA y JA en el establecimiento de respuestas defensivas inducibles frente a diferentes tipos de patógenos.

4- OCP3 interacciona físicamente en levadura con la fosfatasa 2C ABI1 y con FAC1, FAC2 Y FAC3, tres proteínas cuya acumulación es inducida por ABA y sequía. Dichas interacciones están mediadas de manera precisa a través del dominio acídico presente en el extremo N-terminal de la proteína OCP3.

5- Las plantas ocp3 tienen una mayor tolerancia a sequía además de ser hipersensibles al efecto inhibitorio del ABA sobre el crecimiento vegetativo.

6- Las plantas ocp3 no tienen alterada ni la expresión de genes marcadores de la ruta de ABA $(R D 29 A, R D 29 B$ y $R D 22)$, ni la respuesta a desecación, ni el número o disposición de estomas a lo largo de la lámina foliar.

7- Las plantas ocp3 son más sensibles tanto al cierre estomático inducido por ABA como al efecto inhibitorio que esta hormona tiene sobre la apertura estomática inducida por la luz, lo que, en última instancia, explicaría el fenotipo de resistencia a sequía.

8- La mutación dominante abi1-1 suprime todos los aspectos asociados a la mutación ocp3 relacionados con el ABA tales como la hipersensibilidad al efecto inhibitorio del crecimiento vegetativo, la inducción de genes marcadores o la mayor resistencia a sequía. Sin embargo no es capaz de suprimir la resistencia a $B$. cinerea típica de las plantas ocp3.

9- La pérdida de función del gen COI1, un regulador central de la respuesta a JA, no es capaz de suprimir la resistencia a sequía de ocp3, pero sí su resistencia a $B$. cinerea.

10- Por tanto, la resistencia a sequía asociada a la mutación ocp3 es dependiente de una correcta síntesis y percepción de $\mathrm{ABA}$, pero independiente de JA, mientras que, por el contrario, la resistencia a hongos necrotrofos es dependiente de la señalización mediada por COI1 pero independiente de $A B I 1$. 
Materiales y Métodos 


\section{Materiales y Métodos}

\section{Material vegetal utilizado y crecimiento de las plantas.}

Las plantas se crecieron en sustrato compactado Jiffy-7 (Clause-Tezier Iberica, Valencia, España) a $23^{\circ} \mathrm{C}$ con un fotoperiodo de 10 horas de luz y 14 de oscuridad. Para el cultivo in vitro se esterilizaron las semillas añadiendo etanol $70 \%$ durante 2 minutos y lejía comercial al 30\% durante 7 minutos. Posteriormente se realizaron 5-7 lavados con agua estéril y se estratificaron a $4^{\circ} \mathrm{C}$ durante 4 días. El medio de cultivo empleado fue Murashige \& Skoog (MS) (Sigma) suplementado con sacarosa $(10 \mathrm{~g} / \mathrm{L})$ y Agargel a razón de 6g/L (Sigma) en los casos indicados. Las plantas se crecieron durante los periodos de tiempo indicados a $22^{\circ} \mathrm{C}$, un fotoperiodo de 16 horas de luz y 8 de oscuridad, con una intensidad lumínica de $150-200 \mu \mathrm{Em}^{-2} \mathrm{sec}^{-1}$.

Se emplearon los mutantes en fondo genético del ecotipo Columbia-0 (Col-0) de A. thaliana (L.) Heynh. : ocp3, npr1-1, pad4-1, aba2-1, los mutantes abi1-1, abi51, abi1-1R1 en fondo genético del ecotipo Lansberg erecta (Ler) y el mutante eds1-1 en fondo genético del ecotipo Wassilewskija (Ws-0). También se utilizó la línea transgénica $N a h G$ en el fondo genético Col-0.

Para el genotipado de los diferentes mutantes y dobles mutantes se emplearon cebadores específicos detallados a continuación:

\begin{tabular}{|c|c|c|}
\hline MUTACIÓN & CEBADOR & SECUENCIA \\
\hline \multirow[t]{2}{*}{ abi1-1 } & directo & 5'-GATATCTCCGCCGGAGAT-3' \\
\hline & reverso & 5'-CCATTCCACTGAATCACTTT-3' \\
\hline \multirow[t]{2}{*}{$a b a 2-1$} & directo & 5'-GGATACGTGTGAACTGTGTTTCG-3' \\
\hline & reverso & 5'-GATAGACATGATAAATTGGCGG-3' \\
\hline \multirow[t]{2}{*}{ abi1-1R1 } & directo & 5'-GCTAAGGAGAAACCGATGCTC-3' \\
\hline & reverso & 5'-TCACTCGCCAAAATCAGACA-3' \\
\hline \multirow[t]{2}{*}{ оср3 } & directo & 5'-GCTTAAAAGACTGGCTTATGCATTG-3' \\
\hline & reverso & 5'-GCTTTGGAGGCGGGTCACGAAG-3' \\
\hline \multirow[t]{2}{*}{ npr1-1 } & directo & 5'-ATGTCTTCGAATGTACATAAGG3' \\
\hline & reverso & 5'-GAAGGTAGAACCGCACTCATG3' \\
\hline \multirow[t]{2}{*}{ pad4-1 } & directo & 5'-GCGATGCATCAGAAGAG-3' \\
\hline & reverso & 5'-GCGATGCATCAGAAGAG-3' \\
\hline \multirow[t]{2}{*}{ coi1-1 } & directo & 5'-GGTTCTCTTTAGTCTTTAC-3' \\
\hline & reverso & 5'-CAGACAACTATTTCGTTACC-3' \\
\hline \multirow[t]{2}{*}{ NahG } & directo & 5'-ACTGGAACTCTGCCGCTA-3' \\
\hline & reverso & 5'-TGAGTTACTAGGGCGTCG-3' \\
\hline
\end{tabular}

\section{Ensayos de deshidratación y aplicación de ABA exógeno.}

Las plantas fueron crecidas durante 2-3 semanas en medio MS-Agar suplementado con 10g/L de sacarosa. Para los experimentos de deshidratación, las plántulas fueron depositadas en placas Petri cerradas, recolectando las muestras vegetales a los tiempos indicados y congelándolas inmediatamente. Como tiempo 0 se utilizaron plantas recolectadas directamente de las placas de MS-Agar. En el caso de los experimentos de aplicaciones exógenas de ABA, las 
plantas fueron transferidas a $50 \mathrm{~mL}$ de medio MS líquido en agitación suplementado con $10 \mathrm{~g} / \mathrm{L}$ de sacarosa y en los casos indicados con ABA (Sigma) a las concentraciones indicadas. Al cabo de los diferentes tiempos, se tomaron 4-5 plantas por genotipo (150mg aproximadamente) eliminando los restos de medio y se congelaron en nitrógeno líquido.

\section{Ensayos de desecación.}

Para estos ensayos, se utilizaron plantas de 5-6 semanas de edad crecidas en condiciones de día corto. Se cortaron 5-6 hojas de roseta de 3 plantas por genotipo y se colocaron en placas Petri. Se colocaron las placas en una cabina de flujo laminar y se hicieron pesadas secuenciales a los $5,10,15,20,25,30,40$, $50,60,75,90,120,150$ y 180 minutos. Para cada genotipo se generaron tres réplicas independientes de plantas diferentes. Se representó la media de los porcentajes de pérdida de peso de las tres réplicas junto con sus desviaciones estándar, tomando como $100 \%$ el peso inicial. Se repitió el ensayo tres veces con resultados comparables.

\section{Cultivo de $E$. coli}

En la propagación y purificación de plásmidos se utilizó la cepa E. coli DH5 $\alpha$. Se creció E. coli en medio líquido Luria-Bertani (LB) en presencia del antibiótico adecuado (cloranfenicol $25 \mathrm{mg} / \mathrm{L}$, ampicilina $100 \mathrm{mg} / \mathrm{L}$, o kanamicina $50 \mathrm{mg} / \mathrm{L}$ ) a $37^{\circ} \mathrm{C}$ durante una noche con agitación (200 rpm).

\section{Purificación de plásmidos}

Para la extracción de ADN plasmídicos de $E$. coli se realizaron minipreparaciones utilizando el High Pure Plasmid Isolation Kit (Roche), siguiendo las instrucciones del fabricante.

\section{Purificación de fragmentos de ADN}

Las muestras de ADN se resolvieron electroforéticamente en geles de agarosa a las concentraciones apropiadas (1-3\% p/v) teñidos con bromuro de etidio (Sambrook \& Russell, 2001) para su posterior purificación. En cada caso, la banda del tamaño esperado se recortó y el ADN se purificó utilizando el Rapid Gel Extraction System (Marligen), de acuerdo a las instrucciones del fabricante. Las ligaciones se realizaron utilizando T4-Ligasa (New England Biolabs) siguiendo las recomendaciones del fabricante.

\section{Extracción de plásmidos de levadura}

Para la extracción de ADN plasmídico a partir de colonias de levadura se utilizó el Y-DER ${ }^{\mathrm{TM}}$ Yeast DNA Extraction Reagent Kit (Pierce). 


\section{Extracción de ADN}

El ADN de hojas de plantas se extrajo utilizando el método descrito por (Edwards et al., 1991). Se trituraron y congelaron hojas de roseta de plantas de 5 semanas de edad. Para la obtención de ADN genómico total se realizó una extracción con el tampón EDM (Tris-HCl 200 mM pH 7,5 / NaCl 250 mM / ácido etilendiamino tetraacético (EDTA) $25 \mathrm{mM}$ / dodecilsulfato de sodio (SDS) 0,5\% $(\mathrm{p} / \mathrm{v})$ ) en presencia de fenol: cloroformo: isoamílico $(25: 24: 1)$ y posteriormente se precipitó con isopropanol y se lavó con etanol. El ADN obtenido a partir de cada hoja de $A$. thaliana se resuspendió en $100 \mu \mathrm{L}$ de Tris- $\mathrm{HCl} 10 \mathrm{mM} \mathrm{pH} 8$.

\section{Amplificación por PCR}

Las PCR se realizaron utilizando ADN de A. thaliana o levadura con los diferentes cebadores indicados. Las reacciones se realizaron en un volumen final de $20 \mu \mathrm{L}$ conteniendo $0,4 \mathrm{U}$ de la polimerasa Pfu (Fermentas), tampón de reacción 1x (Tris-HCL $75 \mathrm{mM} \mathrm{pH} 9$ / KCL $5 \mathrm{mM} /\left(\mathrm{NH}_{4}\right)_{2} \mathrm{SO}_{4} 20 \mathrm{mM} / \mathrm{MgCl}_{2} 2$ $\mathrm{mM} / \mathrm{BSA} 0,0001 \%(\mathrm{p} / \mathrm{v})$ ), dNTPs $200 \mu \mathrm{M}$ (Fermentas), oligonucleótidos a concentraciones de $0,24 \mu \mathrm{M}$, y $1 \mu \mathrm{L}$ de ADN ( $100 \mathrm{ng}$ ). Los programas de amplificación estándar constaron de 40-50 ciclos, cada uno con 30 s a $95{ }^{\circ} \mathrm{C}$ (desnaturalización), $30 \mathrm{~s}$ a $55^{\circ} \mathrm{C}$ (hibridación), y $2 \mathrm{~min} / \mathrm{kpb}$ a $72 \stackrel{\circ}{ }{ }^{\circ} \mathrm{C}$ (extensión). Las temperaturas de hibridación utilizadas se modificaron según el juego de cebadores utilizado. Se utilizó una máquina Programmable Thermal Controller PTC-100 (MJ Research Inc).

\section{Análisis de la expresión génica por RT-PCR}

Para la determinación de las cantidades relativas de algunos ARNm de interés se utilizó la técnica de RT-PCR semicuantitativa. Para las extracciones de ARN se partió de aproximadamente $150 \mathrm{mg}$ de tejido utilizando Trizol (Invitrogen) siguiendo el protocolo de la compañía. El ARN total fue resuspendido en $50 \mu \mathrm{L}$ de agua libre de ARNsa. La concentración y pureza del ARN se determinó midiendo las absorbancias 260/280 y 260/230 en un espectrofotómetro (Eppendorf Biophotometer, Eppendorf). La relación utilizada fue $A_{260}=1=$ $40 \mu \mathrm{g} / \mu \mathrm{L}$.

El ARN (5 $\mu \mathrm{g}$ ) fue retrotranscrito usando el kit Revertaid H Minus First Strand cDNA Synthesis Kit (Fermentas) con los cebadores Random Hexamer Primers suministrados en el kit. A partir del ADNc obtenido se realizaron las diferentes PCRs con cebadores específicos para cada gen en un termociclador PTC-100 Peltier Thermal Cycler. Los productos de las RT-PCR fueron separados en un gel de agarosa al 3\% en TAE 1X. Los cebadores utilizados para el caso de muestras derivadas de Arabidopsis se muestran en la siguiente tabla: 


\begin{tabular}{|c|c|c|c|c|}
\hline GEN & CEBADOR & SECUENCIA & №CICLOS & $\mathrm{Tm}$ \\
\hline \multirow{2}{*}{$\begin{array}{c}R D 29 A \\
\text { AT5G52310 }\end{array}$} & directo & 5'-TGCACCAGGCGTAACAGGTAA-3' & \multirow[t]{2}{*}{19} & \multirow[t]{2}{*}{58} \\
\hline & reverso & $5^{\prime}$-TTGTCCGATGTAAACGTCGTCC-3' & & \\
\hline \multirow{2}{*}{$\begin{array}{c}R D 29 B \\
\text { AT5G52300 } \\
\end{array}$} & directo & $5^{\prime}$-GCGCACCAGTGTATGAATCCTC-3' & \multirow[t]{2}{*}{23} & \multirow[t]{2}{*}{58} \\
\hline & reverso & 5'-TGTGGTCAGAAGACACGACAGG-3' & & \\
\hline \multirow{2}{*}{$\begin{array}{c}R D 22 \\
\text { AT5G25610 } \\
\end{array}$} & directo & 5'-AGGTGGCTAAGAAGAACGCACC-3' & \multirow[t]{2}{*}{22} & \multirow[t]{2}{*}{58} \\
\hline & reverso & 5'-TGGCAGTAGAACACCGCGAAT-3' & & \\
\hline \multirow{2}{*}{$\begin{array}{c}P R-1 \\
A T 2 G 14610\end{array}$} & directo & 5'-ATGAATTTTACTGGCTATTC-3' & \multirow[t]{2}{*}{22} & \multirow[t]{2}{*}{55} \\
\hline & reverso & 5'-AACCCACATGTTCACGGCGGA-3' & & \\
\hline \multirow{2}{*}{$\begin{array}{c}P R-2 \\
\text { AT3G57260 } \\
\end{array}$} & directo & 5'-GCTTCCTTCTTCAACCCCACA-3' & \multirow[t]{2}{*}{24} & \multirow[t]{2}{*}{57} \\
\hline & reverso & 5'-CTGAACCTTCCTTGAGACGGA-3' & & \\
\hline \multirow{2}{*}{$\begin{array}{c}P R-5 \\
\text { AT1G75040 }\end{array}$} & directo & 5'-CTCTTCCTCGTGTTCATCACA-3' & \multirow[t]{2}{*}{26} & \multirow[t]{2}{*}{57} \\
\hline & reverso & 5'-CATCTACGAGGCTCACATCGT-3' & & \\
\hline \multirow{2}{*}{$\begin{array}{c}\text { PDF1.2 } \\
\text { AT5G4442 }\end{array}$} & directo & 5'-ATGGCTAAGTTTGCTTCCAT-3' & \multirow[t]{2}{*}{35} & \multirow[t]{2}{*}{65} \\
\hline & reverso & 5'-ACATGGGACGTAACAGATAC-3' & & \\
\hline \multirow{2}{*}{$\begin{array}{c}V S P 1 \\
\text { AT5G24780 } \\
\end{array}$} & directo & $\begin{array}{l}5^{\prime} \text {-CTCAAGCCAAACGGATCGAA-3' } \\
\end{array}$ & \multirow[t]{2}{*}{23} & \multirow[t]{2}{*}{58} \\
\hline & reverso & 5'-GGAGCTTAAAAACCCTTCCAGG-3' & & \\
\hline \multirow{2}{*}{$\begin{array}{c}\text { LOX2 } \\
\text { AT3G45140 }\end{array}$} & directo & 5'-TGCACGCCAAAGTCTTGTCA-3' & \multirow[t]{2}{*}{21} & \multirow[t]{2}{*}{58} \\
\hline & reverso & 5'-TCAGCCAACCCCCTTTTGA-3' & & \\
\hline \multirow{2}{*}{$\begin{array}{c}e E F 1 \alpha \\
\text { AT5G60390 }\end{array}$} & directo & 5'-GCACAGTCATTGATGCCCCA-3' & \multirow[t]{2}{*}{18} & \multirow[t]{2}{*}{58} \\
\hline & reverso & 5'-CCTCAAGAAGAGTTGGTCCCT-3' & & \\
\hline
\end{tabular}

\section{RT-PCR cuantitativa en tiempo real}

Las muestras fueron analizadas por triplicado y las reacciones de PCR en tiempo real se realizaron usando Sybr Green PCR Master Mix (Applied Biosystems) en un detector de secuencias ABI PRISM 7000. Los cebadores directo y reverso fueron diseñados usando el paquete informático Primer express software. Las Ct que proporciona el software del equipo se usaron para el análisis de la expresión utilizando el programa Excel 5.0 calculando los valores $2^{\wedge}(40-\mathrm{Ct})$ y normalizándolos respecto al gen de referencia ACT8 (AT1G49240) o APT (AT1G27450). Las secuencias de los cebadores utilizados son:

\begin{tabular}{|c|c|c|}
\hline GEN & CEBADOR & SECUENCIA \\
\hline \multirow{2}{*}{$\begin{array}{c}\text { OCP3 } \\
\text { AT5G11270 }\end{array}$} & directo & $5^{\prime}$-AAGCTGGGCGTCGTAAAACTAGTA-3' \\
\hline & reverso & 5'-TGGCGGTTTTTCATCTGGTAGTGT-3' \\
\hline \multirow{2}{*}{$\begin{array}{c}A B I 1 \\
\text { AT4G26080 }\end{array}$} & directo & 5'-GTCGAGATCCATTGGCGATAGA-3' \\
\hline & reverso & 5'-TGCCATCTCACACGCTTCTTC-3' \\
\hline \multirow{2}{*}{$\begin{array}{c}\text { ACT8 } \\
\text { AT1G49240 }\end{array}$} & directo & 5'AGTGGTCGTACAACCGGTATTGT-3' \\
\hline & reverso & 5'-GAGGATAGCATGTGGAAGTGAGAA-3' \\
\hline \multirow{2}{*}{$\begin{array}{c}A P T \\
\text { AT1G27450 }\end{array}$} & directo & 5'-CCTTTCCCTTAAGCTCTG-3' \\
\hline & reverso & 5'-TCCCAGAATCGCTAAGATTGCC-3' \\
\hline
\end{tabular}

\section{Rastreo por doble híbrido en levadura}

En el rastreo por doble híbrido se utilizó la cepa de Saccharomyces cerevisiae PJ69-4. Se creció S. cerevisiae bien en medio líquido Yeast Extract-PeptoneDextrose (YPAD) a $28{ }^{\circ} \mathrm{C}$ durante un día con agitación (180 rpm), o bien en placas con medio sólido YPAD a $28{ }^{\circ} \mathrm{C}$ durante dos días suplementadas, en ambos casos, con los aminoácidos indicados. 
Para la búsqueda de interactores de OCP3, se realizó un rastreo por doble híbrido en levadura, utilizando una librería de ADNc de A.thaliana en el vector pACTII (Clontech) transformada en la cepa de levadura PJ69-4 $\alpha$, expresando así las proteínas como fusiones al dominio activador de GAL4 (GAL4AD). Como cebo se utilizó el ADNc de OCP3 expresado en la levadura PJ69-4A como fusión al dominio de unión a GAL4 (GAL4BD) en el vector pAS2-1 (Clontech) empleando el método descrito por Soellick y Uhrig para determinar las interacciones. La selección se realizó mediante ensayos de crecimiento de las levaduras en medio SC selectivo sin histidina (que indica interacción entre la proteína cebo y la proteína interactora de la librería) y sin leucina, lisina ni triptófano (para seleccionar los plásmidos pAS2.1, pACTII y la cepa de levadura PJ69-4) además de diferentes concentraciones de 3-amino-triazol (3AT). Para reconfirmar los clones positivos se extrajeron los plásmidos de las levaduras, se transformó E.coli, se secuenciaron utilizando cebadores específicos para el pACTII (5'-CTATTCGATGATGAAGATACCCCAC-3' y ${ }^{\prime}$ 5' ACTTGCGGGGTTTTTCAGTATCTAC-3’) y posteriormente se retransformó la levadura y se comprobó de nuevo la interacción.

La construcción empleada en el rastreo por doble híbrido en levadura se generó clonando el ADNc de OCP3 en el vector pAS2.1 (Clontech) amplificado con los cebadores OCP3-1: GAATTCATGATAAAAGCCATG; y OCP3-2:

GTTAACATTAGATCACCCGGGAGC; que generan sitios de corte EcoRI y SmaI respectivamente.

Las versions truncadas de OCP3 fusionadas al dominio de unión al ADN de GAL4 (fusiones BD) se generaron amplificando por PCR la región codificante de OCP3 con cebadores que incorporaban sitios de restricción para las endonucleasas EcoRI en el extremo 5' y SalI en el extremo 3'. Los productos de PCR fueron ligados, teniendo en cuenta la pauta de lectura, entre los sitios EcoRI y SalI del sitio múltiple de clonaje del vector pAS2.1.

\begin{tabular}{|l|l|l|}
\hline C1 & 5'AGAATTCATGATAAAAGCCATGGC-3' $^{\prime}$ & 5'-TGAGTCGACCATCACTGTTGCAT-3' \\
\hline C2 & 5'-GAAGAATTCGAAAGACCGACTAAGC-3' $^{\prime}$ & 5'-CGTCGACATTAGATCAAACCGG-3' $^{\prime}$ \\
\hline C3 & 5'-AGAATTCATGATAAAAGCCATGGC-3' $^{\prime}$ & 5'-AGCGTCGACGGTCATTCATCTTC-3' \\
\hline C4 & 5'-TGATGGAATTCAGATGGTCTGCT-3' $^{\prime}$ & 5'-CGTCGACATTAGATCAAACCGG-3' $^{\prime}$ \\
\hline C5 & 5'-CCGAAGGAATTCAAAAAGAAAAGTTT-3' $^{\prime}$ & 5'-CGTCGACATTAGATCAAACCGG-3' \\
\hline
\end{tabular}

\section{Medida de la actividad $\beta$-galactosidasa.}

Para las medidas de la actividad $\beta$-galactosidasa partimos de un equivalente a 15 unidades de $\mathrm{DO}$ de cultivo $\left(\mathrm{DO}_{600}=0,5-1\right)$. Centrifugamos a $3500 \mathrm{rpm}$ durante 5 minutos y lavamos varias veces con agua. La lisis de las células se efectuó incubando con tampón $\mathrm{Z}$ y en presencia de bolas de vidrio alternando ciclos de $30 \mathrm{~s}$ en frío (hielo) y temperatura ambiente. A continuación se centrifugó durante 2 minutos a $12000 \mathrm{rpm}$ y se recogió el sobrenadante. A partir de 100 $\mu \mathrm{L}$ de extracto crudo se midió la actividad. Se añadieron $400 \mu \mathrm{L}$ de tampón $\mathrm{Z}$ y 
$\beta$ - mercaptoetanol $\left(27 \mu \mathrm{l} / 10 \mathrm{ml}\right.$ tamponZ) y se incubó 20 minutos a $30^{\circ} \mathrm{C}$. Posteriormente se añadieron $100 \mu \mathrm{l}$ de o-NPG y se detuvo la reacción con $250 \mu \mathrm{l}$ de $\mathrm{Na}_{2} \mathrm{CO}_{3}(1 \mathrm{M})$ cuando vira el color de la muestra a amarillo. Se anotó el tiempo y se leyó la absorbancia $(\lambda=420 \mathrm{~nm})$ en un espectrofotómetro (Eppendorf Biophotometer, Eppendorf). El cálculo de la actividad se efectuó de acuerdo con la siguiente fórmula:

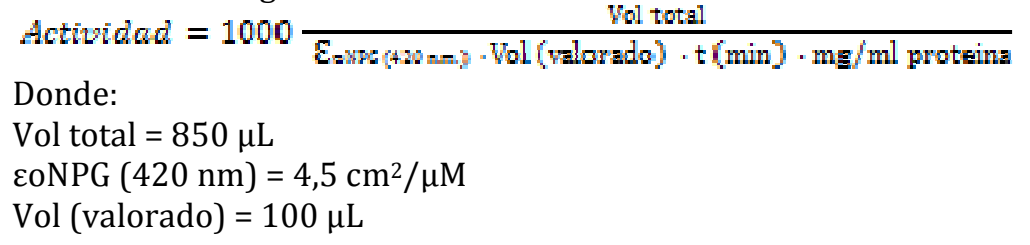

\section{Tampón Z}

$60 \mathrm{mM} \mathrm{Na}_{2} \mathrm{HPO}_{4}$

$40 \mathrm{mM} \mathrm{NaH}_{2} \mathrm{PO}_{4}$

$10 \mathrm{mM} \mathrm{KCl}$

$1 \mathrm{mM} \mathrm{MgSO}_{4}$

$\mathrm{pH}=7.0$

\section{Ensayos de infección con B.cinerea}

Como hongo fitopatógeno se utilizó la cepa BMM1 de B. cinerea aislada de Pelargonium zonale y suministrada por la Dra. B. Mauch-Mani (Universidad de Neuchatel, Suiza)

El hongo fue crecido durante 2 semanas en placas de medio PDA (PotatoDextrose Agar, Duchefa Biochemie, prod. No. P1721.0500) en las mismas condiciones de luz, temperatura y humedad descritas para las plantas.

Para las inoculaciones se utilizaron plantas de 5-6 semanas de edad crecidas en condiciones de día corto. Las esporas del hongo se recolectaron en $\mathrm{MgSO}_{4}$ con ayuda de una espátula a partir de una placa crecida durante 2-3 semanas. Posteriormente se filtraron con ayuda de una jeringa $(50 \mathrm{~mL})$ y un poco de algodón y se lavaron 2-3 veces centrifugándolas y resuspendiéndolas de nuevo. La cuantificación de esporas se realizó con ayuda de una cámara cuentaglóbulos y un microscopio. Se inocularon 5-6 hojas/planta con 5 $\mu \mathrm{L}$ de una suspensión de esporas a una concentración final de $10^{6}$ esporas $/ \mathrm{mL}$. Las plantas inoculadas se mantuvieron en una atmósfera de elevada humedad ambiental y se midió el diámetro de la lesión producida por el hongo a las 72 horas de la inoculación. Los datos se representaron según la media y el error estándar de la media (SEM). Se utilizaron 20 plantas por genotipo y los experimentos se realizaron un mínimo de tres veces. 


\section{Ensayos de infección con Pst DC3000}

Como bacterias fitopatógenas se utilizaron las cepas $P$. syringae pv. tomato DC3000, suministrada por el Dr. J. Dangl de la Universidad de Carolina del Norte (EE.UU.). Se creció P. syringae en medio líquido King's B (KB) en presencia del antibiótico rifampicina $50 \mathrm{mg} / \mathrm{L}$ a $28{ }^{\circ} \mathrm{C}$ durante un día con agitación (200 rpm). Se inoculó una placa de medio sólido KB con rifampicina $50 \mathrm{mg} / \mathrm{L}$ con $1000 \mu \mathrm{L}$ del cultivo anterior. Se creció un día a $28 \stackrel{\circ}{\circ} \mathrm{C}$. Se cosecharon las bacterias con ayuda de un asa de siembra y en $\mathrm{MgSO}_{4} 10 \mathrm{mM}$ estéril.

El crecimiento bacteriano de plantas inoculadas por inmersión se evaluó según (Tornero \& Dangl, 2001). Plántulas de 15 días de edad fueron inoculadas por inmersión durante 10 segundos en una suspensión bacteriana a razón de $5 \times 10^{7}$ ufc/mL de Pst DC3000 en $\mathrm{MgSO}_{4} 10$ mM / Silwet L-77 0,02 \% (v/v). El recuento de bacterias se realizó a los 0, 3 y 5 tras la inoculación, expresándose como el logaritmo de las unidades formadoras de colonia por peso fresco (log ( $\mathrm{ufc} / \mathrm{mg}$ p.f.)). Se realizaron cuatro réplicas por genotipo y día compuestas por $\approx 30 \mathrm{mg}$ de plántulas. A partir de esas muestras se obtuvo una suspensión de las bacterias crecidas incubándolas durante una hora y en agitación a $28^{\circ} \mathrm{C}$ en $\mathrm{MgSO}_{4}$. El crecimiento bacteriano se calculó determinando el número de unidades formadoras de colonia en la muestra recolectada realizando diluciones seriadas de la suspensión bacteriana y sembrándolas en placas de medio sólido KB suplementado con Rifampicina.

En los casos indicados se hicieron tratamientos previos con MeJA o SA por inmersión en $\mathrm{MgSO}_{4} 48 \mathrm{~h}$ antes a la inoculación con bacteria.

\section{Ensayos de infección con $\boldsymbol{H}$. arabidopsidis}

El patógeno fue mantenido en su hospedador natural Col-0 cultivándolo en plántulas de 2 semanas de edad. Se asperjó una suspensión de conidiosporas del oomiceto en agua a razón de $5 \times 10^{8}$ conidiosporas $/ \mathrm{mL}$. A continuación se taparon con plástico las plantas para mantener una humedad relativa próxima al $100 \%$. Después de una semana, las plántulas infectadas se utilizaron como fuente de inóculo recolectando en agua las hojas con los conidióforos del oomiceto para extraer las conidiosporas mediante vortex. La inoculación de los genotipos descritos se realizó de manera análoga.

\section{Ensayos de ISR}

Para los ensayos de ISR se utilizó la rizobacteria $P$. fluorescens WCS417r suministradas por el Dr. C.M.J. Pieterse de la Universidad de Utrecht (Holanda). Las condiciones de crecimiento y manipulación de esta bacteria fueron idénticas a las de Pst DC3000.

La preparación del inóculo de P. fluorescens WCS417r se efectuó partir de un cultivo de $24 \mathrm{~h}$ crecido a $28^{\circ} \mathrm{C}$ en medio KB-Agar. La rizobacteria se recolectó y se resuspendió en $\mathrm{MgSO}_{4}$ hasta una densidad de $10^{9}$ ufc $\mathrm{mL}^{-1}\left(\mathrm{DO}_{600}=1\right)$, antes de ser mezclada con el suelo. Plántulas de dos semanas de edad fueron 
transferidas a recipientes de una capacidad próxima a los 60mL. La suspensión bacteriana se mezcló con el sustrato hasta una densidad final de $5 \times 10^{7}$ ufc g-1 $^{-1}$. El sustrato de las plantas control se mezcló con $\mathrm{MgSO}_{4}$. Se transplantaron las plantas en estas condiciones y se cultivaron según lo descrito anteriormente. A las 4-5 semanas de edad, las plantas se inocularon con los diferentes patógenos según lo descrito (Pst DC3000 o H. arabidopsidis).

\section{Ensayos de resistencia a sequía.}

Para estos ensayos se emplearon 20 plantas por genotipo crecidas en condiciones de día corto durante 5 semanas y regadas 2 veces por semana con solución nutritiva. Al iniciar el periodo de sequía, las plantas de cada genotipo fueron colocadas al azar en diferentes bandejas. A los tiempos indicados en cada caso se tomaron fotografías representativas para cada genotipo.

\section{Medida de la apertura estomática}

Para la determinación de las aperturas de los estomas, se emplearon hojas de roseta totalmente expandidas de plantas de 5-6 semanas de edad crecidas en condiciones de día corto. Primero se incubaron las hojas durante 2 horas en un tampón inductor de la apertura (MES $10 \mathrm{mM}$ ajustando el pH a 6,15 con $\mathrm{KOH}$, $\mathrm{KCl} 30 \mathrm{mM}$ ). Se incubaron hojas con ese mismo tampón suplementado con ABA (Sigma) a las concentraciones indicadas para inducir el cierre de los estomas. A partir de esas hojas obtuvimos muestras epidérmicas (peelings) con ayuda de unas pinzas. Se tomaron 10 fotografías de diferentes peelings de hojas para cada genotipo, tiempo y tratamiento con ayuda de una cámara digital Nikon DXm1200F acoplada a un microscopio Nikon Eclipse E600 y utilizando el software Act-1 (Nikon). Las medidas se realizaron según las consideraciones descritas en Ichida et al., determinando el diámetro interior del ostiolo empleando el software libre Image 1.36b (Broken Symmetry software). El número de estomas medidos superaba los 90 para cada uno de los experimentos. Los datos se representaron según la media y el SEM. Los experimentos se realizaron al menos 5 veces con resultados similares. 
Bibliografía

96

96 
Bibliografía 


\section{Bibliografía}

Aarts, N. (1998). Different requirements for EDS1 and NDR1 by disease resistance genes define at least two $\mathrm{R}$ gene mediated signalling pathways in Arabidopsis. Proceedings of the National Academy of Sciences of the United States of America 95, 10306-10311.

Aarts, N., Metz, M., Holub, E., Staskawicz, B. J., Daniels, M. J. \& Parker, J. E. (1998). Different requirements for EDS1 and NDR1 by disease resistance genes define at least two $\mathrm{R}$ gene-mediated signaling pathways in Arabidopsis. Proceedings of the National Academy of Sciences of the United States of America 95, 10306-10311.

Abe, H., Urao, T., Ito, T., Seki, M., Shinozaki, K. \& Yamaguchi-Shinozaki, K. (2003). Arabidopsis AtMYC2 (bHLH) and AtMYB2 (MYB) function as transcriptional activators in abscisic acid signaling. The Plant cell 15, 63-78.

Abramovitch, R. B., Janjusevic, R., Stebbins, C. E. \& Martin, G. B. (2006). Type III effector AvrPtoB requires intrinsic E3 ubiquitin ligase activity to suppress plant cell death and immunity. Proceedings of the National Academy of Sciences of the United States of America 103, 2851-2856.

Abramovitch, R. B., Kim, Y. J., Chen, S., Dickman, M. B. \& Martin, G. B. (2003). Pseudomonas type III effector AvrPtoB induces plant disease susceptibility by inhibition of host programmed cell death. The EMBO journal 22, 60-69.

Abramovitch, R. B. \& Martin, G. B. (2004). Strategies used by bacterial pathogens to suppress plant defenses. Curr Opin Plant Biol 7, 356-364.

Ade, J., DeYoung, B. J., Golstein, C. \& Innes, R. W. (2007). Indirect activation of a plant nucleotide binding site-leucine-rich repeat protein by a bacterial protease. Proceedings of the National Academy of Sciences of the United States of America 104, 2531-2536.

Ahn, I. P., Lee, S. W. \& Suh, S. C. (2007). Rhizobacteria-induced priming in Arabidopsis is dependent on ethylene, jasmonic acid, and NPR1. Mol Plant Microbe Interact 20, 759-768.

Alonso, J. M., Hirayama, T., Roman, G., Nourizadeh, S. \& Ecker, J. R. (1999). EIN2, a bifunctional transducer of ethylene and stress responses in Arabidopsis. Science 284, 2148-2152.

Allen, G. J., Kuchitsu, K., Chu, S. P., Murata, Y. \& Schroeder, J. I. (1999). Arabidopsis abi1-1 and abi2-1 phosphatase mutations reduce abscisic acid-induced cytoplasmic calcium rises in guard cells. Plant Cell 11, 1785-1798.

Anderson, J. P., Badruzsaufari, E., Schenk, P. M., Manners, J. M., Desmond, 0. J., Ehlert, C., Maclean, D. J., Ebert, P. R. \& Kazan, K. (2004). Antagonistic interaction between abscisic acid and jasmonate-ethylene signaling pathways modulates defense gene expression and disease resistance in Arabidopsis. Plant Cell 16, 3460-3479.

Angot, A., Peeters, N., Lechner, E., Vailleau, F., Baud, C., Gentzbittel, L., Sartorel, E., Genschik, P., Boucher, C. \& Genin, S. (2006). Ralstonia 
solanacearum requires F-box-like domain-containing type III effectors to promote disease on several host plants. Proceedings of the National Academy of Sciences of the United States of America 103, 14620-14625.

Apel, K. \& Hirt, H. (2004). Reactive oxygen species: metabolism, oxidative stress, and signal transduction. Annual review of plant biology 55, 373399.

Asada, K. (1999). The water-water cycle in chloroplasts: Scavenging of active oxygens and dissipation of excess photons. Annual Review of Plant Physiology and Plant Molecular Biology 50, 601-639.

Asai, T., Tena, G., Plotnikova, J., Willmann, M. R., Chiu, W.-L., GomezGomez, L., Boller, T., Ausubel, F. M. \& Sheen, J. (2002a). MAP kinase signalling cascade in Arabidopsis innate immunity. Nature 415, 977983.

Asai, T., Tena, G., Plotnikova, J., Willmann, M. R., Chiu, W. L., Gomez-Gomez, L., Boller, T., Ausubel, F. M. \& Sheen, J. (2002b). MAP kinase signalling cascade in Arabidopsis innate immunity. Nature 415, 977983.

Assaad, F. F., Qiu, J. L., Youngs, H., Ehrhardt, D., Zimmerli, L., Kalde, M., Wanner, G., Peck, S. C., Edwards, H., Ramonell, K., Somerville, C. R. \& Thordal-Christensen, H. (2004). The PEN1 syntaxin defines a novel cellular compartment upon fungal attack and is required for the timely assembly of papillae. Molecular biology of the cell 15, 51185129.

Audenaert, K., Pattery, T., Cornelis, P. \& Hofte, M. (2002). Induction of systemic resistance to Botrytis cinerea in tomato by Pseudomonas aeruginosa 7NSK2: role of salicylic acid, pyochelin, and pyocyanin. Molecular Plant Microbe Interact 15, 1147-1156.

Axtell, M. J., Chisholm, S. T., Dahlbeck, D. \& Staskawicz, B. J. (2003). Genetic and molecular evidence that the Pseudomonas syringae type III effector protein AvrRpt2 is a cysteine protease. Molecular microbiology 49, 1537-1546.

Axtell, M. J. \& Staskawicz, B. J. (2003). Initiation of RPS2-specified disease resistance in Arabidopsis is coupled to the AvrRpt2-directed elimination of RIN4. Cell 112, 369-377.

Badel, J. L., Shimizu, R., Oh, H. S. \& Collmer, A. (2006). A Pseudomonas syringae pv. tomato avrE1/hopM1 mutant is severely reduced in growth and lesion formation in tomato. Molecular Plant Microbe Interact 19, 99-111.

Baker, S. S., Wilhelm, K. S. \& Thomashow, M. F. (1994). The 5'-region of Arabidopsis thaliana cor15a has cis-acting elements that confer cold-, drought- and ABA-regulated gene expression. Plant Molecular Biology 24, 701-713.

Bent, A. (1996). Function meets structure in the study of plant disease resistance genes. Plant Cell 8, 1757-1771.

Bent, A. F., Innes, R. W., Ecker, J. R. \& Staskawicz, B. J. (1992). Disease development in ethylene-insensitive Arabidopsis thaliana infected with virulent and avirulent Pseudomonas and Xanthomonas pathogens. Molecular Plant Microbe Interact 5, 372-378. 
Bestwick, C. S., Brown, I. R., Bennett, M. H. \& Mansfield, J. W. (1997). Localization of hydrogen peroxide accumulation during the hypersensitive reaction of lettuce cells to Pseudomonas syringae pv phaseolicola. Plant Cell 9, 209-221.

Bhat, R. A., Miklis, M., Schmelzer, E., Schulze-Lefert, P. \& Panstruga, R. (2005). Recruitment and interaction dynamics of plant penetration resistance components in a plasma membrane microdomain. Proceedings of the National Academy of Sciences of the United States of America 102, 3135-3140.

Binet, M. N., Humbert, C., Lecourieux, D., Vantard, M. \& Pugin, A. (2001). Disruption of microtubular cytoskeleton induced by cryptogein, an elicitor of hypersensitive response in tobacco cells. Plant physiology 125, 564-572.

Bittel, P. \& Robatzek, S. (2007). Microbe-associated molecular patterns (MAMPs) probe plant immunity. Current Opinion in Plant Biology 10, 335-341.

Block, A., Schmelz, E., Jones, J. B. \& Klee, H. J. (2005). Coronatine and salicylic acid: the battle between Arabidopsis and Pseudomonas for phytohormone control. Molecular Plant Pathology 6, 79-83.

Bolwell, G. P., Bindschedler, L. V., Blee, K. A., Butt, V. S., Davies, D. R., Gardner, S. L., Gerrish, C. \& Minibayeva, F. (2002). The apoplastic oxidative burst in response to biotic stress in plants: a threecomponent system. Journal of experimental botany 53,1367-1376.

Botella, M. A. (1998). Three genes of the Arabidopsis RPP1 complex resistance locus recognize distinct Peronospora parasitica avirulence determinants. Plant Cell 10, 1847-1860.

Bowling, S. A., Clarke, J. D., Liu, Y., Klessig, D. F. \& Dong, X. (1997). The cpr5 mutant of Arabidopsis expresses both NPR1-dependent and NPR1independent resistance. Plant Cell 9, 1573-1584.

Brederode, F. T., Linthorst, H. J. M. \& Bol, J. F. (1991). Differential induction of acquired resistance and PR gene expression in tobacco by virus infection, ethephon treatment, UV light and wounding. Plant Molecular Biology 17, 1117-1125.

Bretz, J. R., Mock, N. M., Charity, J. C., Zeyad, S., Baker, C. J. \& Hutcheson, S. W. (2003). A translocated protein tyrosine phosphatase of Pseudomonas syringae pv. tomato DC3000 modulates plant defence response to infection. Molecular microbiology 49, 389-400.

Bright, J., Desikan, R., Hancock, J. T., Weir, I. S. \& Neill, S. J. (2006). ABAinduced NO generation and stomatal closure in Arabidopsis are dependent on H2O2 synthesis. Plant Journal 45, 113-122.

Cao, H., Bowling, S. A., Gordon, A. S. \& Dong, X. (1994). Characterization of an Arabidopsis Mutant That Is Nonresponsive to Inducers of Systemic Acquired Resistance. Plant Cell 6, 1583-1592.

Cao, H., Glazebrook, J., Clarke, J. D., Volko, S. \& Dong, X. (1997). The Arabidopsis NPR1 gene that controls systemic acquired resistance encodes a novel protein containing ankyrin repeats. Cell 88, 57-63.

Cao, H., Li, X. \& Dong, X. (1998). Generation of broad-spectrum disease resistance by overexpression of an essential regulatory gene in 
systemic acquired resistance. Proceedings of the National Academy of Sciences of the United States of America 95, 6531-6536.

Carrasco, J. L., Ancillo, G., Castello, M. J. \& Vera, P. (2005). A novel DNAbinding motif, hallmark of a new family of plant transcription factors. Plant physiology 137, 602-606.

Carrasco, J. L., Ancillo, G., Mayda, E. \& Vera, P. (2003). A novel transcription factor involved in plant defense endowed with protein phosphatase activity. The EMBO journal 22, 3376-3384.

Carrasco, J. L., Castello, M. J. \& Vera, P. (2006). 14-3-3 mediates transcriptional regulation by modulating nucleocytoplasmic shuttling of tobacco DNA-binding protein phosphatase-1. The Journal of biological chemistry 281, 22875-22881.

Celio, G. J., Mims, C. W. \& Richardson, E. A. (2004). Ultrastructure and immunocytochemistry of the host-pathogen interface in poinsettia leaves infected with powdery mildew. Canadian Journal of BotanyRevue Canadienne De Botanique 82, 421-429.

Clarke, J. D., Liu, Y., Klessig, D. F. \& Dong, X. (1998). Uncoupling PR gene expression from NPR1 and bacterial resistance: characterization of the dominant Arabidopsis cpr6-1 mutant. Plant Cell 10, 557-569.

Clarke, J. D., Volko, S. M., Ledford, H., Ausubel, F. M. \& Dong, X. (2000). Roles of salicylic acid, jasmonic acid, and ethylene in cpr-induced resistance in arabidopsis. Plant Cell 12, 2175-2190.

Coego, A., Ramirez, V., Ellul, P., Mayda, E. \& Vera, P. (2005a). The H2O2regulated Ep5C gene encodes a peroxidase required for bacterial speck susceptibility in tomato. Plant Journal 42, 283-293.

Coego, A., Ramirez, V., Gil, M. J., Flors, V., Mauch-Mani, B. \& Vera, P. (2005b). An Arabidopsis homeodomain transcription factor, OVEREXPRESSOR OF CATIONIC PEROXIDASE 3, mediates resistance to infection by necrotrophic pathogens. Plant Cell 17, 2123-2137.

Cohen, Y. (2001). The BABA story of induced resistance. Phytoparasitica 29, 375-378.

Cohn, J. R. \& Martin, G. B. (2005). Pseudomonas syringae pv. tomato type III effectors AvrPto and AvrPtoB promote ethylene-dependent cell death in tomato. Plant Journal 44, 139-154.

Conrath, U., Pieterse, C. M. \& Mauch-Mani, B. (2002). Priming in plantpathogen interactions. Trends in plant science 7, 210-216.

Creelman, R. A. \& Mullet, J. E. (1997). Biosynthesis and Action of Jasmonates in Plants. Annual Review of Plant Physiology and Plant Molecular Biology 48, 355-381.

Cunnac, S., Occhialini, A., Barberis, P., Boucher, C. \& Genin, S. (2004). Inventory and functional analysis of the large Hrp regulon in Ralstonia solanacearum: identification of novel effector proteins translocated to plant host cells through the type III secretion system. Molecular microbiology 53, 115-128.

Chamnongpol, S., Willekens, H., Moeder, W., Langebartels, C., Sandermann, H., Jr., Van Montagu, M., Inze, D. \& Van Camp, W. (1998). Defense activation and enhanced pathogen tolerance induced by H2O2 in 
transgenic tobacco. Proceedings of the National Academy of Sciences of the United States of America 95, 5818-5823.

Chern, M. S., Fitzgerald, H. A., Yadav, R. C., Canlas, P. E., Dong, X. \& Ronald, P. C. (2001). Evidence for a disease-resistance pathway in rice similar to the NPR1-mediated signaling pathway in Arabidopsis. Plant Journal 27, 101-113.

Chini, A., Fonseca, S., Fernandez, G., Adie, B., Chico, J. M., Lorenzo, O., Garcia-Casado, G., Lopez-Vidriero, I., Lozano, F. M., Ponce, M. R., Micol, J. L. \& Solano, R. (2007). The JAZ family of repressors is the missing link in jasmonate signalling. Nature 448, 666-671.

Choi, H., Hong, J., Ha, J., Kang, J. \& Kim, S. Y. (2000). ABFs, a family of ABAresponsive element binding factors. The Journal of biological chemistry 275, 1723-1730.

Chosed, R., Tomchick, D. R., Brautigam, C. A., Mukherjee, S., Negi, V. S., Machius, M. \& Orth, K. (2007). Structural analysis of Xanthomonas XopD provides insights into substrate specificity of ubiquitin-like protein proteases. The Journal of biological chemistry 282, 6773-6782.

da Cunha, L., McFall, A. J. \& Mackey, D. (2006). Innate immunity in plants: a continuum of layered defenses. Microbes and infection / Institut Pasteur 8, 1372-1381.

Dangl, J. L. \& Jones, J. D. G. (2001a). Plant pathogens and integrated defence responses to infection. Nature 411, 826-833.

Davletova, S., Rizhsky, L., Liang, H., Shengqiang, Z., Oliver, D. J., Coutu, J., Shulaev, V., Schlauch, K. \& Mittler, R. (2005). Cytosolic ascorbate peroxidase 1 is a central component of the reactive oxygen gene network of Arabidopsis. Plant Cell 17, 268-281.

Day, B., Dahlbeck, D., Huang, J., Chisholm, S. T., Li, D. \& Staskawicz, B. J. (2005). Molecular basis for the RIN4 negative regulation of RPS2 disease resistance. Plant Cell 17, 1292-1305.

de Torres-Zabala, M., Truman, W., Bennett, M. H., Lafforgue, G., Mansfield, J. W., Egea, P. R., Bogre, L. \& Grant, M. (2007). Pseudomonas syringae pv. tomato hijacks the Arabidopsis abscisic acid signalling pathway to cause disease. EMBO Journal 26, 1434-1443.

de Torres, M., Mansfield, J. W., Grabov, N., Brown, I. R., Ammouneh, H., Tsiamis, G., Forsyth, A., Robatzek, S., Grant, M. \& Boch, J. (2006). Pseudomonas syringae effector AvrPtoB suppresses basal defence in Arabidopsis. Plant Journal 47, 368-382.

Dean, R. A. \& Kuc, J. (1987). Rapid Lignification in Response to Wounding and Infection as a Mechanism for Induced Systemic Protection in Cucumber. Physiological and Molecular Plant Pathology 31, 69-81.

DebRoy, S., Thilmony, R., Kwack, Y. B., Nomura, K. \& He, S. Y. (2004). A family of conserved bacterial effectors inhibits salicylic acid-mediated basal immunity and promotes disease necrosis in plants. Proceedings of the National Academy of Sciences of the United States of America 101, 9927-9932.

Delaney, T. P., Friedrich, L. \& Ryals, J. A. (1995). Arabidopsis signal transduction mutant defective in chemically and biologically induced 
disease resistance. Proceedings of the National Academy of Sciences of the United States of America 92, 6602-6606.

Delaney, T. P., Uknes, S., Vernooij, B., Friedrich, L., Weymann, K., Negrotto, D., Gaffney, T., Gut-Rella, M., Kessmann, H., Ward, E. \& Ryals, J. (1994). A Central Role of Salicylic Acid in Plant Disease Resistance. Science 266, 1247-1250.

Desaki, Y., Miya, A., Venkatesh, B., Tsuyumu, S., Yamane, H., Kaku, H., Minami, E. \& Shibuya, N. (2006). Bacterial lipopolysaccharides induce defense responses associated with programmed cell death in rice cells. Plant \& cell physiology 47, 1530-1540.

Desikan, R., Griffiths, R., Hancock, J. \& Neill, S. (2002). A new role for an old enzyme: nitrate reductase-mediated nitric oxide generation is required for abscisic acid-induced stomatal closure in Arabidopsis thaliana. Proceedings of the National Academy of Sciences of the United States of America 99, 16314-16318.

Desikan, R., S, A. H.-M., Hancock, J. T. \& Neill, S. J. (2001). Regulation of the Arabidopsis transcriptome by oxidative stress. Plant physiology 127, 159-172.

Desveaux, D., Allard, J., Brisson, N. \& Sygusch, J. (2002). A new family of plant transcription factors displays a novel ssDNA-binding surface. Nature structural biology 9, 512-517.

Dewdney, J., Reuber, T. L., Wildermuth, M. C., Devoto, A., Cui, J., Stutius, L. M., Drummond, E. P. \& Ausubel, F. M. (2000). Three unique mutants of Arabidopsis identify eds loci required for limiting growth of a biotrophic fungal pathogen. Plant Journal 24, 205-218.

Dinesh-Kumar, S. P. \& Baker, B. J. (2000). Alternatively spliced N resistance gene transcripts: their possible role in tobacco mosaic virus resistance. Proceedings of the National Academy of Sciences of the United States of America 97, 1908-1913.

Dixon, M. S., Golstein, C., Thomas, C. M., van Der Biezen, E. A. \& Jones, J. D. (2000). Genetic complexity of pathogen perception by plants: the example of Rcr3, a tomato gene required specifically by Cf- 2 . Proceedings of the National Academy of Sciences of the United States of America 97, 8807-8814.

Doares, S. H., Narvaez-Vasquez, J., Conconi, A. \& Ryan, C. A. (1995). Salicylic Acid Inhibits Synthesis of Proteinase Inhibitors in Tomato Leaves Induced by Systemin and Jasmonic Acid. Plant Physiology 108, 17411746.

Doke, N., Miura, Y., Sanchez, L. M., Park, H. J., Noritake, T., Yoshioka, H. \& Kawakita, K. (1996). The oxidative burst protects plants against pathogen attack: mechanism and role as an emergency signal for plant bio-defence--a review. Gene 179, 45-51.

Dombrecht, B., Xue, G. P., Sprague, S. J., Kirkegaard, J. A., Ross, J. J., Reid, J. B., Fitt, G. P., Sewelam, N., Schenk, P. M., Manners, J. M. \& Kazan, K. (2007). MYC2 differentially modulates diverse jasmonate-dependent functions in Arabidopsis. Plant Cell 19, 2225-2245.

Dong, X. (1998). SA, JA, ethylene, and disease resistance in plants. Current opinion in plant biology 1, 316-323. 
Dong, X. (2004). NPR1, all things considered. Curr Opin Plant Biol 7, 547-552.

Dubouzet, J. G., Sakuma, Y., Ito, Y., Kasuga, M., Dubouzet, E. G., Miura, S., Seki, M., Shinozaki, K. \& Yamaguchi-Shinozaki, K. (2003). OsDREB genes in rice, Oryza sativa L., encode transcription activators that function in drought-, high-salt- and cold-responsive gene expression. Plant Journal 33, 751-763.

Duijff, B. J., Pouhair, D., Olivain, C., Alabouvette, C. \& Lemanceau, P. (1998). Implication of systemic induced resistance in the suppression of fusarium wilt of tomato by Pseudomonas fluorescens WCS417r and by nonpathogenic Fusarium oxysporum Fo47. European Journal of Plant Pathology 104, 903-910.

Durrant, W. E. \& Dong, X. (2004). Systemic acquired resistance. Annual Review of Phytopathology 42, 185-209.

Durrant, W. E., Rowland, O., Piedras, P., Hammond-Kossak, K. E. \& Jones, J. D. G. (2000). cDNA-AFLP reveals a striking overlap in the race-specific resistance and wound response expression profiles. Plant Cell 12, 963 977.

Ecker, J. R. (1995). The ethylene signal transduction pathway in plants. Science 268, 667-675.

Edwards, K., Johnstone, C. \& Thompson, C. (1991). A simple and rapid method for the preparation of plant genomic DNA for PCR analysis. Nucleic Acids Research 19, 1349.

Ekengren, S. K., Liu, Y., Schiff, M., Dinesh-Kumar, S. P. \& Martin, G. B. (2003). Two MAPK cascades, NPR1, and TGA transcription factors play a role in Pto-mediated disease resistance in tomato. Plant Journal 36, 905-917.

Ellis, C., Karafyllidis, I. \& Turner, J. G. (2002a). Constitutive activation of jasmonate signaling in an Arabidopsis mutant correlates with enhanced resistance to Erysiphe cichoracearum, Pseudomonas syringae, and Myzus persicae. Molecular Plant Microbe Interaction 15, 1025-1030.

Ellis, C., Karafyllidis, I., Wasternack, C. \& Turner, J. G. (2002b). The Arabidopsis mutant cev1 links cell wall signaling to jasmonate and ethylene responses. Plant Cell 14, 1557-1566.

Ellis, C. \& Turner, J. G. (2001). The Arabidopsis mutant cev1 has constitutively active jasmonate and ethylene signal pathways and enhanced resistance to pathogens. Plant Cell 13, 1025-1033.

Ellis, J., Dodds, P. \& Pryor, T. (2000). Structure, function, and evolution of plant disease resistance genes. Current Opinion in Plant Biology 3, 278284.

Espinosa, A., Guo, M., Tam, V. C., Fu, Z. Q. \& Alfano, J. R. (2003). The Pseudomonas syringae type III-secreted protein HopPtoD2 possesses protein tyrosine phosphatase activity and suppresses programmed cell death in plants. Molecular microbiology 49, 377-387.

Eulgem, T., Rushton, P. J., Robatzek, S. \& Somssich, I. E. (2000). The WRKY superfamily of plant transcription factors. Trends Plant Science 5, 199206. 
Falk, A., Feys, B. J., Frost, L. N., Jones, J. D., Daniels, M. J. \& Parker, J. E. (1999). EDS1, an essential component of $\mathrm{R}$ gene-mediated disease resistance in Arabidopsis has homology to eukaryotic lipases. Proceedings of the National Academy of Sciences of the United States of America 96, 3292-3297.

Fan, W. \& Dong, X. (2002). In vivo interaction between NPR1 and transcription factor TGA2 leads to salicylic acid-mediated gene activation in Arabidopsis. Plant Cell 14, 1377-1389.

Felix, G. \& Boller, T. (2003). Molecular sensing of bacteria in plants. The highly conserved RNA-binding motif RNP-1 of bacterial cold shock proteins is recognized as an elicitor signal in tobacco. The Journal of biological chemistry 278, 6201-6208.

Felix, G., Duran, J. D., Volko, S. \& Boller, T. (1999). Plants have a sensitive perception system for the most conserved domain of bacterial flagellin. Plant Journal 18, 265-276.

Felton, G. W., Korth, K. L., Bi, J. L., Wesley, S. V., Huhman, D. V., Mathews, M. C., Murphy, J. B., Lamb, C. \& Dixon, R. A. (1999). Inverse relationship between systemic resistance of plants to microorganisms and to insect herbivory. Current Biology 9, 317-320.

Feys, B. J. \& Parker, J. E. (2000). Interplay of signaling pathways in plant disease resistance. Trends in Genetics 16, 449-455.

Feys, B. J. F., Benedetti, C. E., Penfold, C. N. \& Turner, J. G. (1994). Arabidopsis Mutants Selected for Resistance to the Phytotoxin Coronatine Are Male-Sterile, Insensitive to Methyl Jasmonate, and Resistant to a Bacterial Pathogen. Plant Cell 6, 751-759.

Finkelstein, R. R. \& Somerville, C. R. (1990). Three Classes of Abscisic Acid (ABA)-Insensitive Mutations of Arabidopsis Define Genes that Control Overlapping Subsets of ABA Responses. Plant physiology 94, 11721179.

Flor, H. H. (1971). Current status of the gene-for-gene concept. Annual Revision Phytopathology 9, 275-296.

Foyer, C. H. \& Noctor, G. (2005). Redox homeostasis and antioxidant signaling: a metabolic interface between stress perception and physiological responses. Plant Cell 17, 1866-1875.

Freialdenhoven, A., Peterhansel, C., Kurth, J., Kreuzaler, F. \& SchulzeLefert, P. (1996). Identification of Genes Required for the Function of Non-Race-Specific mlo Resistance to Powdery Mildew in Barley. Plant Cell 8, 5-14.

Freialdenhoven, A., Scherag, B., Hollricher, K., Collinge, D. B., ThordalChristensen, H. \& Schulze-Lefert, P. (1994). Nar-1 and Nar-2, Two Loci Required for Mla12-Specified Race-Specific Resistance to Powdery Mildew in Barley. Plant Cell 6, 983-994.

Fritz-Laylin, L. K., Krishnamurthy, N., Tor, M., Sjolander, K. V. \& Jones, J. D. (2005). Phylogenomic analysis of the receptor-like proteins of rice and Arabidopsis. Plant physiology 138, 611-623.

Fry, S. C. (1989). Cellulases, Hemicelluloses and Auxin-Stimulated Growth - a Possible Relationship. Physiologia Plantarum 75, 532-536. 
Fujita, M., Fujita, Y., Noutoshi, Y., Takahashi, F., Narusaka, Y., YamaguchiShinozaki, K. \& Shinozaki, K. (2006). Crosstalk between abiotic and biotic stress responses: a current view from the points of convergence in the stress signaling networks. Current opinion in plant biology $\mathbf{9}$, 436-442.

Fukuda, H., Ogawa, T. \& Tanase, S. (1993). Ethylene Production by Microorganisms. In Advances in Microbial Physiology, Vol 35, pp. 275306.

Gaffney, T. (1993). Requirement for salicylic acid for the induction of systemic acquired resistance. Science 261, 754-756.

Gehring, C. A., Irving, H. R., Kabbara, A. A., Parish, R. W., Boukli, N. M. \& Broughton, W. J. (1997). Rapid, plateau-like increases in intracellular free calcium are associated with nod-factor-induced root-hair deformation. Molecular Plant-Microbe Interactions 10, 791-802.

Gibson, S., Arondel, V., Iba, K. \& Somerville, C. (1994). Cloning of a temperature-regulated gene encoding a chloroplast omega-3 desaturase from Arabidopsis thaliana. Plant physiology 106, 16151621.

Gilmour, S. J., Sebolt, A. M., Salazar, M. P., Everard, J. D. \& Thomashow, M. F. (2000). Overexpression of the Arabidopsis CBF3 transcriptional activator mimics multiple biochemical changes associated with cold acclimation. Plant physiology 124, 1854-1865.

Glazebrook, J. (2001). Genes controlling expression of defense responses in Arabidopsis--2001 status. Current opinion in plant biology 4, 301-308.

Glazebrook, J. (2005). Contrasting mechanisms of defense against biotrophic and necrotrophic pathogens. Annual Review Phytopathology 43, 205227.

Glazebrook, J., Rogers, E. E. \& Ausubel, F. M. (1996). Isolation of Arabidopsis mutants with enhanced disease susceptibility by direct screening. Genetics 143, 973-982.

Glazebrook, J. \& Ton, J. (2007). Recurring themes and expanding scales. Current Opinion in Plant Biology 10, 331-334.

Goggin, F. L. (2007). Plant-aphid interactions: molecular and ecological perspectives. Current Opinion in Plant Biology 10, 399-408.

Gomez-Gomez, L. \& Boller, T. (2000a). FLS2: an LRR receptor-like kinase involved in the perception of the bacterial elicitor flagellin in Arabidopsis. Molecular Cell 5, 1003-1011.

Gomez-Gomez, L. \& Boller, T. (2000b). FLS2: an LRR receptor like kinase involved in the perception of the bacterial elicitor flagellin in Arabidopsis. Molecular Cell 5, 1003-1011.

Govrin, E. M. \& Levine, A. (2000). The hypersensitive response facilitates plant infection by the necrotrophic pathogen Botrytis cinerea. Current Opinion 10, 751-757.

Gross, D. C. \& Cody, Y. S. (1985). Mechanisms of Plant Pathogenesis by Pseudomonas Species. Canadian Journal of Microbiology 31, 403-410.

Gupta, V., Willits, M. G. \& Glazebrook, J. (2000). Arabidopsis thaliana EDS4 contributes to salicylic acid (SA)-dependent expression of defense 
responses: evidence for inhibition of jasmonic acid signaling by SA. Mol Plant Microbe Interaction 13, 503-511.

Gus-Mayer, S., Naton, B., Hahlbrock, K. \& Schmelzer, E. (1998). Local mechanical stimulation induces components of the pathogen defense response in parsley. Proceedings of the National Academy of Sciences of the United States of America 95, 8398-8403.

Halterman, D., Zhou, F., Wei, F., Wise, R. P. \& Schulze-Lefert, P. The Mla6 coiled-coil, NBS-LRR protein functions in barley and wheat to confer resistance specificity to Blumeria graminis f. sp. hordei. Plant Journal 63, 167-178.

Hammerschmidt, R. (1999). PHYTOALEXINS: What Have We Learned After 60 Years? Annual Review Phytopathology37, 285-306.

Hann, D. R. \& Rathjen, J. P. (2007). Early events in the pathogenicity of Pseudomonas syringae on Nicotiana benthamiana. Plant Journal 49, 607-618.

Harberd, N. P. (2003). Botany. Relieving DELLA restraint. Science 299, 18531854.

Hardham, A. R., Jones, D. A. \& Takemoto, D. (2007). Cytoskeleton and cell wall function in penetration resistance. Current opinion in plant biology 10, 342-348.

Hauck, P., Thilmony, R. \& He, S. Y. (2003). A Pseudomonas syringae type III effector suppresses cell wall-based extracellular defense in susceptible Arabidopsis plants. Proceedings of the National Academy of Sciences of the United States of America 100, 8577-8582.

He, P., Chintamanani, S., Chen, Z., Zhu, L., Kunkel, B. N., Alfano, J. R., Tang, X. \& Zhou, J. M. (2004). Activation of a COI1-dependent pathway in Arabidopsis by Pseudomonas syringae type III effectors and coronatine. Plant Journal 37, 589-602.

Hetherington, A. M. (2001). Guard cell signaling. Cell 107, 711-714.

Hilpert, B., Bohlmann, H., op den Camp, R. O., Przybyla, D., Miersch, O., Buchala, A. \& Apel, K. (2001). Isolation and characterization of signal transduction mutants of Arabidopsis thaliana that constitutively activate the octadecanoid pathway and form necrotic microlesions. Plant Journal 26, 435-446.

Himmelbach, A., Hoffmann, T., Leube, M., Hohener, B. \& Grill, E. (2002). Homeodomain protein ATHB6 is a target of the protein phosphatase $\mathrm{ABI} 1$ and regulates hormone responses in Arabidopsis. The EMBO journal 21, 3029-3038.

Holmberg, N. \& Bulow, L. (1998). Improving stress tolerance in plants by gene transfer. Trends in plant science 3, 61-66.

Hotson, A., Chosed, R., Shu, H., Orth, K. \& Mudgett, M. B. (2003). Xanthomonas type III effector XopD targets SUMO-conjugated proteins in planta. Molecular microbiology 50, 377-389.

Huang, X., Stettmaier, K., Michel, C., Hutzler, P., Mueller, M. J. \& Durner, J. (2004). Nitric oxide is induced by wounding and influences jasmonic acid signaling in Arabidopsis thaliana. Planta 218, 938-946.

Jabs, T., Colling, C., Tschope, M., Hahlbrock, K. \& Scheel, D. (1997). Elicitorstimulated ion fluxes and reactive oxygen species from the oxidative 
burst signal defense gene activation and phytoalexin synthesis in parsley. Proceedings of the National Academy of Sciences of the United States of America 94, 4800-4805.

Jakab, G., Cottier, V., Toquin, V., Rigoli, G., Zimmerli, L., Metraux, J. P. \& Mauch-Mani, B. (2001). beta-Aminobutyric acid-induced resistance in plants. European Journal of Plant Pathology 107, 29-37.

Jakab, G., Ton, J., Flors, V., Zimmerli, L., Metraux, J. P. \& Mauch-Mani, B. (2005). Enhancing Arabidopsis salt and drought stress tolerance by chemical priming for its abscisic acid responses. Plant physiology 139, 267-274.

Janjusevic, R., Abramovitch, R. B., Martin, G. B. \& Stebbins, C. E. (2006). A bacterial inhibitor of host programmed cell death defenses is an E3 ubiquitin ligase. Science 311, 222-226.

Jefferson, R. A., Kavanagh, T. A. \& Bevan, M. W. (1987). GUS fusions: betaglucuronidase as a sensitive and versatile gene fusion marker in higher plants. The EMBO journal 6, 3901-3907.

Jensen, A. B., Raventos, D. \& Mundy, J. (2002). Fusion genetic analysis of jasmonate-signalling mutants in Arabidopsis. Plant Journal 29, 595606.

Jin, H., Liu, Y., Yang, K.-Y., Kim, C. Y., Baker, B. \& Zhang, S. (2003). Function of a mitogen-activated protein kinase pathway in $\mathrm{N}$ gene-mediated resistance in tobacco. Plant Journal 33, 719-731.

Jirage, D., Tootle, T. L., Reuber, T. L., Frost, L. N., Feys, B. J., Parker, J. E., Ausubel, F. M. \& Glazebrook, J. (1999). Arabidopsis thaliana PAD4 encodes a lipase-like gene that is important for salicylic acid signaling. Proceedings of the National Academy of Sciences of the United States of America 96, 13583-13588.

Jirage, D., Zhou, N., Cooper, B., Clarke, J. D., Dong, X. \& Glazebrook, J. (2001). Constitutive salicylic acid-dependent signaling in cpr1 and cpr6 mutants requires PAD4. Plant Journal 26, 395-407.

Jones, D. A. \& Jones, J. D. G. (1996). The roles of leucine rich repeats in plant defences. Advances in Botanical Research incorporating Advances in Plant Patholology 24, 90-167.

Jones, D. A., Thomas, C. M., Hammond-Kosack, K. E., Balint-Kurti, P. J. \& Jones, J. D. G. (1994). Isolation of the tomato Cf-9 gene for resistance to Cladosporium fulvum by transposon tagging. Science 266, 789-793.

Jones, J. D. \& Dangl, J. L. (2006). The plant immune system. Nature 444, 323329.

Jorgensen, J. H. (1996). Effect of three suppressors on the expression of powdery mildew resistance genes in barley. Genome 39, 492-498.

Kachroo, A., Lapchyk, L., Fukushige, H., Hildebrand, D., Klessig, D. \& Kachroo, P. (2003). Plastidial fatty acid signaling modulates salicylic acid- and jasmonic acid-mediated defense pathways in the Arabidopsis ssi2 mutant. Plant Cell 15, 2952-2965.

Kachroo, P., Shanklin, J., Shah, J., Whittle, E. J. \& Klessig, D. F. (2001). A fatty acid desaturase modulates the activation of defense signaling pathways in plants. Proceedings of the National Academy of Sciences of the United States of America 98, 9448-9453. 
Kajava, A. V. (1998). Structural diversity of leucine-rich repeat proteins. Journal Molecular Biology 277, 519-527.

Kaku, H., Nishizawa, Y., Ishii-Minami, N., Akimoto-Tomiyama, C., Dohmae, N., Takio, K., Minami, E. \& Shibuya, N. (2006). Plant cells recognize chitin fragments for defense signaling through a plasma membrane receptor. Proceedings of the National Academy of Sciences of the United States of America 103, 11086-11091.

Kang, J. Y., Choi, H. I., Im, M. Y. \& Kim, S. Y. (2002). Arabidopsis basic leucine zipper proteins that mediate stress-responsive abscisic acid signaling. Plant Cell 14, 343-357.

Kasuga, M., Liu, Q., Miura, S., Yamaguchi-Shinozaki, K. \& Shinozaki, K. (1999). Improving plant drought, salt, and freezing tolerance by gene transfer of a single stress-inducible transcription factor. Nature biotechnology 17, 287-291.

Kennard, J. L. \& Cleary, A. L. (1997). Pre-mitotic nuclear migration in subsidiary mother cells of Tradescantia occurs in G1 of the cell cycle and requires F-actin. Cell motility and the cytoskeleton 36, 55-67.

Khokhlatchev, A. V., Canagarajah, B., Wilsbacher, J., Robinson, M., Atkinson, M., Goldsmith, E. \& Cobb, M. H. (1998). Phosphorylation of the MAP kinase ERK2 promotes its homodimerization and nuclear translocation. Cell 93, 605-615.

Kiessling, K. H. (1986). Biochemical-Mechanism of Action of Mycotoxins. Pure and Applied Chemistry 58, 327-338.

Kim, C. Y., Liu, Y., Thorne, E. T., Yang, H., Fukushige, H., Gassmann, W., Hildebrand, D., Sharp, R. E. \& Zhang, S. (2003). Activation of a stress-responsive mitogen-activated protein kinase cascade induces the biosynthesis of ethylene in plants. Plant Cell 15, 2707-2718.

Kim, M. G., da Cunha, L., McFall, A. J., Belkhadir, Y., DebRoy, S., Dangl, J. L. \& Mackey, D. (2005). Two Pseudomonas syringae type III effectors inhibit RIN4-regulated basal defense in Arabidopsis. Cell 121, 749-759.

Kinkema, M., Fan, W. \& Dong, X. (2000). Nuclear localization of NPR1 is required for activation of PR gene expression. Plant Cell 12, 23392350.

Kitigawa, K., Skowyra, D., Elledge, S. J., Harper, J. W. \& Hieter, P. (1999). SGT1 encodes an essential component of the yeast kinetochore assembly pathway and a novel subunit of the SCF ubiquitin complex. Molecular Cell 4, 21-33.

Klessig, D. F. \& Malamy, J. (1994). The salicylic acid signal in plants. Plant molecular biology 26, 1439-1458.

Kloek, A. P., Verbsky, M. L., Sharma, S. B., Schoelz, J. E., Vogel, J., Klessig, D. F. \& Kunkel, B. N. (2001). Resistance to Pseudomonas syringae conferred by an Arabidopsis thaliana coronatine-insensitive (coi1) mutation occurs through two distinct mechanisms. Plant Journal 26, 509-522.

Knogge, W. (1996). Fungal Infection of Plants. The Plant cell 8, 1711-1722.

Kobayashi, I. \& Hakuno, H. (2003). Actin-related defense mechanism to reject penetration attempt by a non-pathogen is maintained in tobacco BY-2 cells. Planta 217, 340-345. 
Koga, H., Dohi, K. \& Mori, M. (2004). Abscisic acid and low temperatures suppress the whole plant-specific resistance reaction of rice plants to the infection of Magnaporthe grisea. Physiological and Molecular Plant Pathology 65, 3-9.

Koornneef, M., Hanhart, C. J., Hilhorst, H. W. \& Karssen, C. M. (1989). In Vivo Inhibition of Seed Development and Reserve Protein Accumulation in Recombinants of Abscisic Acid Biosynthesis and Responsiveness Mutants in Arabidopsis thaliana. Plant physiology 90, 463-469.

Koornneef, M., Leon-Kloosterziel, K. M., Schwartz, S. H. \& Zeevaart, J. A. D. (1998). The genetic and molecular dissection of abscisic acid biosynthesis and signal transduction in Arabidopsis. Plant Physiology and Biochemistry 36, 83-89.

Koornneef, M., Reuling, G. \& Karssen, C. M. (1984). THE ISOLATION AND CHARACTERIZATION OF ABSCISIC-ACID INSENSITIVE MUTANTS OF ARABIDOPSIS-THALIANA. Physiologia Plantarum 61, 377-383.

Kotchoni, S. 0. \& Gachomo, E. W. (2006). The reactive oxygen species network pathways:an essential prerequisite for perception of pathogen attack and the acquired disease resistance in plants. Journal of biosciences 31, 389-404.

Kovats, K., Binder, A. \& Hohl, H. R. (1991). Cytology of Induced Systemic Resistance of Cucumber to Colletotrichum-Lagenarium. Planta 183, 484-490.

Kovtun, Y., Chiu, W. L., Tena, G. \& Sheen, J. (2000). Functional analysis of oxidative stress-activated mitogen-activated protein kinase cascade in plants. Proceedings of the National Academy of Sciences of the United States of America 97, 2940-2945.

Krishna, P. (2003). Brassinosteroid-Mediated Stress Responses. J Plant Growth Regul 22, 289-297.

Kumar, D. \& Klessig, D. F. (2003). High-affinity salicylic acid-binding protein 2 is required for plant innate immunity and has salicylic acid-stimulated lipase activity. Proceedings of the National Academy of Sciences of the United States of America 100, 16101-16106.

Kunkel, B. N. \& Brooks, D. M. (2002). Cross talk between signaling pathways in pathogen defense. Current Opinion in Plant Biology 5, 325-331.

Kunze, G., Zipfel, C., Robatzek, S., Niehaus, K., Boller, T. \& Felix, G. (2004). The $\mathrm{N}$ terminus of bacterial elongation factor $\mathrm{Tu}$ elicits innate immunity in Arabidopsis plants. Plant Cell 16, 3496-3507.

Kwak, J. M., Mori, I. C., Pei, Z. M., Leonhardt, N., Torres, M. A., Dangl, J. L., Bloom, R. E., Bodde, S., Jones, J. D. \& Schroeder, J. I. (2003). NADPH oxidase AtrbohD and AtrbohF genes function in ROS-dependent ABA signaling in Arabidopsis. The EMBO journal 22, 2623-2633.

Lamb, C. \& Dixon, R. A. (1997). The Oxidative Burst in Plant Disease Resistance. Annual Review in Plant Physiololy and Plant Molecular Biology 48, 251-275.

Lambrecht, M., Okon, Y., Vande Broek, A. \& Vanderleyden, J. (2000). Indole-3-acetic acid: a reciprocal signalling molecule in bacteria-plant interactions. Trends in Microbiology 8, 298-300. 
Lawton, K., Weymann, K., Friedrich, L., Vernooij, B., Uknes, S. \& Ryals, J. (1995). Systemic acquired resistance in Arabidopsis requires salicylic acid but not ethylene. Molecular Plant-Microbe Interaction 8, 863-870.

Lee, S. W., Han, S. W., Bartley, L. E. \& Ronald, P. C. (2006). From the Academy: Colloquium review. Unique characteristics of Xanthomonas oryzae pv. oryzae AvrXa21 and implications for plant innate immunity. Proceedings of the National Academy of Sciences of the United States of America 103, 18395-18400.

Leeman, M., Vanpelt, J. A., Denouden, F. M., Heinsbroek, M., Bakker, P. \& Schippers, B. (1995). Induction of Systemic Resistance by Pseudomonas-Fluorescens in Radish Cultivars Differing in Susceptibility to Fusarium-Wilt, Using a Novel Bioassay. European Journal of Plant Pathology 101, 655-664.

Leon-Kloosterziel, K. M., Gil, M. A., Ruijs, G. J., Jacobsen, S. E., Olszewski, N. E., Schwartz, S. H., Zeevaart, J. A. \& Koornneef, M. (1996). Isolation and characterization of abscisic acid-deficient Arabidopsis mutants at two new loci. Plant Journal 10, 655-661.

Leung, J., Merlot, S. \& Giraudat, J. (1997). The Arabidopsis ABSCISIC ACIDINSENSITIVE2 (ABI2) and ABI1 genes encode homologous protein phosphatases 2C involved in abscisic acid signal transduction. Plant Cell 9, 759-771.

Levine, A., Tenhaken, R., Dixon, R. \& Lamb, C. (1994). H2O2 from the oxidative burst orchestrates the plant hypersensitive disease resistance response. Cell 79, 583-593.

Levitt, J. (1972) Responses of Plants to Environmental Stresses. New York: Academic Press.

Li, H., Xu, H., Zhou, Y., Zhang, J., Long, C., Li, S., Chen, S., Zhou, J. M. \& Shao, F. (2007). The phosphothreonine lyase activity of a bacterial type III effector family. Science 315, 1000-1003.

Li, J., Brader, G. \& Palva, E. T. (2004). The WRKY70 transcription factor: a node of convergence for jasmonate-mediated and salicylate-mediated signals in plant defense. Plant Cell 16, 319-331.

Li, L., Li, C. \& Howe, G. A. (2001). Genetic analysis of wound signaling in tomato. Evidence for a dual role of jasmonic acid in defense and female fertility. Plant physiology 127, 1414-1417.

Li, X., Lin, H., Zhang, W., Zou, Y., Zhang, J., Tang, X. \& Zhou, J. M. (2005). Flagellin induces innate immunity in nonhost interactions that is suppressed by Pseudomonas syringae effectors. Proceedings of the National Academy of Sciences of the United States of America 102, 12990-12995.

Lindeberg, M., Cartinhour, S., Myers, C. R., Schechter, L. M., Schneider, D. J. \& Collmer, A. (2006). Closing the circle on the discovery of genes encoding Hrp regulon members and type III secretion system effectors in the genomes of three model Pseudomonas syringae strains. Molecular Plant-Microbe Interaction 19, 1151-1158.

Lindow, S. E. \& Brandl, M. T. (2003). Microbiology of the phyllosphere. Applied and environmental microbiology 69, 1875-1883. 
Lipka, V., Dittgen, J., Bednarek, P., Bhat, R., Wiermer, M., Stein, M., Landtag, J., Brandt, W., Rosahl, S., Scheel, D., Llorente, F., Molina, A., Parker, J., Somerville, S. \& Schulze-Lefert, P. (2005). Pre- and postinvasion defenses both contribute to nonhost resistance in Arabidopsis. Science 310, 1180-1183.

Lipka, V. \& Panstruga, R. (2005). Dynamic cellular responses in plantmicrobe interactions. Current opinion in plant biology 8, 625-631.

Liu, Q., Kasuga, M., Sakuma, Y., Abe, H., Miura, S., Yamaguchi-Shinozaki, K. \& Shinozaki, K. (1998). Two transcription factors, DREB1 and DREB2, with an EREBP/AP2 DNA binding domain separate two cellular signal transduction pathways in drought- and low-temperature-responsive gene expression, respectively, in Arabidopsis. Plant Cell 10, 1391-1406.

Lorenzo, 0., Chico, J. M., Sanchez-Serrano, J. J. \& Solano, R. (2004). JASMONATE-INSENSITIVE1 encodes a MYC transcription factor essential to discriminate between different jasmonate-regulated defense responses in Arabidopsis. Plant Cell 16, 1938-1950.

Lorenzo, O., Piqueras, R., Sanchez-Serrano, J. J. \& Solano, R. (2003). ETHYLENE RESPONSE FACTOR1 integrates signals from ethylene and jasmonate pathways in plant defense. Plant Cell 15, 165-178.

Mackey, D., Belkhadir, Y., Alonso, J. M., Ecker, J. R. \& Dangl, J. L. (2003). Arabidopsis RIN4 is a target of the type III virulence effector AvrRpt2 and modulates RPS2-mediated resistance. Cell 112, 379-389.

Mackey, D., Holt, B. F., 3rd, Wiig, A. \& Dangl, J. L. (2002). RIN4 interacts with Pseudomonas syringae type III effector molecules and is required for RPM1-mediated resistance in Arabidopsis. Cell 108, 743-754.

Mackey, D. \& McFall, A. J. (2006). MAMPs and MIMPs: proposed classifications for inducers of innate immunity. Molecular microbiology 61, 1365-1371.

Malamy, J., Hennig, J. \& Klessig, D. F. (1992). Temperature-Dependent Induction of Salicylic Acid and Its Conjugates during the Resistance Response to Tobacco Mosaic Virus Infection. Plant Cell 4, 359-366.

Maldonado, A. M., Doerner, P., Dixon, R. A., Lamb, C. J. \& Cameron, R. K. (2002). A putative lipid transfer protein involved in systemic resistance signalling in Arabidopsis. Nature 419, 399-403.

Marois, E., Van den Ackerveken, G. \& Bonas, U. (2002). The xanthomonas type III effector protein AvrBs3 modulates plant gene expression and induces cell hypertrophy in the susceptible host. Molecular PlantMicrobe Interaction 15, 637-646.

Martinez, C., Pons, E., Prats, G., Leon, J. (2004). Salicylic acid regulates flowering time and links defence responses and reproductive development. Plant Journal 37, 209-217.

Mauch-Mani, B. \& Mauch, F. (2005). The role of abscisic acid in plantpathogen interactions. Current opinion in plant biology 8, 409-414.

Mayda, E., Marques, C., Conejero, V. \& Vera, P. (2000a). Expression of a pathogen-induced gene can be mimicked by auxin insensitivity. Molecular Plant-Microbe Interaction 13, 23-31. 
Mayda, E., Mauch-Mani, B. \& Vera, P. (2000b). Arabidopsis dth9 mutation identifies a gene involved in regulating disease susceptibility without affecting salicylic acid-dependent responses. Plant Cell 12, 2119-2128.

McAinsh, M. R., Brownlee, C. \& Hetherington, A. M. (1990). ABSCISIC ACIDINDUCED ELEVATION OF GUARD-CELL CYTOSOLIC CA-2+ PRECEDES STOMATAL CLOSURE. Nature 343, 186-188.

McDowell, J. M. (1998). Intragenic recombination and diversifying selection contribute to the evolution of Downy Mildew resistance at the RPP8 locus of Arabidopsis. Plant Cell 10, 1861-1874.

McDowell, J. M. (2000). Downy mildew (Peronospora parasitica) resistance genes in Arabidopsis vary in functional requirements for NDR1, EDS1, NPR1, and Salicylic Acid accumulation. Plant Journal 22, 523-530.

McDowell, J. M., Cuzick, A., Can, C., Beynon, J., Dangl, J. L. \& Holub, E. B. (2000). Downy mildew (Peronospora parasitica) resistance genes in Arabidopsis vary in functional requirements for NDR1, EDS1, NPR1 and salicylic acid accumulation. Plant Journal 22, 523-529.

McDowell, J. M., Dhandaydham, M., Long, T. A., Aarts, M. G., Goff, S., Holub, E. B. \& Dangl, J. L. (1998). Intragenic recombination and diversifying selection contribute to the evolution of downy mildew resistance at the RPP8 locus of Arabidopsis. Plant Cell 10, 1861-1874.

McGrath, K. C., Dombrecht, B., Manners, J. M., Schenk, P. M., Edgar, C. I., Maclean, D. J., Scheible, W. R., Udvardi, M. K. \& Kazan, K. (2005). Repressor- and activator-type ethylene response factors functioning in jasmonate signaling and disease resistance identified via a genomewide screen of Arabidopsis transcription factor gene expression. Plant physiology 139, 949-959.

Medzhitov, R. (1998). MyD88 is an adaptor protein in the hToll/IL-1 receptor family signaling pathways. Molecular Cell 2, 253-258.

Melotto, M., Underwood, W., Koczan, J., Nomura, K. \& He, S. Y. (2006). Plant stomata function in innate immunity against bacterial invasion. Cell 126, 969-980.

Mellersh, D. G., Foulds, I. V., Higgins, V. J. \& Heath, M. C. (2002). H2O2 plays different roles in determining penetration failure in three diverse plant-fungal interactions. Plant Journal 29, 257-268.

Mengiste, T., Chen, X., Salmeron, J. \& Dietrich, R. (2003). The BOTRYTIS SUSCEPTIBLE1 gene encodes an R2R3MYB transcription factor protein that is required for biotic and abiotic stress responses in Arabidopsis. Plant Cell 15, 2551-2565.

Merlot, S., Gosti, F., Guerrier, D., Vavasseur, A. \& Giraudat, J. (2001). The ABI1 and ABI2 protein phosphatases 2C act in a negative feedback regulatory loop of the abscisic acid signalling pathway. Plant Journal 25, 295-303.

Meszaros, T., Helfer, A., Hatzimasoura, E., Magyar, Z., Serazetdinova, L., Rios, G., Bardoczy, V., Teige, M., Koncz, C., Peck, S. \& Bogre, L. (2006). The Arabidopsis MAP kinase kinase MKK1 participates in defence responses to the bacterial elicitor flagellin. Plant Journal 48, 485-498. 
Meyers, B. C. (1998). The major resistance gene cluster in lettuce is highly duplicated and spans several megabases. Plant Cell 10, 1817-1832.

Michelmore, R. W. \& Meyers, B. C. (1998). Clusters of resistance genes in plants evolve by divergent selection and a birth-and-death process. Genome Research 8, 1113-1130.

Mishra, G., Zhang, W., Deng, F., Zhao, J. \& Wang, X. (2006a). A bifurcating pathway directs abscisic acid effects on stomatal closure and opening in Arabidopsis. Science 312, 264-266.

Mishra, N. S., Tuteja, R. \& Tuteja, N. (2006b). Signaling through MAP kinase networks in plants. Archives of Biochemistry and Biophysics 452, 55-68.

Mittler, R. (2002). Oxidative stress, antioxidants and stress tolerance. Trends in plant science $\mathbf{7}, 405-410$.

Mittler, R., Vanderauwera, S., Gollery, M. \& Van Breusegem, F. (2004). Reactive oxygen gene network of plants. Trends in plant science $\mathbf{9}, 490$ 498.

Mohr, P. G. \& Cahill, D. M. (2003). Abscisic acid influences the susceptibility of Arabidopsis thaliana to Pseudomonas syringae pv. tomato and Peronospora parasitica. Functional Plant Biology 30, 461-469.

Mohr, P. G. \& Cahill, D. M. (2007). Suppression by ABA of salicylic acid and lignin accumulation and the expression of multiple genes, in Arabidopsis infected with Pseudomonas syringae pv. tomato. Functional \& integrative genomics 7, 181-191.

Mongrand, S., Morel, J., Laroche, J., Claverol, S., Carde, J. P., Hartmann, M. A., Bonneu, M., Simon-Plas, F., Lessire, R. \& Bessoule, J. J. (2004). Lipid rafts in higher plant cells: purification and characterization of Triton X-100-insoluble microdomains from tobacco plasma membrane. The Journal of biological chemistry 279, 36277-36286.

Moon, H., Lee, B., Choi, G., Shin, D., Prasad, D. T., Lee, O., Kwak, S. S., Kim, D. H., Nam, J., Bahk, J., Hong, J. C., Lee, S. Y., Cho, M. J., Lim, C. O. \& Yun, D. J. (2003). NDP kinase 2 interacts with two oxidative stressactivated MAPKs to regulate cellular redox state and enhances multiple stress tolerance in transgenic plants. Proceedings of the National Academy of Sciences of the United States of America 100, 358-363.

Mou, Z., Fan, W. \& Dong, X. (2003). Inducers of plant systemic acquired resistance regulate NPR1 function through redox changes. Cell 113, 935-944.

Munemasa, S., Oda, K., Watanabe-Sugimoto, M., Nakamura, Y., Shimoishi, Y. \& Murata, Y. (2007). The coronatine-insensitive 1 mutation reveals the hormonal signaling interaction between abscisic acid and methyl jasmonate in Arabidopsis guard cells. Specific impairment of ion channel activation and second messenger production. Plant physiology 143, 1398-1407.

Murphy, A. M., PryceJones, E., Johnstone, K. \& Ashby, A. M. (1997). Comparison of cytokinin production in vitro by Pyrenopeziza brassicae with other plant pathogens. Physiological and Molecular Plant Pathology 50, 53-65.

Nakagami, H., Pitzschke, A. \& Hirt, H. (2005). Emerging MAP kinase pathways in plant stress signalling. Trends in plant science 10, 339-346. 
Nakashita, H., Yasuda, M., Nitta, T., Asami, T., Fujioka, S., Arai, Y., Sekimata, K., Takatsuto, S., Yamaguchi, I. \& Yoshida, S. (2003). Brassinosteroid functions in a broad range of disease resistance in tobacco and rice. Plant Journal 33, 887-898.

Nandi, A., Kachroo, P., Fukushige, H., Hildebrand, D. F., Klessig, D. F. \& Shah, J. (2003). Ethylene and jasmonic acid signaling affect the NPR1independent expression of defense genes without impacting resistance to Pseudomonas syringae and Peronospora parasitica in the Arabidopsis ssi1 mutant. Molecular Plant Microbe Interaction 16, 588599.

Nandi, A., Welti, R. \& Shah, J. (2004). The Arabidopsis thaliana dihydroxyacetone phosphate reductase gene SUPPRESSSOR OF FATTY ACID DESATURASE DEFICIENCY1 is required for glycerolipid metabolism and for the activation of systemic acquired resistance. Plant Cell 16, 465-477.

Navarro, L., Dunoyer, P., Jay, F., Arnold, B., Dharmasiri, N., Estelle, M., Voinnet, O. \& Jones, J. D. (2006). A plant miRNA contributes to antibacterial resistance by repressing auxin signaling. Science 312, 436-439.

Navarro, L., Zipfel, C., Rowland, O., Keller, I., Robatzek, S., Boller, T. \& Jones, J. D. (2004). The transcriptional innate immune response to flg22. Interplay and overlap with Avr gene-dependent defense responses and bacterial pathogenesis. Plant physiology 135, 11131128.

Nawrath, C. \& Metraux, J. P. (1999). Salicylic acid induction-deficient mutants of Arabidopsis express PR-2 and PR-5 and accumulate high levels of camalexin after pathogen inoculation. Plant Cell 11, 1393-1404.

Neill, S., Desikan, R. \& Hancock, J. (2002). Hydrogen peroxide signalling. Current opinion in plant biology 5, 388-395.

Nemhauser, J. L., Hong, F. \& Chory, J. (2006). Different plant hormones regulate similar processes through largely nonoverlapping transcriptional responses. Cell 126, 467-475.

Niki, T., Mitsuhara, I., Seo, S., Ohtsubo, N. \& Ohashi, Y. (1998). Antagonistic effect of salicylic acid and jasmonic acid on the expression of pathogenesis-related (PR) protein genes in wounded mature tobacco leaves. Plant and Cell Physiology 39, 500-507.

Nimchuk, Z., Eulgem, T., Holt, B. F., 3rd \& Dangl, J. L. (2003). Recognition and response in the plant immune system. Annual Review in Genetics 37, 579-609.

Nimchuk, Z. L., Fisher, E. J., Desveaux, D., Chang, J. H. \& Dangl, J. L. (2007). The HopX (AvrPphE) family of Pseudomonas syringae type III effectors require a catalytic triad and a novel $\mathrm{N}$-terminal domain for function. Molecular Plant-Microbe Interaction 20, 346-357.

Nishimura, M. T., Stein, M., Hou, B. H., Vogel, J. P., Edwards, H. \& Somerville, S. C. (2003). Loss of a callose synthase results in salicylic aciddependent disease resistance. Science 301, 969-972.

Nissan, G., Manulis-Sasson, S., Weinthal, D., Mor, H., Sessa, G. \& Barash, I. (2006). The type III effectors HsvG and HsvB of gall-forming Pantoea 
agglomerans determine host specificity and function as transcriptional activators. Molecular microbiology 61, 1118-1131.

Nomura, K., Debroy, S., Lee, Y. H., Pumplin, N., Jones, J. \& He, S. Y. (2006). A bacterial virulence protein suppresses host innate immunity to cause plant disease. Science 313, 220-223.

Norman-Setterblad, C., Vidal, S. \& Palva, E. T. (2000). Interacting signal pathways control defense gene expression in Arabidopsis in response to cell wall-degrading enzymes from Erwinia carotovora. Molecular Plant-Microbe Interaction 13, 430-438.

Nuhse, T. S., Peck, S. C., Hirt, H. \& Boller, T. (2000). Microbial elicitors induce activation and dual phosphorylation of the Arabidopsis thaliana MAPK 6. The Journal of biological chemistry 275, 7521-7526.

Nurnberger, T., Brunner, F., Kemmerling, B. \& Piater, L. (2004). Innate immunity in plants and animals: striking similarities and obvious differences. Immunology Review 198, 249-266.

O'Donnell, P. J., Jones, J. B., Antoine, F. R., Ciardi, J. \& Klee, H. J. (2001). Ethylene-dependent salicylic acid regulates an expanded cell death response to a plant pathogen. Plant Journal 25, 315-323.

O'Donnell, P. J., Schmelz, E. A., Moussatche, P., Lund, S. T., Jones, J. B. \& Klee, H. J. (2003). Susceptible to intolerance--a range of hormonal actions in a susceptible Arabidopsis pathogen response. Plant Journal 33, 245-257.

Ochsenbein, C., Przybyla, D., Danon, A., Landgraf, F., Gobel, C., Imboden, A., Feussner, I. \& Apel, K. (2006). The role of EDS1 (enhanced disease susceptibility) during singlet oxygen-mediated stress responses of Arabidopsis. Plant Journal 47, 445-456.

Orozco-Cardenas, M. L. \& Ryan, C. A. (2002). Nitric oxide negatively modulates wound signaling in tomato plants. Plant Physiology 130, 487-493.

Pei, Z. M., Murata, Y., Benning, G., Thomine, S., Klusener, B., Allen, G. J., Grill, E. \& Schroeder, J. I. (2000). Calcium channels activated by hydrogen peroxide mediate abscisic acid signalling in guard cells. Nature 406, 731-734.

Penacortes, H., Albrecht, T., Prat, S., Weiler, E. W. \& Willmitzer, L. (1993). Aspirin Prevents Wound-Induced Gene-Expression in Tomato Leaves by Blocking Jasmonic Acid Biosynthesis. Planta 191, 123-128.

Penninckx, I. A., Eggermont, K., Terras, F. R., Thomma, B. P., De Samblanx, G. W., Buchala, A., Metraux, J. P., Manners, J. M. \& Broekaert, W. F. (1996). Pathogen-induced systemic activation of a plant defensin gene in Arabidopsis follows a salicylic acid-independent pathway. Plant Cell 8, 2309-2323.

Penninckx, I. A., Thomma, B. P., Buchala, A., Metraux, J. P. \& Broekaert, W. F. (1998). Concomitant activation of jasmonate and ethylene response pathways is required for induction of a plant defensin gene in Arabidopsis. Plant Cell 10, 2103-2113.

Peterhansel, C., Freialdenhoven, A., Kurth, J., Kolsch, R. \& Schulze-Lefert, P. (1997). Interaction Analyses of Genes Required for Resistance 
Responses to Powdery Mildew in Barley Reveal Distinct Pathways Leading to Leaf Cell Death. Plant Cell 9, 1397-1409.

Petersen, M., Brodersen, P., Naested, H., Andreasson, E., Lindhart, U., Johansen, B., Nielsen, H. B., Lacy, M., Austin, M. J., Parker, J. E., Sharma, S. B., Klessig, D. F., Martienssen, R., Mattsson, O., Jensen, A. B. \& Mundy, J. (2000). Arabidopsis MAP kinase 4 negatively regulates systemic acquired resistance. Cell 103, 1111-1120.

Piedras, P., Hammond-Kosack, K. E., Harrison, K. \& Jones, J. D. G. (1998). Rapid, Cf-9 and Avr9 dependent, production of active oxygen species in tobacco suspension cultures. Molecular Plant-Microbe Interaction 11, 1155-1166.

Pieterse, C. M. \& van Loon, L. C. (1999). Salicylic acid-independent plant defence pathways. Trends in plant science 4, 52-58.

Pieterse, C. M. \& Van Loon, L. C. (2004). NPR1: the spider in the web of induced resistance signaling pathways. Current Opinion in Plant Biology 7, 456-464.

Pieterse, C. M., van Wees, S. C., Hoffland, E., van Pelt, J. A. \& van Loon, L. C. (1996). Systemic resistance in Arabidopsis induced by biocontrol bacteria is independent of salicylic acid accumulation and pathogenesis-related gene expression. Plant Cell 8, 1225-1237.

Pieterse, C. M., van Wees, S. C., van Pelt, J. A., Knoester, M., Laan, R., Gerrits, H., Weisbeek, P. J. \& van Loon, L. C. (1998). A novel signaling pathway controlling induced systemic resistance in Arabidopsis. Plant Cell 10, 1571-1580.

Pieterse, C. M. J., van Wees, S. C. M., Ton, J., Leon-Kloosterziel, K. M., van Pelt, J. A., Keurentjes, J. J. B., Knoester, M. \& van Loon, L. C. (2000). Rhizobacteria-mediated induced systemic resistance (ISR) in Arabidopsis: Involvement of jasmonate and ethylene. In Biology of Plant-Microbe Interactions 2, 291-296.

Pieterse, C. M. J., Van Wees, S. C. M., Ton, J., Van Pelt, J. A. \& Van Loon, L. C. (2002). Signalling in rhizobacteria-induced systemic resistance in Arabidopsis thaliana. Plant Biology 4, 535-544.

Prats, E., Mur, L. A. J., Sanderson, R. \& Carver, T. L. W. (2005). Nitric oxide contributes both to papilla-based resistance and the hypersensitive response in barley attacked by Blumeria graminis f. sp hordei. Molecular Plant Pathology 6, 65-78.

Rao, M. V. \& Davis, K. R. (1999). Ozone-induced cell death occurs via two distinct mechanisms in Arabidopsis: the role of salicylic acid. Plant Journal 17, 603-614.

Raskin, I. (1992). Salicylate, A New Plant Hormone. Plant physiology 99, 799803.

Remans, R., Spaepen, S. \& Vanderleyden, J. (2006). Auxin signaling in plant defense. Science 313, 171.

Reuber, T. L. (1998). Correlation of defense gene induction defects with powdery mildew susceptibility in Arabidopsis enhanced disease susceptibility mutants. Plant Journal 16, 473-485.

Reuber, T. L., Plotnikova, J. M., Dewdney, J., Rogers, E. E., Wood, W. \& Ausubel, F. M. (1998). Correlation of defense gene induction defects 
with powdery mildew susceptibility in Arabidopsis enhanced disease susceptibility mutants. Plant Journal 16, 473-485.

Reymond, P. \& Farmer, E. E. (1998). Jasmonate and salicylate as global signals for defense gene expression. Current Opinion in Plant Biology 1, 404-411.

Robatzek, S., Chinchilla, D. \& Boller, T. (2006). Ligand-induced endocytosis of the pattern recognition receptor FLS2 in Arabidopsis. Genes and Development 20, 537-542.

Robert-Seilaniantz, A., Navarro, L., Bari, R. \& Jones, J. D. G. (2007). Pathological hormone imbalances. Current Opinion in Plant Biology 10, 372-379.

Robinette, D. \& Matthysse, A. G. (1990). Inhibition by Agrobacterium tumefaciens and Pseudomonas savastanoi of development of the hypersensitive response elicited by Pseudomonas syringae pv. phaseolicola. Journal of bacteriology 172, 5742-5749.

Roden, J., Eardley, L., Hotson, A., Cao, Y. \& Mudgett, M. B. (2004). Characterization of the Xanthomonas AvrXv4 effector, a SUMO protease translocated into plant cells. Molecular Plant-Microbe Interaction 17, 633-643.

Ross, A. F. (1961). Systemic acquired resistance induced by localized virus infections in plants. Virology 14, 340-358.

Ryals, J., Uknes, S. \& Ward, E. (1994). Systemic Acquired Resistance. Plant physiology 104, 1109-1112.

Ryals, J., Weymann, K., Lawton, K., Friedrich, L., Ellis, D., Steiner, H. Y., Johnson, J., Delaney, T. P., Jesse, T., Vos, P. \& Uknes, S. (1997). The Arabidopsis NIM1 protein shows homology to the mammalian transcription factor inhibitor I kappa B. Plant Cell 9, 425-439.

Ryals, J. A., Neuenschwander, U. H., Willits, M. G., Molina, A., Steiner, H. Y. \& Hunt, M. D. (1996). Systemic Acquired Resistance. Plant Cell 8, 18091819.

Sakuma, Y., Maruyama, K., Osakabe, Y., Qin, F., Seki, M., Shinozaki, K. \& Yamaguchi-Shinozaki, K. (2006). Functional analysis of an Arabidopsis transcription factor, DREB2A, involved in droughtresponsive gene expression. Plant Cell 18, 1292-1309.

Salmeron, J. M. (1996). Tomato Prf is a member of the leucine-rich repeat class of plant disease resistance genes and lies embedded within the Pto kinase gene cluster. Cell 86, 123-133.

Sambrook, J. \& Russell, D. W. (2001). Molecular cloning. A laboratory manual. New York: Cold Spring Harbor Laboratory Press.

Sanders, D., Brownlee, C. \& Harper, J. F. (1999). Communicating with calcium. Plant Cell 11, 691-706.

Sardar, H. S., Yang, J. \& Showalter, A. M. (2006). Molecular interactions of arabinogalactan proteins with cortical microtubules and F-actin in Bright Yellow-2 tobacco cultured cells. Plant physiology 142, 14691479.

Scandalios, J. G. (1997). Oxidative stress and defense mechanisms in plants: introduction. Free radical biology \& medicine 23, 471-472. 
Schaffrath, U., Freydl, E. \& Dudler, R. (1997). Evidence for Different Signaling Pathways Activated by Inducers of Acquired Resistance in Wheat. Molecular Plant-Microbe Interaction 10, 779-783.

Scheel, D. (1998). Resistance response physiology and signal transduction. Current Opinion in Plant Biology 1, 305-310.

Schenk, P. M., Kazan, K., Wilson, I., Anderson, J. P., Richmond, T., Somerville, S. C. \& Manners, J. M. (2000). Coordinated plant defense responses in Arabidopsis revealed by microarray analysis. Proceedings of the National Academy of Sciences of the United States of America 97, $11655-11660$.

Schmelz, E. A., Engelberth, J., Alborn, H. T., O'Donnell, P., Sammons, M., Toshima, H. \& Tumlinson, J. H., 3rd (2003). Simultaneous analysis of phytohormones, phytotoxins, and volatile organic compounds in plants. Proceedings of the National Academy of Sciences of the United States of America 100, 10552-10557.

Schmelzer, E. (2002). Cell polarization, a crucial process in fungal defence. Trends in plant science 7, 411-415.

Schornack, S., Meyer, A., Romer, P., Jordan, T. \& Lahaye, T. (2006). Genefor-gene-mediated recognition of nuclear-targeted AvrBs3-like bacterial effector proteins. Journal of plant physiology 163, 256-272.

Schroeder, J. I., Allen, G. J., Hugouvieux, V., Kwak, J. M. \& Waner, D. (2001a). Guard Cell Signal Transduction. Annual Review in Plant Physiology and Plant Molecular Biology 52, 627-658.

Schroeder, J. I., Kwak, J. M. \& Allen, G. J. (2001b). Guard cell abscisic acid signalling and engineering drought hardiness in plants. Nature 410, 327-330.

Schweizer, P., Buchala, A. \& Metraux, J. P. (1997). Gene-Expression Patterns and Levels of Jasmonic Acid in Rice Treated with the Resistance Inducer 2,6-Dichloroisonicotinic Acid. Plant Physiology 115, 61-70.

Shah, J., Kachroo, P. \& Klessig, D. F. (1999). The Arabidopsis ssi1 mutation restores pathogenesis-related gene expression in npr1 plants and renders defensin gene expression salicylic acid dependent. Plant Cell 11, 191-206.

Shah, J., Kachroo, P., Nandi, A. \& Klessig, D. F. (2001). A recessive mutation in the Arabidopsis SSI2 gene confers SA- and NPR1-independent expression of PR genes and resistance against bacterial and oomycete pathogens. Plant Journal 25, 563-574.

Shah, J., Tsui, F. \& Klessig, D. F. (1997). Characterization of a salicylic acidinsensitive mutant (sai1) of Arabidopsis thaliana, identified in a selective screen utilizing the SA-inducible expression of the tms 2 gene. Molecular Plant-Microbe Interaction 10, 69-78.

Shao, F., Golstein, C., Ade, J., Stoutemyer, M., Dixon, J. E. \& Innes, R. W. (2003). Cleavage of Arabidopsis PBS1 by a bacterial type III effector. Science 301, 1230-1233.

Sharma, P. C., Ito, A., Shimizu, T., Terauchi, R., Kamoun, S. \& Saitoh, H. (2003). Virus-induced silencing of WIPK and SIPK genes reduces resistance to a bacterial pathogen, but has no effect on the INF1- 
induced hypersensitive response (HR) in Nicotiana benthamiana. Molecular Genetics Genomics 269, 583-591.

Shen, Q. H., Saijo, Y., Mauch, S., Biskup, C., Bieri, S., Keller, B., Seki, H., Ulker, B., Somssich, I. E. \& Schulze-Lefert, P. (2007). Nuclear activity of MLA immune receptors links isolate-specific and basal diseaseresistance responses. Science 315, 1098-1103.

Shinozaki, K., Yamaguchi-Shinozaki, K. \& Seki, M. (2003). Regulatory network of gene expression in the drought and cold stress responses. Current Opinion in Plant Biology 6, 410-417.

Shirasu, K., Lahaye, T., Tan, M. W., Zhou, F., Azevedo, C. \& Schulze-Lefert, P. (1999). A novel class of eukaryotic zinc-binding proteins is required for disease resistance signaling in barley and development in C. elegans. Cell 99, 355-366.

Shiu, S. H. \& Bleecker, A. B. (2001). Receptor-like kinases from Arabidopsis form a monophyletic gene family related to animal receptor kinases. Proceedings of the National Academy of Sciences of the United States of America 98, 10763-10768.

Silverman, P., Seskar, M., Kanter, D., Schweizer, P., Metraux, J. P. \& Raskin, I. (1995). Salicylic-Acid in Rice - Biosynthesis, Conjugation, and Possible Role. Plant physiology 108, 633-639.

Skipp, R. A. \& Deverall, B. J. (1973). Studies on Cross-Protection in Anthracnose Disease of Bean. Physiological Plant Pathology 3, 299-\&.

Song, W. Y. (1995). A receptor kinase-like protein encoded by the rice disease resistance gene, Xa21. Science 270, 1804-1806.

Spoel, S. H., Koornneef, A., Claessens, S. M., Korzelius, J. P., Van Pelt, J. A., Mueller, M. J., Buchala, A. J., Metraux, J. P., Brown, R., Kazan, K., Van Loon, L. C., Dong, X. \& Pieterse, C. M. (2003). NPR1 modulates crosstalk between salicylate- and jasmonate-dependent defense pathways through a novel function in the cytosol. Plant Cell 15, 760-770.

Staswick, P. E., Su, W. \& Howell, S. H. (1992). Methyl jasmonate inhibition of root growth and induction of a leaf protein are decreased in an Arabidopsis thaliana mutant. Proceedings of the National Academy of Sciences of the United States of America 89, 6837-6840.

Staswick, P. E. \& Tiryaki, I. (2004). The oxylipin signal jasmonic acid is activated by an enzyme that conjugates it to isoleucine in Arabidopsis. Plant Cell 16, 2117-2127.

Stavrinides, J., Ma, W. \& Guttman, D. S. (2006). Terminal reassortment drives the quantum evolution of type III effectors in bacterial pathogens. PLoS pathogens 2, e104.

Stein, M., Dittgen, J., Sanchez-Rodriguez, C., Hou, B. H., Molina, A., SchulzeLefert, P., Lipka, V. \& Somerville, S. (2006). Arabidopsis PEN3/PDR8, an ATP binding cassette transporter, contributes to nonhost resistance to inappropriate pathogens that enter by direct penetration. Plant Cell 18, 731-746.

Sticher, L., Mauch-Mani, B. \& Metraux, J. P. (1997). Systemic acquired resistance. Annual Review in Phytopathology35, 235-270.

Suarez-Rodriguez, M. C., Adams-Phillips, L., Liu, Y., Wang, H., Su, S. H., Jester, P. J., Zhang, S., Bent, A. F. \& Krysan, P. J. (2007). MEKK1 is 
required for flg22-induced MPK4 activation in Arabidopsis plants. Plant physiology 143, 661-669.

Suhita, D., Kolla, V. A., Vavasseur, A. \& Raghavendra, A. S. (2003). Different signaling pathways involved during the suppression of stomatal opening by methyl jasmonate or abscisic acid. Plant Science 164, 481488.

Suhita, D., Raghavendra, A. S., Kwak, J. M. \& Vavasseur, A. (2004). Cytoplasmic alkalization precedes reactive oxygen species production during methyl jasmonate- and abscisic acid-induced stomatal closure. Plant physiology 134, 1536-1545.

Takemoto, D. \& Hardham, A. R. (2004). The cytoskeleton as a regulator and target of biotic interactions in plants. Plant physiology 136, 3864-3876.

Takemoto, D., Jones, D. A. \& Hardham, A. R. (2003). GFP-tagging of cell components reveals the dynamics of subcellular re-organization in response to infection of Arabidopsis by oomycete pathogens. Plant Journal 33, 775-792.

Talarczyk, A. \& Hennig, J. (2001). Early defence responses in plants infected with pathogenic organisms. Cellular \& molecular biology letters 6, 955970.

Tang, X. (1996). Physical interaction of avrPto and the Pto kinase defines a recognition event involved in plant disease resistance. Science 274, 2060-2063.

Thilmony, R., Underwood, W. \& He, S. Y. (2006). Genome-wide transcriptional analysis of the Arabidopsis thaliana interaction with the plant pathogen Pseudomonas syringae pv. tomato DC3000 and the human pathogen Escherichia coli 0157:H7. Plant Journal 46, 34-53.

Thines, B., Katsir, L., Melotto, M., Niu, Y., Mandaokar, A., Liu, G., Nomura, K., He, S. Y., Howe, G. A. \& Browse, J. (2007). JAZ repressor proteins are targets of the SCF(COI1) complex during jasmonate signalling. Nature 448, 661-665.

Thomma, B., Penninckx, I., Broekaert, W. F. \& Cammue, B. P. A. (2001a). The complexity of disease signaling in Arabidopsis. Current Opinion in Immunology 13, 63-68.

Thomma, B. P., Eggermont, K., Penninckx, I. A., Mauch-Mani, B., Vogelsang, R., Cammue, B. P. \& Broekaert, W. F. (1998). Separate jasmonatedependent and salicylate-dependent defense-response pathways in arabidopsis are essential for resistance to distinct microbial pathogens. Proceedings of the National Academy of Sciences of the United States of America 95, 15107-15111.

Thomma, B. P., Eggermont, K., Tierens, K. F. \& Broekaert, W. F. (1999). Requirement of functional ethylene-insensitive 2 gene for efficient resistance of Arabidopsis to infection by Botrytis cinerea. Plant physiology 121, 1093-1102.

Thomma, B. P., Penninckx, I. A., Broekaert, W. F. \& Cammue, B. P. (2001b). The complexity of disease signaling in Arabidopsis. Current opinion in immunology 13, 63-68.

ThordalChristensen, H., Zhang, Z. G., Wei, Y. D. \& Collinge, D. B. (1997). Subcellular localization of $\mathrm{H} 2 \mathrm{O} 2$ in plants. H2O2 accumulation in 
papillae and hypersensitive response during the barley-powdery mildew interaction. Plant Journal 11, 1187-1194.

Ton, J., Davison, S., Van Wees, S. C., Van Loon, L. \& Pieterse, C. M. (2001). The arabidopsis ISR1 locus controlling rhizobacteria-mediated induced systemic resistance is involved in ethylene signaling. Plant physiology 125, 652-661.

Ton, J., De Vos, M., Robben, C., Buchala, A., Metraux, J. P., Van Loon, L. C. \& Pieterse, C. M. (2002). Characterization of Arabidopsis enhanced disease susceptibility mutants that are affected in systemically induced resistance. Plant Journal 29, 11-21.

Ton, J., Jakab, G., Toquin, V., Flors, V., Iavicoli, A., Maeder, M. N., Metraux, J. P. \& Mauch-Mani, B. (2005). Dissecting the beta-aminobutyric acidinduced priming phenomenon in Arabidopsis. Plant Cell 17, 987-999.

Ton, J. \& Mauch-Mani, B. (2004). Beta-amino-butyric acid-induced resistance against necrotrophic pathogens is based on ABA-dependent priming for callose. Plant Journal 38, 119-130.

Ton, J., Pieterse, C. M. \& Van Loon, L. C. (1999). Identification of a locus in arabidopsis controlling both the expression of rhizobacteria-mediated induced systemic resistance (ISR) and basal resistance against Pseudomonas syringae pv. tomato. Molecular Plant-Microbe Interaction 12, 911-918.

Tornero, P. \& Dangl, J. L. (2001). A high-throughput method for quantifying growth of phytopathogenic bacteria in Arabidopsis thaliana. Plant Journal 28, 475-481.

Torp, J. \& Jorgensen, J. H. (1986). Modification of Barley Powdery Mildew Resistance Gene Ml-A12 by Induced Mutation. Canadian Journal of Genetics and Cytology 28, 725-731.

Uno, Y., Furihata, T., Abe, H., Yoshida, R., Shinozaki, K. \& YamaguchiShinozaki, K. (2000). Arabidopsis basic leucine zipper transcription factors involved in an abscisic acid-dependent signal transduction pathway under drought and high-salinity conditions. Proceedings of the National Academy of Sciences of the United States of America 97, 1163211637.

Uppalapati, S. R., Ayoubi, P., Weng, H., Palmer, D. A., Mitchell, R. E., Jones, W. \& Bender, C. L. (2005). The phytotoxin coronatine and methyl jasmonate impact multiple phytohormone pathways in tomato. Plant Journal 42, 201-217.

Valinsky, L., Manulis, S., Nizan, R., Ezra, D. \& Barash, I. (1998). A pathogenicity gene isolated from the pPATH plasmid of Erwinia herbicola pv. gypsophilae determines host specificity. Molecular Plant Microbe Interaction 11, 753-762.

van der Biezen, E. A. \& Jones, J. D. G. (1998). Plant disease resistance proteins and the gene-for-gene concept. Trends in Biochemical Science 23, 454456.

van Loon, L. C., Bakker, P. A. \& Pieterse, C. M. (1998). Systemic resistance induced by rhizosphere bacteria. Annual review of phytopathology 36, 453-483. 
van Loon, L. C., Geraats, B. P. \& Linthorst, H. J. (2006). Ethylene as a modulator of disease resistance in plants. Trends in plant science 11, 184-191.

van Wees, S. C., Luijendijk, M., Smoorenburg, I., van Loon, L. C. \& Pieterse, C. M. (1999). Rhizobacteria-mediated induced systemic resistance (ISR) in Arabidopsis is not associated with a direct effect on expression of known defense-related genes but stimulates the expression of the jasmonate-inducible gene Atvsp upon challenge. Plant Molecular Biology 41, 537-549.

Van Wees, S. C., Pieterse, C. M., Trijssenaar, A., Van 't Westende, Y. A., Hartog, F. \& Van Loon, L. C. (1997). Differential induction of systemic resistance in Arabidopsis by biocontrol bacteria. Molecular PlantMicrobe Interaction 10, 716-724.

Vanacker, H., Lu, H., Rate, D. N. \& Greenberg, J. (2001). A role for salicylic acid and NPR1 in regulating cell growth in Arabidopis. Plant Journal 28, 209-216.

Vanpeer, R., Niemann, G. J. \& Schippers, B. (1991). Induced Resistance and Phytoalexin Accumulation in Biological-Control of Fusarium-Wilt of Carnation by Pseudomonas Sp Strain Wcs417r. Phytopathology 81, 728-734.

Veronese, P., Chen, X., Bluhm, B., Salmeron, J., Dietrich, R. \& Mengiste, T. (2004). The BOS loci of Arabidopsis are required for resistance to Botrytis cinerea infection. Plant Journal 40, 558-574.

Veronese, P., Nakagami, H., Bluhm, B., Abuqamar, S., Chen, X., Salmeron, J., Dietrich, R. A., Hirt, H. \& Mengiste, T. (2006). The membraneanchored BOTRYTIS-INDUCED KINASE1 plays distinct roles in Arabidopsis resistance to necrotrophic and biotrophic pathogens. Plant Cell 18, 257-273.

Verslues, P.E., Agarwal, M., Katiyar-Agarwal, S., Zhu, J. and Zhu, J.K. (2006). Methods and concepts in quantifying resistance to drought, salt and freezing, abiotic stresses that affect plant water status. Plant Journal, 45, 523-539.

Vidal, S., deLeon, I. P., Denecke, J. \& Palva, E. T. (1997). Salicylic acid and the plant pathogen Erwinia carotovora induce defense genes via antagonistic pathways. Plant Journal 11, 115-123.

Vidal, S., Eriksson, A. R. B., Montesano, M., Denecke, J. \& Palva, E. T. (1998). Cell Wall-Degrading Enzymes from Erwinia carotovora Cooperate in the Salicylic Acid-Independent Induction of a Plant Defense Response. Molecular Plant-Microbe Interaction 11, 23-32.

Walters, D. R. \& McRoberts, N. (2006). Plants and biotrophs: a pivotal role for cytokinins? Trends in plant science 11, 581-586.

Warren, R. F., Merritt, P. M., Holub, E. \& Innes, R. W. (1999). Identification of three putative signal transduction genes involved in $\mathrm{R}$ gene-specified disease resistance in Arabidopsis. Genetics 152, 401-412.

Weigel, D. (1995). The APETALA2 domain is related to a novel type of DNA binding domain. Plant Cell 7, 388-389. 
Wick, P., Gansel, X., Oulevey, C., Page, V., Studer, I., Durst, M. \& Sticher, L. (2003). The expression of the t-SNARE AtSNAP33 is induced by pathogens and mechanical stimulation. Plant physiology 132, 343-351.

Wiermer, M., Feys, B. J. \& Parker, J. E. (2005). Plant immunity: the EDS1 regulatory node. Current Opinion in Plant Biology 8, 383-389.

Wright, C. A. \& Beattie, G. A. (2004). Pseudomonas syringae pv. tomato cells encounter inhibitory levels of water stress during the hypersensitive response of Arabidopsis thaliana. Proceedings of the National Academy of Sciences of the United States of America 101, 3269-3274.

Xiao, S. (2001). Broad-spectrum mildew resistance in Arabidopsis thaliana mediated by RPW8. Science 291, 118-120.

Xie, D. X., Feys, B. F., James, S., Nieto-Rostro, M. \& Turner, J. G. (1998). COI1: an Arabidopsis gene required for jasmonate-regulated defense and fertility. Science 280, 1091-1094.

Xiong, L., Gong, Z., Rock, C. D., Subramanian, S., Guo, Y., Xu, W., Galbraith, D. \& Zhu, J. K. (2001). Modulation of abscisic acid signal transduction and biosynthesis by an Sm-like protein in Arabidopsis. Developmental Cell 1, 771-781.

Xiong, L. \& Yang, Y. (2003). Disease resistance and abiotic stress tolerance in rice are inversely modulated by an abscisic acid-inducible mitogenactivated protein kinase. Plant Cell 15, 745-759.

Xu, L. H., Liu, F. Q., Lechner, E., Genschik, P., Crosby, W. L., Ma, H., Peng, W., Huang, D. F. \& Xie, D. X. (2002). The SCFCOl1 ubiquitin-ligase complexes are required for jasmonate response in Arabidopsis. Plant Cell 14, 1919-1935.

Xu, W. H., Wang, Y. S., Liu, G. Z., Chen, X., Tinjuangjun, P., Pi, L. Y. \& Song, W. Y. (2006). The autophosphorylated Ser686, Thr688, and Ser689 residues in the intracellular juxtamembrane domain of XA21 are implicated in stability control of rice receptor-like kinase. Plant Journal 45, 740-751.

Xu, Y., Chang, P., Liu, D., Narasimhan, M. L., Raghothama, K. G., Hasegawa, P. M. \& Bressan, R. A. (1994). Plant Defense Genes Are Synergistically Induced by Ethylene and Methyl Jasmonate. Plant Cell 6, 1077-1085.

Yamaguchi-Shinozaki, K. \& Shinozaki, K. (1994). A novel cis-acting element in an Arabidopsis gene is involved in responsiveness to drought, lowtemperature, or high-salt stress. Plant Cell 6, 251-264.

Yang, S., Zhang, Q., Guo, J., Charkowski, A. O., Glick, B. R., Ibekwe, A. M., Cooksey, D. A. \& Yang, C. H. (2007). Global effect of indole-3-acetic acid biosynthesis on multiple virulence factors of Erwinia chrysanthemi 3937. Applied and environmental microbiology 73, 10791088.

Yoshida, R., Umezawa, T., Mizoguchi, T., Takahashi, S., Takahashi, F. \& Shinozaki, K. (2006). The regulatory domain of SRK2E/OST1/SnRK2.6 interacts with ABI1 and integrates abscisic acid (ABA) and osmotic stress signals controlling stomatal closure in Arabidopsis. The Journal of biological chemistry 281, 5310-5318. 
Yuan, H. Y., Yao, L. L., Jia, Z. Q., Li, Y. \& Li, Y. Z. (2006). Verticillium dahliae toxin induced alterations of cytoskeletons and nucleoli in Arabidopsis thaliana suspension cells. Protoplasma 229, 75-82.

Yun, M. H., Torres, P. S., El Oirdi, M., Rigano, L. A., Gonzalez-Lamothe, R., Marano, M. R., Castagnaro, A. P., Dankert, M. A., Bouarab, K. \& Vojnov, A. A. (2006). Xanthan induces plant susceptibility by suppressing callose deposition. Plant physiology 141, 178-187.

Zeevaart, J. A. D. \& Creelman, R. A. (1988). METABOLISM AND PHYSIOLOGY OF ABSCISIC-ACID. Annual Review of Plant Physiology and Plant Molecular Biology 39, 439-473.

Zhang, S. \& Liu, Y. (2001). Activation of salicylic acid-induced protein kinase, a mitogen-activated protein kinase, induces multiple defense responses in tobacco. Plant Cell 13, 1877-1889.

Zhang, Y., Fan, W., Kinkema, M., Li, X. \& Dong, X. (1999). Interaction of NPR1 with basic leucine zipper protein transcription factors that bind sequences required for salicylic acid induction of the PR-1 gene. Proceedings of the National Academy of Sciences of the United States of America 96, 6523-6528.

Zhang, Z., Feechan, A., Pedersen, C., Newman, M. A., Qiu, J. L., Olesen, K. L. \& Thordal-Christensen, H. (2007). A SNARE-protein has opposing functions in penetration resistance and defence signalling pathways. Plant Journal 49, 302-312.

Zhou, J. M., Trifa, Y., Silva, H., Pontier, D., Lam, E., Shah, J. \& Klessig, D. F. (2000). NPR1 differentially interacts with members of the TGA/OBF family of transcription factors that bind an element of the PR-1 gene required for induction by salicylic acid. Molecular Plant-Microbe Interaction 13, 191-202.

Zimmerli, L., Jakab, G., Metraux, J. P. \& Mauch-Mani, B. (2000). Potentiation of pathogen-specific defense mechanisms in Arabidopsis by beta aminobutyric acid. Proceedings of the National Academy of Sciences of the United States of America 97, 12920-12925.

Zimmerli, L., Metraux, J. P. \& Mauch-Mani, B. (2001). beta-Aminobutyric acid-induced protection of Arabidopsis against the necrotrophic fungus Botrytis cinerea. Plant physiology 126, 517-523.

Zipfel, C. \& Felix, G. (2005). Plants and animals: a different taste for microbes? Current Opinion in Plant Biology 8, 353-360.

Zipfel, C., Kunze, G., Chinchilla, D., Caniard, A., Jones, J. D., Boller, T. \& Felix, G. (2006). Perception of the bacterial PAMP EF-Tu by the receptor EFR restricts Agrobacterium-mediated transformation. Cell 125, 749-760.

Zipfel, C., Robatzek, S., Navarro, L., Oakeley, E. J., Jones, J. D., Felix, G. \& Boller, T. (2004). Bacterial disease resistance in Arabidopsis through flagellin perception. Nature 428, 764-767.

Zoubenko, O., Uckun, F., Hur, Y., Chet, I. \& Tumer, N. (1997). Plant resistance to fungal infection induced by nontoxic pokeweed antiviral protein mutants. Nature biotechnology 15, 992-996. 